Florida International University FIU Digital Commons

3-27-1996

\title{
A comparison of a distance education and locally based course in an urban university setting
}

Phyllis P. Cordover

Florida International University

DOI: $10.25148 /$ etd.FI14061513

Follow this and additional works at: https://digitalcommons.fiu.edu/etd

Part of the Education Commons

\section{Recommended Citation}

Cordover, Phyllis P., "A comparison of a distance education and locally based course in an urban university setting" (1996). FIU

Electronic Theses and Dissertations. 2639.

https://digitalcommons.fiu.edu/etd/2639

This work is brought to you for free and open access by the University Graduate School at FIU Digital Commons. It has been accepted for inclusion in FIU Electronic Theses and Dissertations by an authorized administrator of FIU Digital Commons. For more information, please contact dcc@fiu.edu. 
FLORIDA INTERNATIONAL UNIVERSITY

Miami, Florida

A COMPARISON OF A DISTANCE EDUCATION AND LOCALLY BASED COURSE IN AN URBAN UNIVERSITY SETTING

A thesis submitted in partial satisfaction of the requirments for the degree of

DOCTOR OF EDUCATION

by

Phyllis P. Cordover

1996 
To: Dr. Ira Goldenberg

College of Education

This dissertation written by Phyllis p. Cordover, and entitled A Comparison of A Distance Education And Locally Based Course In An Urban University setting, having been approved in respect to style and intellectual content, is referred to you for judgement.

We have read this dissertation and recommend that it be approved.

\author{
Lorraine Gay \\ Joyce Fine \\ Patrick Wagner \\ Douglas smith, Major \\ Professor
}

Date of Defense: March 27,1996

The dissertation of Phyl1is p. Cordover is approved.

Dean Ira Goldenberg

College of Education.

Dr. Richard L. Campbell

Dean of Graduate studies

Florida International University, 1996 
(C) COPYRIGHT 1996 by Phyllis Cordover

All rights reserved 
I dedicate this dissertation to three very important women in my life; without their support the completion of this work would not have been possible. My mother, Gertrude, has always enthusiastically supported me in my desire for education. My daughter, Allison, has been an unwavering source of encouragement to me and is my best friend. My mentor, Dr. I.R. Gay, has graciously supported me throughout this project and has generously given of her expertise and time. 
I dedicate this dissertation to three very important women in my life; without their support the completion of this work would not have been possible. My mother, Gertrude, has always enthusiastically supported me in my desire for education. My daughter, Allison, has been an unwavering source of encouragement to me and is my best friend. My mentor, Dr. I.R. Gay, has graciously supported me throughout this project and has generously given of her expertise and time. 


\section{ACKNOWLEDGEMENTS}

I wish to thank the members of my committee for their generous help: Dr. Patrick Wagner, the university's expert on distance education, who made it possible for me to conduct this study; Dx. Joyce Fine who graciously allowed me to use her course for the pilot study; Dr. Douglas Smith, my Major Professor, who spent long hours directing and editing my work; Dr. L.R. Gay who patiently and expertly guided me through this dissertation.

A special thanks to Dr. Richard Hodgetts, a very inspiring instructor, for allowing me to use his class for this study. Dr. David Hall, Coordinator, Planning and Institutional Research was very helpful in accessing student information for the study. Dr. Paulette Johnson, Statistical Consultant at Florida International University, supported me in the statistical analysis of the data. Dr. Charles Divita, my professor for numerous courses, inspired me to pursue this degree because of his dedication and brilliance in the field of Adult Education.

My father, Harry, has been the source of my inspiration for continuous education throughout my life. His high intellectual standards have strongly influenced me and my family in our quest for education. My husband, Howard, made it possible for me to attend class 100 miles away from home 
by supporting me with transportation to class and allowed me to spend long undisturbed hours of concentrated work. All of my children and their wonderful spouses, along with my grandson Alexander, have served as my personal cheering squad bringing me encouragement and optimism throughout this long process.

Sincere appreciation to The American Journal of Distance Education for permitting me to use Figures $3,4,5$, and 6 from E.D.Wagner's, 1994 article, In support of a Functional Definition of Interaction in the The American Journal of Distance Education 8(2), 6-29. Thank you to Michael $G$. Moore, editor of The American Journal of Distance Education, for his work in bringing distance education to America and for inspiring me, as editor of the journal, to keep expanding my knowledge of the field.

Thank you to Florida Power and Light Company's Nuclear Division's Training Staff for their support and help during my years of study. 


\section{ABSTRACT OF THE DISSERTATION}

Empirical Case Study of a Televised Course in a Multiethnic Urban University Setting

by

Phyllis P. Cordover

Florida International University, 1996

Professor Douglas Smith, Major Professor

The purpose of this research was to compare the academic performance and attitudes of students at the instructor-based site of a televised course and the distant site. An earlier pilot program indicated the need for certain technical and structural interventions at the distant site such as multiple "press-to-touch" microphones, a site-administrator and participative seating arrangements. At the beginning of the class, demographic data were collected from the students at both sites through a questionnaire and supplemented with information from students' records. Factors such as age, gender, ethnicity, marital status, number of children, current class status, major, work status and CLAST scores (achievement tests) were examined. There were no significant differences between the students at the sites except ethnicity and reading CLAST scores. The instructor-based 
site had a higher percentage of Hispanic students and the distant site had a larger percentage of Caucasian and Black Americans. The distant site scored significantly better on the reading section of the CLAST achievement test. An evaluation instrument was distributed to both sites, at the midpoint of the semester, measuring their attitude toward the organizational, technical, and pedagogical factors of the course. A second evaluation instrument, measuring similar factors, but more in-depth, was distributed to both sites near the end of the term. Nine students at the distant site were interviewed along with the site administrator to collect additional information.

Course completion rates, dropout rates, pass rates and final grades of students at both sites were compared. There were no significant differences in academic performance between the students at both sites, however, there were significant differences in their attitudes. Those at the instructor-based site gave better ratings to most of items in the evaluation instruments. Problems at the distant site included audio and visual clarity, lack of available assistance, too much nonrelated talking, not enough opportunities to ask questions or to interact with the instructor during class. 


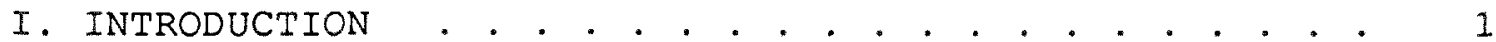

Background of the Problem . . . . . . . . . . . 4

Statement of the Problem . . . . . . . . . . 10

Research Questions . . . . . . . . . . . . . . . . 11

Conceptual Framework of the study . . . . . . . . 12

Purpose of the Study . . . . . . . . . . . . . . 22

Significance of the Study . . . . . . . . . . . . 23

Definition of Terms ............... . . . 25

Assumptions . . . . . . . . . . . . . . . . . 27

Limitations . . . . . . . . . . . . . . . . . 28

II. REVIEW OF RELATED LITERATURE . . . . . . . . . . . . 30

Theoretical Review . . . . . . . . . . . . . 31

Distance Education . . . . . . . . . . . . . . . . 31

Theories of autonomy and independence. . . . 32

Theories of industrialization of teaching. . . 41

Theories of interaction and communication. . . 44

Adult Education . . . . . . . . . . . . . 53

Communication . . . . . . . . . . . . . . . . 59

Empirical Review . . . . . . . . . . . . . 69

Summary

University Setting . . . . . . . . . . . 70

Military Setting . . . . . . . . . . . 77

81

III. METHODOLOGY . . . . . . . . . . . . . . . . . . 86

Methodological Rationale . . . . . . . . . . 86

Subjects . . . . . . . . . . . . . . . 88

Pilot Study . . . . . . . . . . . . . . 88

The Study . . . . . . . . . . . . . . . . . . 91

Instrument and Data Collection . . . . . . . . 93

Treatment of Data . . . . . . . . . . . . 96

IV. ANALYSIS Of ThE DATA . . . . . . . . . . . . . . 99

Data Analysis . . . . . . . . . . . . . . . 99

Question one................. . . . 100

Question two . . . . . . . . . . . . . 107

Question three ............... . . 107

Question four . . . . . . . . . . . . . 108

Question five ................ . . 108

Interim evaluation forms. . . . . . . 109

T-tests on the sections of the Distance

Education Evaluation form. . . . 120

Statistical tests on individual items of

Distance Education Evaluation form. . 122 
Sumrary

Overall attitudes toward distance education experience.

V. SUMMARY, CONCLUSION AND RECOMMENDATIONS . . . . . . 154

Summary $\quad$. . . . . . . . . . . . . . . . . . 154

Theoretical Review . . . . . . . . . . . . 154

Empirical Review . . . . . . . . . . . . . . . 156

The Study . . . . . . . . . . . . . . . . . . . . 158

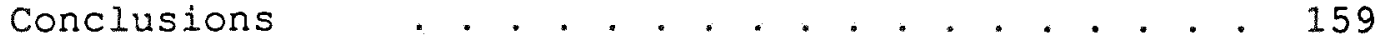

Question 1 . . . . . . . . . . . . . . . 160

Question 2 . . . . . . . . . . . . . . . . 160

Question 3 ................... 161

Question 4 . . . . . . . . . . . . . . . . 161

Question 5 . . . . . . . . . . . . . . . . . 161

Recommendations . . . . . . . . . . . . . . . 165

Recommendations for Future Distance Learning

Programs . . . . . . . . . . . . . . . 165

Interim Evaluation . . . . . . . . . . . . 165

Organizational section. . . . . . . . . 165

Technical section. . . . . . . . . . . 166

Pedagogical section. . . . . . . . . . . 166

Distance Education Evaluation form . . . . 168

Organizational factors. . . . . . . . . . 168

Pedagogical factors . . . . . . . . . 169

Technical analysis. . . . . . . . . . . 170

Recommendations for Future Research . . . . 173
. . . . . . . . . . . . . 175

REFERENCES . . . . . . . . . . . . . . . . . . . . 177

APPENDIXES . . . . . . . . . . . . . . . . . . . . . 187

VITA ................... 209 
TABLE

1 Reliability Estimates for the Distance Education Evaluation Form . . . . . . . . 95

2 Demographic Responses by Location . . . . . . 102

3 CLAST Scores by Location and Subtest . . . . . . 106

4 Comparison of Grades Between Sites . . . . . . . 108

5 T-Tests on the sections of the Interim

Evaluation Form . . . . . . . . . . . 110

6 Responses to Interim Evaluation Form . . . . . 112

7 Interim Comments by Both Sites . . . . . . . . . 119

8 T-Test on the Sections of the Distance Education Evaluation Eorm . . . . . . . 120

9 Chi Square Analysis of Individual Items in

Organizational Factors section of the

Distance Education Evaluation Form . . . .

10 Distribution of Ratings by Sites for Pedagogical

Factors in Distance Education Evaluation Form

11 T-Tests of the Individual Items in Pedagogical

Analysis Section of the Distance

Education Evaluation Form . . . . . . . . .

12 Distribution of Ratings by Sites for Technical

Analysis in Distance Education Evaluation Form

13 T-tests on Individual Items Under Technical

Analysis Section of the Distance

Education Evaluation Form . . . . . . . 140

14 Comments by Both Sites on the Distance

Education Evaluation Form

15 T-Test on Sites' Overall Attitudes Toward Distance . 146 Education 


\section{LIST OF FIGURES}

FIGURES

PAGE

1 Framework For Effective Distance Education . . . . 13

2 The Shannon-Weaver Communication Model . . . . . 65

3 The Shannon-Schramm Communication Model

Showing Information Exchanged In Both

Directions. . . . . . . . . . . . . . . 66

4 The Shannon-Shramm Communication Model Adapted

By Chute Showing The Mechanics of Interactive Telecommunications. . . . . . . 67

5 Interactive Information Transport Model . . . . . 68

6 An Interactive Information Transport Model

Showing System Interactivity As Well As

Interpersonal Interaction. 
CHAPTER 1

\section{INTRODUCTION}

Background of the Problem

Distance education is a mode of learning with certain characteristics that distinguish it from campus based education. The four defining elements of distance education are:

1. The separation of teacher and learner during at least a majority of the instructional process

2. The influence of an educational organization, including the provision of student evaluation

3. The use of educational media to unite teacher and learner and carry course content

4. The provision of two-way communication between teacher, tutor, or educational agency and learner (Verduin \& Clark, 1991, p. 11).

According to Nipper (in Evans \& Nation, 1993), three generations of distance education exist. The first occurred during the nineteenth century with the development of printing and railways which allowed production and distribution of materials to learners in geographicallydispersed areas. Correspondence was the main medium for communication in distance education until the 1960 s (second generation) when print was combined with broadcast media, cassettes, computers, telephone and occasional face-to-face 
meetings. Even though the target population for this type of education was large, most of the learning was on an individual basis.

In the 1980s, with interactive communications (third generation) such as computer and video and audio conferencing, learning between learners, or groups of learners, as well as the instructor became possible, and distance education was no longer geared to individuals. According to Moore (1993) "inter-learner dialogue can occur between learners and other learners, alone or in groups, with or without the real-time presence of an instructor" (Moore, p. 22). Faster and more individual dialogue is possible than in traditional correspondence education, and students can interact when it is convenient for them as well as when they feel ready to initiate dialogue. Feedback can be synchronous (immediate) or asynchronous (two-way communication that involves a time delay). Students studying at a distance have an equivalent opportunity to interact with their instructors as do students in many of the large, campus-based classes. Telecommunication technologies involve the transfer of voice, data, text and/or video signals through the distribution media of telephone lines, fiberoptics, coaxial cable, satellites and microwaves. The user-end equipment involved in presenting the transmitted information includes telephones, speaker phones, facsimile machines, electronic 
white boards, computers, video cameras, and television monitors for broadcasts and videoconferences (Wagner, 1992).

In America, distant education, in a university setting, began in 1874 at Illinois Wesleyan University where both graduate and undergraduate degrees could be pursued by correspondence (Rumble, 1986). Moore (cited in Verduin \& Clark, 1991) credited the Chautauqua movement, founded on the hope of providing education to all Americans, as the first significant post- secondary, distance education effort in America. Rainey Harper, from Chautauqua, went on to become the first president of the University of Chicago and founded the first university correspondence study division in America (Goodspeed in Verduin \& Clark, 1991). The University of Wisconsin-Extension program founded in 1906 was one of the more important developments in university distance education. In 1922 the university started the first federal licensed radio station for educational broadcasting. Educational television was instituted at the University of Iowa in the 1940s. In 1961 the Open University of the United Kingdom began operations and by 1971 had enrolled 60,000-70,000 undergraduates a year. According to Verduin and Clark (1991) distance education in the university arena was reintroduced in America in 1987 by Bjorn Holmberg and Michael Moore. Toward the end of the 1980 s an abundance of information on the subject began appearing in print and surfacing at 
professional conferences. Accessibility to computers and the increased use of audio and videoconferencing have accelerated the rapid interest in distance education at the postsecondary level.

Today distance education is a worldwide phenomena with about ten million people a year studying at a distance. It is used in the military, business, industry, hospitals, prisons, institutions, and organizations. A study of international distance education conducted at the FernUniversitaet in West Germany in 1986 lists some 1500 distance education institutions throughout the world (Holmberg, 1989). Perry (in Verduin \& Clark, 1991) in a 1984 survey of 52 countries found 142 associate or bachelor degree programs and 61 postgraduate degree programs. Most students in these programs are employed adults between the ages of 2535 .

The typology approach to distance education, as opposed to the generational approach of classification, is based on a threefold typology: (1) those set up exclusively to provide distance education, (2) dual mode institutions offering both distance and face-to-face education, and (3) those institutions which provide a few distance education courses alongside the predominant traditional face-to-face courses (Kaye, in Bell \& Tight, 1993). Verduin and Clark (1991) further refined the threefold classification model into five 
types. Type one institutions grant degrees and course credit to students not taught directly by them. Examples include Regents College in New York and Thomas A. Edison College in New Jersey; neither have a campus or faculty at a central location. Students earn credit by demonstrating their mastery of knowledge through exams, military service, independent study, courses at other colleges, experiential learning, and life and work experiences.

Type two institutions offer degrees to students to whom they provide courses for a portion of their degree as well as offer credit for life and work experience, credit by exam, distance education courses, and experiential learning. Nova University in Florida is an example of a program where students are organized around clusters (geographically grouped) and meet on weekends or in the summertime while taking courses and remaining employed.

Type three institutions provide the majority of distance study in the U.S., and are conventional universities that offer distance education as well as regular programs on campus. They employ regular and part-time faculty offering correspondence study and use television, computer and other media. Pennsylvania State University is one of the largest providers in this type category in the U.S. Some distance programs in this category are considered less important than regular campus-based programs. 
Type four institutions involve consortia of educationrelated institutions that share the costs of program development, materials, and programs and grant credit for participation. The National Technological University (NTU) and the International Consortium at the University of Maryland are examples. NTU comprises 24 engineering schools and has no campus or faculty. It is headquartered at Colorado State University and coordinates the distribution of courses produced by member institutions. Students register with their own institution and work with the centrally developed materials and receive credit from their home institution. The advantage is to link institutions with different strengths.

Type five institutions provide only distance education courses. In the U. S. they are only found in technical and vocational private schools. The Open University of the United Kingdom and two universities in Canada are well known examples. Rumble (1990) referred to this as the Sole Responsibility Model because the needs of the students, which are often different from campus students, are continually addressed.

The requirements of a successful distance education program are long lead times for the development and production of materials, curriculum and infrastructure to support it. A great deal of information about the sponsoring 
organization needs to be known and open communication channels need to exist since there are more people involved than in a traditional course. Learning materials must be high quality, well organized, and clear since many students often work without direct supervision. A team involving editors, instructional designers, media specialists, printers, broadcast producers, technicians, instructors, tutors, and support service people often develops and implements a course.

Students in a distance education course or program need to be internally motivated and self-directed to work without direct supervision and immediate feedback and evaluation. Some critics of distance education question the effects on the independence and autonomy of students. They feel the high degree of structure sometimes found in a distance education course creates a strict interpretation of course materials and limits a student's learning to only what is specifically included in the course materials. "Any course with prespecified objectives and content runs the risk of presenting students with ready made solutions and definite truths making students passive receivers" (Holmberg, $1980 \mathrm{p}$. 142). Others feel that distance education can increase selfdirected learning and greater student autonomy. Many professors wrestle with the issue of autonomy knowing it is difficult for students who work and have personal 
responsibilities to keep up with their classes. Holmberg (1995) states:

those in favour of full student autonomy feel that any non-invited intervention in adult students' work (sometimes even offers of assistance in coping with specific problems) encroach on the personal integrity of students, whereas those prepared to limit students' independence by various control measures consider it a moral and social duty as far as possible to prevent failure. (p. 168)

Educators question whether teaching at a distance requires different methods than a traditional classroom. Is it sufficient to place a camera and microphone in front of a classroom without a change in teaching techniques? Charles Wedemeyer, in his 1981 book, (in Purdy \& Wright, 1992) said what is different about learning via technology today is the scope of learning facilitated by technology, the altered role of teachers and learners, and the changed environment for learning necessitated by technology. Instructors are often relieved from conveying course matter and can spend time in aiding students' motivation, providing individual support, structuring course content, identifying problems and establishing connections roles. (p. 3) 
Ideally, the role of faculty in distance education changes from teacher centered to learner centered with the focus on learning rather than teaching. What students do assumes more importance than what teachers do. The instructor no longer has to be the exclusive source of information, but just one of many. Instructors need to learn new teaching skills, organize instructional resources for independent study, and understand how technology works with learning. "Faculty engaged in distance education must be adept at facilitating students' learning through particular attention to process, unlike classroom-based teachers whose traditional role is largely confined to selecting and sharing content" (Beaudoin, p. 21). Distance education instructors need help in learning about different technological delivery systems, training in how to teach and motivate students, how to monitor and evaluate their work and how to access information from databases, libraries and other sources. Many instructors will need ongoing support to overcome the barriers of time and distance.

The Center for Distance Education, University of Maine in Augusta (1991) conduced a faculty and staff training needs assessment. A survey was mailed to faculty who taught at a distance, those who were scheduled to teach at a distance, and those who received grants to adapt existing courses or develop new courses for delivery. The survey was designed 
to assess faculty and professional staff perceptions of the relevance, on a scale of $1-5$ (not at all relevant to highly relevant), of each of 39 skills used in their work with distant students. Overall the faculty chose the following as the items of most concern: communicating with students during class, assessing students' performance in class, personalizing the experience for remote students, communicating with students outside of class and incorporating interactive strategies.

The future for distance education is rapidly expanding as society needs to train and educate large numbers of entering workers as well as those workers whose skills have become outdated or unnecessary as a result of new technology and lost markets. In the past, distance education has been regarded as inferior to campus-based classes. Today, with the advent of new technologies, new opportunities exist to ensure that students studying at a distance achieve an equivalent education and enjoy the same degree of satisfaction, or more than those in campus based classes. Statement of the problem

Many colleges and universities use distance education as an alternative strategy to offer affordable education to the greater numbers of students. Students and workers who are unable or unwilling to attend classes at a specific location or time are able to receive the training and education they 
require through distance education. Many colleges and universities are plagued by budget constraints and are unable to offer the same courses at all their campus locations or hire instructors to teach more classes.

Since distance education courses are appearing with more and more frequency in college catalogs, it is necessary to know if students in distance education courses can achieve equivalent academic results, and enjoy the same level of satisfaction as those in instructor-based classes. If so, what interventions need to occur to make this happen? According to Wedemeyer, interventions that address student motivation and provide individual support through two-way communication with an instructor or sponsoring organization are needed.

\section{Research Questions}

Having explored the problems associated with distance education, and the potential role of distance education in college and universities, the intent of this study is to answer the following research question.

Basic Research question: If certain technical and structural interventions are implemented at the distant site of a televised course, how does the performance of students and their attitudes and perceptions at that site compare with that of students at the instructor-based site? To answer this basic research question, five specific questions will 
serve as the core of the study and will collectively answer the basic research question.

\section{Questions:}

1) Is the demographic make-up of students at the instructor-based site and distant site comparable?

2) How does the course completion rate compare between the instructor-based site and the distant site utilizing the technical and structural interventions of a site facilitator, multiple telephones, and a pre-configured classroom at the distant site of a televised course?

3) How do final grades of students at the instructor-based site and the distant site compare utilizing the interventions in question two?

4) How do the pass rates of the instructor-based site and the distant site compare utilizing the interventions in question two?

5) How do the attitudes and perceptions of students at the instructor-based site and the distant site compare on the interim evaluations, the Distance Education Evaluation form, instructor ratings, and the distance education experience rating?

Conceptual Eramework of the Study

The ultimate purpose of education, whether it be in a traditional classroom setting with a live instructor or delivered through media, is to encourage students to develop 
new perspectives based on the integration of existing knowledge with newly-acquired knowledge. Adult education strives to help each individual student to become more selfdirected in learning situations. To support the selfdirected efforts of adult students in expanding their knowledge, there needs to be collaboration between teacher and students whether working through media or at the instructor-based site. Two-way interactive communication, whether live or asynchronous (delayed), is needed for distance education to be effective.

Eigure 1 depicts the framework of distance education, adult education, and communication and integrates them to show the basis of effective distance education.

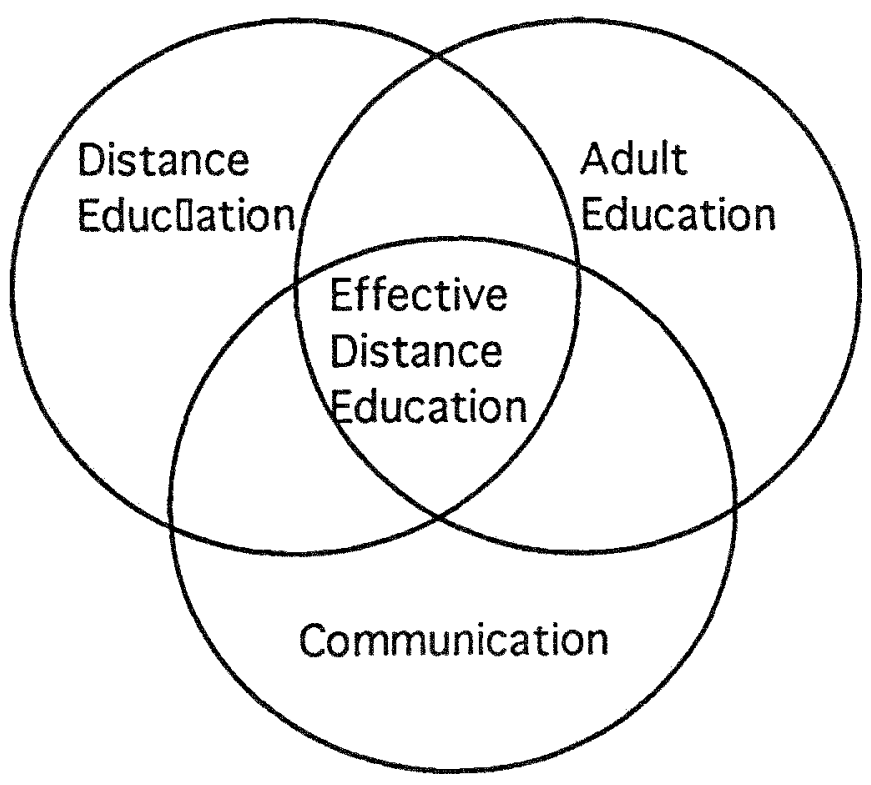

Figure 1. Framework for effective distance education model. 
Conducting research in the area of distance education requires that one examine theories of distance education as well as literature on adult education and theories of communication.

Regarding the theoretical framework of distance education, Giddens (in Jarvis, 1990, p. 167), states that "in pre-modern societies, space and place largely coincide..." This means that students attending school in that era had to be in the same location as their teachers in order to hear them. Students had to physically be present with an instructor in order to earn a degree. Today students can earn degrees from universities without ever being present and can even earn a degree from a university located in a different country without ever being present. A distance teaching institution needs no campus or geographical location. "Distance education provides the opportunity for people to continue their education individually in their own space and at their own time and pace..." (Jarvis, 1990, p. 167) .

Distance learning situations challenge traditional education to the point that there is much debate as to whether education, as we know it, can occur in a distance learning environment. Some researchers and practitioners further question if distance education is a separate discipline from general education. 
Keegan (1990), a prolific writer and researcher in the field of distance education, questioned if distance education is a separate discipline or an educational activity. He explained that in distance education the course developer may never use the prepared materials, or they may be used for the first time several years after being developed. "The structuring of the learning materials, instructional design, and execution may be assigned to persons other than the teacher and to persons not skilled in the content to be taught" (p. 109). A course may even outlast the longevity of the person responsible for producing it. Materials may be developed alone or in a group. "Writing, tutoring and counselling can be contracted out to staff employed only for the period of the presentation of the course" (p. 109). The tapes of the classroom sessions might be delivered at another institution several years after they were made, or be included as part of another course with a live instructor present, or be delivered as a self-study module.

Keegan (1986) concluded that, even though distance education has some of the characteristics of entertainment, the role of education is more dominant and the theoretical foundations for education in general are integral to distance education theory. For distance education to be considered education, it must be "a shared experience in which teacher and learner are united by a common zeal" (p. 118); this 
occurs through reintegration of the act of teaching and learning. Reintegration can occur through print and nonprint materials that serve to achieve interpersonal communication and by telephone, on-line computer communication, comments on assignments, and teleconferences.

In the Journal of Distance Education (Spring, 1989), Coldeway moderated a debate on whether distance education was a discipline in its own right. He stated that Holmberg, in his writings, had identified the factors that give distance education a separate status as a discipline. Devlin, in this dialogue, stated that Holmberg's arguments are based on the following:

some universities offer distance education courses to train practitioners; that professional bodies have adopted post-graduate study as a standard for practice; that academic courses on distance education have a common content and viewpoint, and that both traditional and non-traditional institutions have established departments for research and development work in distance education. (p. 56)

Coldeway (1989) stated that Otto peters in the theory of the industrialization of teaching also regarded distance education as a separate independent discipline.

Rumble, as explained by Coldeway (1989) in this debate maintained that distance education lacked the autonomy and 
independence from education in general and did not represent an independent discipline in its own right. Devlin, as part of the Coldeway debate (1989), stated that "distance education is a derivative field of adult education which itself is not a discipline. Rather, both are professionalizing vocations--areas of skilled practice... Which draw on core disciplines for their intellectual foundations" (p.56).

In conclusion, Coldeway (1989) stated that an educational expert would know little about distance education simply through studying education. He would have to learn about new rules, attitudes and values. He contended that, in the future, distance education may flourish as a separate academic discipline. Kirby (1989), as part of the Coldeway debate, believed that to reduce the stigma sometimes attached to distance education and elevate it to the level of face-toface education, educators "should view themselves as educational technologists with skills and capabilities of use to the institution, whether it be to teach students on or off campus" (p. 72).

In summary, distance education allows individuals to continue their education and training whenever and wherever it is convenient for them. However, critics contend that real education does not occur in a distant learning situation. Proponents believe that by following the 
principles of instructional design, by encouraging interactive synchronous or asynchronous communication between instructor and student and between students, and by allowing flexibility in course structure, distance education can increase student autonomy and may even be superior to traditional face-to-face education. In the review of literature section, there is a detailed examination of the three categories of theories of distance education as classified by Keegan (1990) .

The second theoretical framework for this study is adult education because historically adult learners were the first to adopt distance education using the mail as a delivery system. Today, adults are still the largest users of distance education because of work place emphasis on continuous learning to keep pace with technological changes and re-engineering. Adults want to have education delivered to them wherever and whenever it is needed.

After World War I adult education grew rapidly in the United States. However, the only model available, pedagogy, gave the instructor full responsibility for the learning process. The learner was dependent on the instructor and had to learn only what the teacher taught (Knowles, 1990).

Many adults are self directed in most aspects of their lives, but when they enter an educational setting they revert to behavior from their earlier time in school and display 
dependent behavior. Maslow's (1968) definition of learner dependence is "the teacher is the active one, who teaches a passive person who gets shaped and taught and who is given something which he then accumulates and which he may then lose or retain depending upon the efficiency of the initial indoctrination process" (p. 57). Moore (1980) stated that some adults need guidance in learning while others are autonomous. The goal of adult educators is to help create ...a fully autonomous learner who can identify his learning need when he finds a problem to be solved, a skill to be acquired, or information to be obtained. He is able to articulate his need in the form of a general goal, differentiate that goal into several specific objectives and define fairly explicitly his criteria for successful achievement. In implementing his need, he gathers the information he desires, collects ideas, practices skills, works to resolve his problems, and achieves his goals... He reaches conclusions, accepting or rejecting material, and eventually decides his goals have been achieved, or can be abandoned. (p.22)

As a group, adults have a greater amount of experience and a wider range of individual differences than a group of youth. Adult learners are..."more heterogeneous in terms of background, learning style, motivation, needs, interest, and goals than is true of a group of youth. Hence, the greater 
emphasis in adult education on individualization of teaching and learning strategies" (Knowles, 1990, p. 59). Adult education, within the theoretical constructs of andragogy, is concerned with producing individuals competent to engage in lifelong self-directed learning. Adult educators should focus, according to Knowles (1980s), on helping participants develop skills of inquiry and provide resources and support for self-directed inquiry.

Jarvis (1993) feels that learning is a basic human need and is motivated by a lack of harmony between an individual's experience and his perception of things. Adults like to participate in learning and bring their own experiences to the learning situation. They need to feel they are treated as adults and function best when they are encouraged to learn at their own speed and in their own preferred style in a nonthreatening environment.

$$
\text { Freire's ( in Jarvis, 1993) description of the }
$$
relationship of teacher and learner is well suited to adult education. The teacher teaches the learners who learn and teach the teacher as well. The teacher has to reach out to the learners and learn from them in order to be able to contribute effectively to the teaching and learning process.

Mezirow (1981) feels that learning occurs as a result of reflecting upon experience. Learning is a new interpretation of an experience. He describes perspective transformation or 
learning as

...an emancipatory process of becoming critically aware of how and why the structure of psycho-cultural assumptions has come to constrain the way we see ourselves and our relationships, reconstituting the structure to permit a more inclusive and discriminating integration of experience and acting upon these new understandings. (p. 5)

Adult learners are more heterogeneous in background, learning styles, motivation, needs, and interests than a group of youth. They also need time to reflect upon new experiences in order to expand their old constraints and integrate new ideas into their thinking. Adult education theory, with its emphasis on self-directed learning and transformative learning, can easily be integrated with distance education. These theoretical concepts are further discussed in the Review of Literature chapter.

The third conceptual framework is based on communication theory. Communication in distance education was made possible through the development of the railroads and the postal system. However, the frequency of communication in early correspondence education was sparse, and, therefore, it was difficult to maintain momentum. Drop-out rates were high.

Even today, many educators believe that courses based on 
one-way transmission of information through tapes, broadcasts and videos, with no mechanism for timely feedback, cannot be classified as education. However, today's generation of distance education, with the availability of modern communication technology, can easily support learner independence as well as increased interaction among students and instructor. Telecommunications can now bring materials beyond the traditional campus and instructor expertise into the students' experiences. According to Long, (1983) better communication can reduce dependency on the automobile and the classroom and increase encounters with leading scholars and practitioners as well as provide more opportunity for individual attention and individualization of instruction. Students can set their own pace of learning, receive timely feedback, and learn in a relatively risk-free environment. Asynchronous communication (delayed communication) allows students the time to reflect on their learning and respond when ready as well as work individually or in a group. The Review of Literature, chapter two, further examines the role of communication in distance education and how it needs to be structured to support the effective delivery of distance education.

Purpose of the Study

The purpose of this study is to find out if certain interventions are adequately implemented at the distant site 
of a televised course, how does the performance, attitudes and perceptions of the students at that site compare with those of students at the instructor-based site. The results of the study will help the institution decide if distance education can be used to increase the availability of courses and increase cost effectiveness without sacrificing achievement and satisfaction.

Significance of the study

The significance of the study is based on three factors. First is the increasing number of Hispanics, blacks and women who are traditionally undereducated entering the work force. According to a Hudson Institute study (in Verduin \& Clark, 1991), more than 75 percent of the 21 million new workers entering the work force between 1986 and 2000 will have limited verbal and writing skills that will qualify them for only 40 percent of the jobs created during the same period. Approximately 50 million workers will need to be trained or retrained in the next 12 years. This includes thirty million current workers who need retraining due to the fast changing pace of technology and the 21 million new entrants (Bernstein, in Verduin \& Clark, 1991). To train these new workers, as well as retrain those who are technologically displaced, distance education with its flexibility to learn at the work place, home or convenient location can be used. The second significant factor is that adults make up 
approximately $45 \%$ of college students. They are more likely to study part-time and possibly at a distance when offered the choice. When surveyed, many distance education students often cite such reasons for enrollment such as no travel time, conflict with work or personal schedules, preference for working at home, and geographical remoteness. Some perceive it to be the only option available or feel psychologically distant from conventional education (Verduin \& Clark, 1991).

The third factor contributing to the significance of this study is that in the second half of the 1990s the U.S. will be facing a shortage of college level faculty compared to the 1960s. One hundred thousand new faculty will be needed. However, less people are choosing to enter college teaching and many are reaching retirement age (Dirr, 1990). Institutions of higher learning are facing large budget cutbacks and are often unable to replace departing faculty or increase the number of new positions needed to keep pace with growing student enrollments. Distance education programs educate larger numbers of students with less faculty.

In summary, distance education can play a major role in helping colleges and universities train and educate learners and those unable to leave their homes to attend classes. Affordable, two-way, interactive technologies have the potential to provide an environment where distance education 
students achieve the same level of academic success and satisfaction as campus-based students. Distance education with its potential to save costs, ability to provide encounters with leading scholars and practitioners, opportunity to receive individual attention through interactive technologies, and flexibility to learn at home, at work, or at a nearby convenient location all point to a growing future for this innovative type of education. Definition of Terms

Adult Education A process used by adults for their self-development or to prepare for a future anticipated change. It can be done alone or with others, and is often used by institutions for the growth and development of their employees, members, and clients. All organized classes, study groups, lecture series, planned reading programs, guided discussions, conferences, institutes, workshops, and correspondence courses are included (Knowles, 1980).

Asynchronous A type of two-way communication that occurs with a time delay allowing participants to respond at their own convenience (Willis, 1993). Audioconference An electronic meeting where participants in different locations use telephones or microphones to communicate with each other in real time (Willis, 1993). 
Dialogue Two-way communication between

teacher/institution and student (Moore, 1993).

Didactic Conversation Conversation that can be simulated in a pre-produced course between course developers and individual students or through telecommunications (Holmberg, 1989). Distance Education set of tools, techniques, and technologies applied in the process of independent education sponsored through an institution and having feedback and evaluation as part of the process (Keegan, 1990).

Eield Dependent Students who need dialogue with professors for support other than academic discourse (Moore, 1993).

Immediacy Behaviors Instructor behaviors which contribute to effective teaching such as eye contact, gestures and facial expressions which need to be adapted for distance delivery classes (Moore, 1989).

Independent Learning study in which the time, place, and pace are often controlled by the learner and often lacks face-to-face meetings between teacher and student (Knowles, 1980).

Instructional Television Eixed Service (ITES) Lowpower microwave frequencies set aside by the FCC for the transmission of educational programming. It requires a 
specialized antenna and a converter to change signals to those used by a standard television set and requires direct line of sight to operate (Willis, 1993).

Site-facilitator In a distance education program, a local coordinator at the distant site (Moore, 1995). Technical and Structural Interventions site facilitator, microphones and seating at the distant site of a televised class.

Telecommunication The process of transmitting or receiving information over a distance by any electrical or electromagnetic medium. Information can be in the form of voice, video, or data (Willis, 1993).

Teleconference Interactive communication among people at two or more locations using telecommunication (Willis, 1993).

Transactional Distance Expression of sense of distance felt by the learner in an educational transaction (Moore, 1993).

Video conference $A$ meeting or conversation between people at a different location using video technology as the communication link (Willis, 1993).

\section{Assumptions}

The students in this study are typical of those at the university who did not choose the distant delivery format. The course content is the same as the other sections of the 
course delivered by the professor during the same term except for the distance delivery method. The researcher had no control over the course and how it is delivered but assumptions are made that the best available delivery system will be used.

This study is applicable only to distance education programs in the college and university environment.

\section{Limitations}

Management 3025 was offered on Wednesday evenings at eight o'clock with the live instructor at the main campus of the university. Those who want to take the televised course at the north campus were allowed to register for the distant delivery section. Some students, when registering, were placed in the distant education section, without their knowledge, because there was no room left in the instructorbased section.

The interim evaluation forms and the final evaluation forms were anonymous, therefore, making it impossible to compare any changes in ratings.

\section{Summary}

This section presented the background of the problem, the statement of the problem, the research questions, the conceptual framework, and definitions and assumptions of the study. The next chapter provides an in-depth review of the theoretical and empirical literature that contributed to the 
formation of the conceptual framework. 


\section{CHAPTER 2}

\section{REVIEW OF RELATED IITERATURE}

Chapter two reviews the literature that is central to the conceptual framework of this study: distance education, adult education and communication. The theoretical review discusses Keegan's (1990) classification of the three categories of theories of distance education: autonomy and independence, industrialization of teaching, and interaction and communication. The role of adult education is explored as well as how distance education assists adult learners in keeping pace with today's fast changing world. The role communication plays in making distance education effective is explored. Some theories of communication are discussed to support the contention that the media used in distance education has to have interactivity (immediate or delayed) and students must be engaged in interpersonal interactions with the instructor or institution.

Since much research and writing in distance education has been conducted and published in other countries and other languages, the number of primary sources available for this review has been limited. Several authors, whose works could not be obtained firsthand, have been quoted in other books and cited.

The empirical review section reviewed studies conducted in a university setting, medical school and the military. 
These experiments compared performance and attitudes between sites with a live instructor and distant sites. Some experiments involved two-way video and two-way audio or oneway video, two-way audio.

Even though many studies have been conducted as to whether

distance education course are as good as on-campus courses... the question cannot be laid to rest. Each course will have its own characteristics, strengths and weaknesses. Each research has its own characteristics, strengths and weaknesses. Each research design has its own limitations. Each person who asks the question brings his own biases with the questions. I suspect this will be a question each researcher will continue to be asked through the next decade. (Dirr, 1990, p. 405) Theoretical Review

Research into the theories of distance education, adult education and communication was conducted for the framework of the dissertation. Distance education is discussed first followed by adult education and concluding with communication. The empirical review section follows the theoretical review section.

\section{Distance Education}

In The Foundations of Distance Education, Keegan (1990) classified the theories of distance education into three 
categories: autonomy and independence, industrialization of teaching, and interaction and communication. These three categories provided the basis for the following review of the literature in distance education.

Theories of autonomy and independence. Wedemeyer (1983) considered "non-traditional learners and their achievements ...the equivalent of a great natural resource in America... that spreads and renews itself at little cost and great benefits to the nation" (p. 129). Wedemeyer examined the adult population who returned to school part-time for baccalaureate degrees after World War II. He found most attended night schools that were replications of day schools and did not consider the time and hours available for study, mobility and the demands of working adults. He realized that education needed to adapt to fit adult life (Wedemeyer, 1969). He also stressed educational access to those who might be denied because of lack of economic opportunity, geographical barriers, poor health or physical and social barriers (Rumble, 1986). As a result, Wedemeyer introduced the Articulated Instructional Media Program of University Extension at The University of Wisconsin (1964-1968) that attracted worldwide attention. Wedemeyer (1983) reminded critics in the U.S. that non-traditional learning is not new, but rests upon a long history of learning before education was 
institutionalized by schools, academies, colleges and universities... to preserve the elitism in education that was part of the European heritage of the American seekers. ( pp.129-130)

He answered critics who refused recognition to nontraditional programs by explaining that non-traditional schools may be below standards as well as traditional schools, but that non-traditional schools have been prejudged as inferior.

According to Simonson, Schlosser \& Anderson (1993), Wedemeyer noted four elements of every teachinglearning situation: a teacher, a learner or learners, a communications system or mode, and something to be taught or learned. He proposed a reorganization of these elements that would accommodate physical space and allow greater learner freedom. (p. 14)

Wedemeyer concluded that independent study, or distance education, can take place anywhere, anytime, offer a wider variety of choices, and meet a single learner's or multiple learners' needs.

Sammons (1990) also supported Wedemeyer by contending that individual differences can easily be accommodated in distance education because students are often given the opportunity to work at their own pace and receive guidance through a tutor (instructor). "Meaningful learning can occur 
because each student comes to the learning situation with his/her own concepts and purposes and can be guided to bring new ideas into his own conceptual scheme and to integrate them or change the scheme" (p. 158).

Wedemeyer cautioned that a good relationship between a teacher and a student is lost when schools depend solely on the use of check-off type lessons, multiple-choice and other objective scoring. He does not consider closed-circuit television, radio, telephone, teaching machines, computer or satellite as forms of independent study or distance education if they are "employed merely to replicate a regular class without broadening opportunity and shifting responsibility and freedom to the learner..." (in Keegan, 1990, p. 61).

Wedemeyer became critical of higher education's failure to use modern technology to emphasize learner independence and place greater responsibility for learning on the student. He contended that learning should take place through student activities that are made convenient for the student (cited in Keegan, 1990).

The concept of pacing, which can offer more opportunity for autonomy in distance education is addressed by Daniel and Marquis (1983). They feel that if a system has respect for the freedom and autonomy of individual students as its main priority, then it will allow students to begin and end a course whenever they choose. They cite that institutions 
involved in correspondence education in the nineteenth century allowed students to begin and complete a course when convenient as a sign of respect for the learner's freedom and autonomy. To keep students on track, schools often sent notes and considered financial incentives for completion. However, completion rates were very low with often the majority of the class not completing. Today, distance education programs actively encourage students to complete courses by building in events such as group meetings, scheduled broadcasts, and assignments with due dates. Pacing requires that an institution examine the concept of flexible rules as well as what resources students need to attain their goals.

Moore's (1993) theory of distance education is similar to Wedemeyer's in that he is concerned with the amount of autonomy learners have in setting objectives, choosing methods of study, selecting resource persons and media, and determining evaluation strategies. Moore also bemoaned the fact that teachers are often active but students passive. Moore used the term learner autonomy to describe the situation in which the learner rather than the teacher determines the goals, experiences and evaluation in a course. The degree of control and autonomy exhibited by a student is often dependent on the type of communications used and the quality of the communication process between the teacher and 
students (Garrison \& Baynton 1987). In very distant type programs, learners may take more responsibility, act more autonomous by making decisions about how to follow a course and "...use goals of their own, in their own way, under their own control" (Moore, 1993, p. 31). However, those goals may not coincide with those of the instructor or institution. According to Moore (1993), the sense of distance felt by the learner (transactional distance) is expressed by the amount of dialogue and structure found in a program or course. Dialogue refers to the interaction between the learner and the teacher; distance is greater when there is little dialogue. The possibility for dialogue can occur during the planning and learning phases of a course and is concerned with students' intellectual, physical, and emotional needs and should always be constructive, respectful and of value to all parties. Moore (1993) stated that the extent and nature of dialogue is determined by the educational philosophy of the individual or group responsible for the design of the course, by the personalities of the teacher and the learner, by the subject-matter of the course, and by environmental factors.

The type of communication used in an educational program has an important influence on the kind of dialogue between the instructor and the students. By utilizing different media, teachers can lessen the transactional 
distance. Moore (in Verduin \& Clark, 1991, p. 122) offers the following examples of the categories of transactional distance.

Example

Program

Program with no dialogue and Independent readings no structure

Programs with no dialogue but Radio or telecourses with structure

Programs with structure and Correspondence study dialogue

Programs with dialogue and no Rogerian tutorials structure

Some programs are very responsive to the needs of individual learners while others are highly structured and allow no flexibility based on learner feedback. A recorded television program, an audio and video tape, or a self-help book are examples of very structured programs because they allow no flexibility or human dialogue based on learner feedback. Correspondence education uses mail for two way interaction (dialogue). Computer conferencing allows for more individual dialogue as well as dialogue between students. It allows each student to interact with others whenever the timing is right for the student. Moore (1993) stated that "such dialogue by learners to learners within and between groups makes it possible for distance learners to 
share in the creation of knowledge" (p. 33). He placed teleconferencing above the tutorial and below correspondence. While some educators contend that students using teleconferencing media, compared to self-directed study, are less autonomous, Moore believed the increase in student participation through media eventually resulted in more autonomous learning. He claimed that the development of teleconference media allowed faster dialogue and a less structured program. He is, however, concerned that some instructors who use interactive media overstructure their classes and make them into one way mediums and lose the potential dialogue that is possible in a looser structure. Moore contends that much effort is required to develop and implement a successful distance education program because so much is dependent on content, level of instruction, learner and instructor characteristics, use of media and the right degree of autonomy. Generally, programs with little transactional distance that employ dialogue, and have an open structure best support the individual growth of students.

Delling (in Ljosa \& Sandvold, 1988) addressed student autonomy from the perspective of the student. He considered a school to be a helping organization that initially assisted students in doing everything they were unable to do for themselves. Eventually the learner, in this environment, becomes autonomous and the functions of the school become 
that of an information and documentation center.

Verduin \& Clark (1991) expanded on Moore's concept of distance and autonomy to include the ideas of student support, general learning competencies and specialized competencies. Field independent students (those not needing emotional support from the home institution) may only need support to answer questions concerned with subject matter but field-dependent students may also need emotional support. Distance education students should also possess general learning competence, often referred to as self-directedness, which refers to an adult's skill in taking part in discussions, studying, reading and writing and creating adequate research papers. Structure and specialized competencies refer to the amount of specialized knowledge needed on the part of the learner to be successful in a particular course and should be required before allowing students to participate. An example is knowing algebra before moving on to statistics (Verduin \& Clark, 1991). Holmberg (1988) contended that a rigid course structure that all students have to follow results in learning that is teacher centered as opposed to student centered. He believes it should be possible to offer choices of material to study along with different approaches to increase learner autonomy. Gibson (1993) reported that individuals who preferred independent study and telecommunications for courses felt 
they should have the primary responsibility for decisions affecting their education. Those learners exhibited a greater need for autonomy and flexibility and wanted to set their own goals and make decisions on their objectives. Computers have made it possible to design learning material "in non-linear text and to create multiple pathways for readers with different interests to permit them to determine their own individual sequence based on their individual needs" (Jones, Kirkup \& Kirkwood, 1993, p. 32). Through the use of desktop publishing, the options for custom learning becomes possible and this leads to increased learner choice and power (Bell \& Tight, 1993; Bosworth, 1991).

The constructionist learning theory has readily been integrated with distance learning. Students are encouraged to be active learners and take more responsibility for designing their own learning. Students construct their own knowledge by mediating input from the outside world to determine what they will learn. They perform meaningful activities by gaining information through multimedia such as internet, e-mail and electronic library resources and construct their own meaning through the design of their own projects in conjunction with a support person. This person serves as a coach and challenges thinking while modeling behavior to help students construct their own knowledge. To enable students to become empowered learners, the 
instructor's role is no longer to know all the answers but how and where to find them (Crotty, in Distance Education enline Sympesium, 1995). However, with freedom comes greater responsibility for learning on the part of the students than in traditional education and the possibility of higher dropout rates (Gillard, 1993).

The distance education theorists, under the category of autonomy and independence, believe that learners in a distant learning environment have the potential freedom to learn more and be more responsible for their learning than in a traditional face-to-face classroom. Since students learn at different speeds, individual differences can easily be accommodated in a distance learning setting where students have the potential to control their own pacing and use their own ideas and thoughts as springboards to new learning. Ideally, students should select their own goals and objectives, choose their methods of study, select their own resources and media and plan evaluation strategies in conjunction with the instructor. In distance education the potential exists for the instructor to take a more passive role in the teaching process and adapt a coaching role to help students expand their own knowledge and growth.

Theories of industrialization of teaching. In 1967 otto Peters, from Germany, categorized education as "face-to-face or industrialized teaching which is based on an objectivised, 
rationalised, technologically-based interaction" (in Keegan, 1990, p.13). Industrialized teaching or distance study is compatible with the organization, principles and values of an industrial society (Amundsen, 1993). Medieval universities relied mainly on lecture and seminars, and education in the industrial age stayed that way except for distance study. Distance education was made possible in Europe and the U. S. about 130 years ago due to a reliable and quick postal service and the opening up of railway lines (Peters, 1983). Peters, in the 1960s, used the theory of industrial production to interpret the phenomena of distance education. However, he did not equate the teaching and learning process to an industrial process, just the operational activities of an educational system.

walker (1993) referred to the industrial model as Fordist (Henry Ford) because it required a mass audience, long term planning, high development costs, a relatively stable product, research and development, advertising, promotion, maintenance and a strong infrastructure. By applying the industrial concepts of the division of labor, assembly line and mass production to distance education, Peters (1983) concluded the amount of input, time and money required for distance education could be reduced.

Peters (1983) believed that through industrialization, the entire teaching process can be scientifically analyzed, 
reproduced, made available anytime to an unlimited number of people in geographically, underpopulated and dispersed locations and be more scientifically evaluated and improved. Material for the development of a course could be gathered by experts and conveyed by a different group of people while others may counsel and assess student progress. A lecturer may no longer lecture but revise written instruction to make the process more effective. "Tutors/instructors can be relieved from having to convey course materials and instead aid motivation, provide individual support, structure course contents, identify problems and establish connections" ( $p$. 108).

Mechanization is embodied in the communication and electronic data processing utilized in distance education programs. The assembly line concept comes into play when teaching materials are passed from one area of responsibility to another. Materials may be printed, stored, sent to the learner, returned by the learner to be checked, evaluated and recorded by the administration. Teachers and students may never meet throughout this process in one place. Peters (1983) compares this to the concept of "no longer sending workers to a car to work on it but transporting the necessary parts to the worker so he can participate at his work station" (p. 102).

with the advent of a post industrial society, Peters (in 
Amundsen, 1993) contended that distance education must change to correspond more closely. New communication technology, along with decentralized decision-making, and an emphasis on personal values, has lead him to focus more on interdependence in distance education rather than independence.

Theories of interaction and communication. Holmberg, (1981) wrote that distance education has long been criticized for encouraging rote learning. A teacher should be a facilitator of learning not just a disseminator of information. Holmberg (1989) and Burge \& Haughey (1993) stated that students should have activities over and above reading, watching and listening. Education needs to engage students in an intellectual activity that makes them try out new ideas, reflect, compare and apply critical judgement to what is studied. "Students and teachers need to confront paradoxes, ambiguities, uncertainty and disorder by reflecting on experiences" (Walker, 1993, p. 33). Holmberg stressed interaction within materials through exercises, questions and self-check activities. Increased dialogue in distance education, made possible through new communications media, also encourages the skills of critical reflection and transformative learning (Burge \& Haughey 1993). Distance students can be in a more intimate relation with a teacher who communicates with them as individuals as opposed to a 
large lecture hall with the instructor present (Gillard, 1993).

Holmberg (1986) is well known for his theory of guided didactic conversation which emphasizes rapport between a course developer and students. This conversation can be simulated in pre-produced courses through written materials, communicated through telecommunications, or face-to-face. To actively involve students and check their understanding, as opposed to just receiving information, Lockwood (1994) wrote that self-assessment questions along with in-text questions and exercises had to be included in distance education texts to reproduce communication that would normally take place between teacher and student during the learning process. The instructor can raise questions, have learners formulate answers and then provide follow up comments. Cookson (1990) has shown that drop-outs in correspondence programs tend to desire a preference for additional methods to support correspondence. Studies conducted at Norway's NKI school (Cookson, 1990) demonstrated how guided didactic conversation when applied to inactive or potential drop-outs made a significant difference. Postcards and two letters were sent to students to encourage resumption of their activities when they failed to submit at least one assignment during a one month period. Positive results were achieved and many students resumed their academic activities. 
Holmberg (1986) contended that messages given and received in conversational forms are more easily understood and remembered. He encouraged the used of personal and possessive pronouns, (I, my, you, your) in written materials to increase feelings of personal relationships and motivation. Guided didactic conversations give advice and suggestions on what to do and what to avoid, what to pay attention to, and consider with reasons why. Students are invited to exchange views in an attempt to involve them emotionally.

Many experts in the field caution instructors that when commenting on assignments it is necessary to speak to each individual student using a personal, informal and flexible style (Clenell, Peters \& Sewart, 1983; Daniel \& Marquis, 1988; Wlodkowski, 1985). To do this effectively, instructors have to know their students' level of knowledge and then convey relevant advice. Comments need to be supportive of students' self-esteem and positively worded to avoid being abrupt or curt. Thorpe's (1988) work showed that whether or not there was a grade given to an assignment, the learner looked for feedback on progress and specific help. It is important that the quality of feedback encourage distance learners who may easily be discouraged. Comments also need to be specific and clear and include examples for modeling. Rekkedal (1983) and Holmberg (1989) conducted studies 
measuring the effects of turnaround time on assignments for students in distance education programs. When median turnaround time on assignments was reduced from 8.3 days to 5.6 days, completion rates for assignments soared from 69 to 91 percent (in Cookson, 1990). Rekkedal's students were satisfied with a turn-around time of one week or less; more than one week resulted in a large amount of student dissatisfaction. Willis (1993) found that turnaround on assignments can easily be reduced today through the use of electronic mail and fax.

Moore (1995) and Threlkeld \& Brozoska (1994) concurred on the necessity for the presence of a local coordinator at distant sites in programs using real-time interactive technologies. Effective communication between an instructor and a local coordinator allowed the instructor to know what was going on at the distant site and helped identify any student problems or opportunities. At sites where there is no live interaction, a facilitator is needed to mediate between the learners and the goals set by the material and to meet learners' interpersonal needs.

In order for a local coordinator to communicate information to the instructor, the coordinator must be able to communicate easily with students and have their respect and confidence. Coordinators should be competent in the technical aspects of the medium, be able to handle 
administrative procedures and have some instructional competence. Preferably an individual who has previously taken the course and knows the subject matter is a good choice. The coordinator, working in conjunction with the instructor can create an environment that is friendly, supportive and relaxed and demonstrates good planning. Thomas (in Daniel \& Marquis, 1983) described the role of a counselor (site-administrator) in distance education as a caring manager who has a positive regard for the students and exhibits enthusiasm, initiative, sympathy, empathy and helpfulness. The environment is extremely important because studies (Winn, 1979) have shown that highly anxious students learn better when they are closely supervised while less anxious ones are more capable of working on their own. Hudspeth \& Brey (1986) wrote that a supportive environment is communicated through verbal and non-verbal attitudes that ensures that everyone who desires can participate in a discussion. Thorpe's (1994) work demonstrated that what is learned is influenced by the immediate social relationships through which the learning takes place. Some learners wanted to share their interpretation of course materials and be informed of their progress throughout the course. Some stated it was harder to think of examples when studying alone, and some experienced feelings of never really being sure you have done it right. Other students desired to 
relate things to direct experience and receive responses back from others. Thiel (cited in Brookfield, 1986) reported that successful independent learners stated that learning networks of fellow learners were their most important resources.

Other learners can be used for information sharing, as models and resources and for providing an evaluation measurement.

Several studies (Oliver, 1994; J. Gorham, 1988; Willis, 1993) showed that teacher immediacy behaviors (behaviors that encourage interpersonal communication) in both distance and traditional classes reduced distances between instructor and student, and increased student learning and attitudes toward instruction. These behaviors focused on the students not the delivery system and included choice of words, tone of voice, body movements, direct eye contact, facial expressions, smiling, humor, asking questions to involve students and praising contributions. Moore (1989) contended that many visual instructor behaviors found in traditional classrooms need to be replaced in a distance education setting. This can be accomplished by starting class on time, using a natural style, speaking slowly and clearly and avoiding reading from a script, using visuals effectively, employing a frequent change of pace or stimuli and frequently drawing the students into discussions and referring to them by name.

Cyrs \& Smith (1990) and Ostendorf (1989) cautioned about students' fear of technology and embarrassment that can serve 
as a barrier to two-way communication. They advised initiating interaction within the first twenty minutes of each session, using a student's name when asking a question, posing questions orally and in writing, waiting for answers, and planning questions in advance.

Bath (in Holmberg, 1986) from Sweden did most of his research in the area of correspondence education. He integrated the concepts of modern educational research into distance education by incorporating the teaching models of Skinner, Ausubel, Bruner, Rogers, and Gagne. He focused on the concept of two-way communication and how it supported individualizing with regard to students' previous learning patterns, readiness to learn, need to learn, anchoring the material to previous knowledge, evaluating students' comprehension of the basic concepts and principles, assessing progress toward objectives, evaluating the quality of learning, assigning a grade, establishing a good personal relationship with the learners, and helping them develop positive self concepts.

Baath especially focused on Gagne's instructional functions. To arouse attention and motivation, Baath addressed the factors of structure and function. Structure referred to external factors such as color, design and other factors of perception geared towards arousing attention. These are evident in a document that has an attractive cover, 
is carefully planned, easy to read, has good use of print and uses appropriate diagrams, drawings and media. Function referred to motivation and addressed aspects such as needs, experience and attitudes. A motivating presentation of objectives addresses what the student can achieve from taking the course and appeals to the students' needs for success and security. Bath also suggested linking the subject to current developments and practical life as well using concrete examples, linking to previous knowledge and interests, developing a timetable, informing the students about their progress, making assignments in order of difficulty and ensuring rapid feedback on them with timely correction of students' solutions.

Bath stressed the importance of texts in distance education and stated they should be logical, orderly and have continuity and consistency. Logical arrangement of materials with headlines, paragraphs, italics, underlining, capitals, indentation of paragraphs, lists, advance organizers, similarities and contrasts with previous material, exercises, summaries and anticipating and addressing in advance possible questions by students helps guide and structure course material to make it more understandable to students.

Bath stated that learning occurs when a teacher helps students learn about themselves. Encouraging distance students to be active learners ensures this will happen. 
Exercises, games, assignments, supplementary material, enlisting the aid of students in constructing part of the instructional material helps make learning active (Baath, 1983, pp. 276-288).

The distance education theorists included in the category of interaction and communication believed a teacher should function in the role of a facilitator and encourage students to actively try out new ideas, reflect on new material and apply critical judgment. Interaction between instructor and students can occur through printed exercises or through telecommunication media to encourage students to do more than listen, read or watch. A natural style of communication, combined with a familiarity with students and frequent interactions can reduce the sense of distance between instructor and students. The best distance education programs integrate the concepts of modern educational theory and encourage the use of good objectives, well planned materials, linking to students' current level of knowledge and using examples pertinent to the students.

Adult educators were one of the earliest adopters of distance education because they realized that adults, even after graduation from school, would continue to need education at various times throughout their lives and possibly while engaged in full-time work. The home study movement for adults acknowledged that learning needs could be 
satisfied wherever and whenever they occur. Adult Education

In 1874, distance education in America had its beginning with the Chautauqua Institute. (Jarvis, 1993). W. Rainey Harper, of Yale, who headed the program was very confident about the future of this kind of education. He felt the student who studied through correspondence learned better than the student who learned in the traditional classroom. He was optimistic that eventually more study would be done through correspondence than in the classroom (Simonson, Schlosser \& Anderson, 1993).

Distance education is extremely well suited for today's adult learners because almost $80 \%$ of them are employed and have too little time to attend to too many demands. In a survey by Brey \& Grisby (in Verduin \& Clark, 1991) the majority of telecourse students stated that no travel time and conflict with work schedules were the prime reasons for enrollment. Many adults also preferred to learn at their own pace while employers are more likely to allow employees to purchase a module to study, or use teleconferencing, than they are to send them off to study at a location remote from the work place. Knowles stated that "...learning is most effective when it is related to and integrated with working and living" (in Garrison, 1989, p. 107).

Despite the strong relationship between distance 
education and adult education, little has been done to join these fields. Holmberg wrote distance education is basically an educational discipline and in part it could be regarded as a special kind of adult education. Any progress we make in understanding distance education must be first based upon an appreciation of education with its assumptions and theories; ... and must be based on what the adjective 'distance' means to the practice of education. (Garrison, 1989, p. 108)

As distance education becomes more critical to adult education, an understanding of adult learners is necessary to design and deliver worthwhile programs. Technology without knowledge of the learner, and knowledge of the learner without technological methods to support communication will ensure failure (Garrison, 1989).

Adult education prides itself on meeting the needs of learners throughout their lifetimes. Knowles stated that the most visible characteristic of adult education is its expansiveness and flexibility. "Adult education has a history of adapting to new social needs and serving elements of the population previously unreached..." (Garrison, 1989, p.106).

According to Knowles (1975), "... half of what a person has acquired at age twenty may be obsolete by the time that 
person is thirty" (p.15). Education is no longer preparation for a productive adulthood; what is needed is a continual updating to compete, because high technology employment requires the learning of new skills (Long, 1983). According to Toffler (1990), today's, working adult can look forward to at least seven possible career changes. With the Industrial Revolution, second wave factories as described by Toffler (1990) needed interchangeable workers whereas third wave (non-industrial type jobs) required diverse and continually evolving skills that no longer allowed workers to be interchangeable. According to Toffler (1985) separation rates per employee have escalated almost $50 \%$ in some industries while new hire rates have climbed tremendously and are drawn from groups until recently minimally represented in the work place. What is needed is training and retraining on a tremendous scale for more than simple occupational skills.

In 1970 older students accounted for $28 \%$ of college level students. Today, adult students make up over $83 \%$, or ten million of the country's 12 million college students (Portway \& Lane, 1994).

Increasing life expectancy rates, in conjunction with the rapid decline of social security funds and lowered pension benefits, necessitate that adults not retire but retrain to compete in a technologically advanced society. In the United States in 1900 four percent of the 
population was sixty-five years and over; this percentage had doubled by 1960, and the numbers had risen from three million to twelve million. The median or middle age in 1900 was sixteen years; in 1960 it was thirty-one years. Life expectancy tables in 1955 provided the prediction that forty-year olds could expect approximately thirty-three more years of life. (Kidd, 1973)

Education used to end when people began working full-time, however, today it will go on throughout life and adulthood. Lower skilled minorities and women, entering the work place at a faster pace than ever before, will require education and training to keep pace with work place needs.

Cross wrote that adults assumed many roles related to occupation, family and community, and a change in any of these roles had a strong influence on the need for more learning. The role of an adult today requires continuous learning while still maintaining the responsibilities of caring for oneself, and possibly children and parents.

Research on adult learning demonstrates that adults can learn well beyond their fifties and can continue to learn throughout their lives especially when they set their own pace. Knox (cited in Brookfield, 1986) stated that "almost any adult can learn anything they want to, given time, persistence, and assistance" (p. 28). 
Knowles (1975) and Boyd \& Apps (1980s) wrote that adults need to be self directed in their learning. However, Knowles believed that the tendency of adults to be selfdirected is not generally transferred to educational settings. Many adults were exposed to the kind of education where their minds were filled with information decided on by another party. "People who take the initiative in learning (pro-active learners) learn more things and learn better, than do people who sit at the feet of the teacher passively waiting to be taught" (reactive learners) (Knowles, 1975, p. 14). Knowles described self-directed learning ... as a process in which individuals take the initiative with or without the help of others, in diagnosing their learning needs, formulating learning goals, identifying human and material resources for learning, choosing and implementing appropriate learning strategies, and evaluating learning outcomes. (p. 18) According to Knowles, as adult learners mature they have a need to move from dependency toward increasing selfdirectedness. Adults accumulate a large amount of experiences that can become resources for learning. They remember best from doing as opposed to reading, listening and writing, and are very motivated when they develop a need to cope with real life problems. Some adults are fearful of learning and need to be in a supportive and caring 
environment where they are free to express themselves, reveal their feelings and receive acknowledgement of their achievements. Since adult education is learner centered, instructors should serve as resource persons, and not try to control or manipulate students.

Carl Rogers is representative of the humanistic school of psychology which concerned itself deeply with the problems of learning. He taught that human beings have a natural potential to learn when they see the relevance of the subject and when external threats are minimized. He concurred with Knowles that learning is acquired when the learner is involved and participating. He believed that when learners learn the process of learning and retain an openness to experiences, the process of change occurs (Rogers, 1969). Tough (1971) identified the desired characteristics of an adult instructor as having a high regard for learners' self-planning competencies and viewing themselves as participating in a dialogue between equals with learners. Sunanmali (in Brookfield, 1986) stated that a facilitator should encourage the adult learner to function as selfdirected by progressively decreasing the learner's dependency on the educator. Rogers (1969) wrote the roles of facilitation are: setting the climate for the group, helping to clarify the purpose of individual and group study, being a flexible resource while making available the widest resources 
for learners, accepting the intellectual and emotional sides of students, participating in the learning group and recognizing and accepting one's own limitations.

The majority of today's college students are adult learners who often work full-time and need to update their skills as well as new entrants to the work place who may lack the needed skills. These adults possess a large store of experiences which can easily be used to facilitate the learning experience. Adult learners have a propensity for self-directed learning, want involvement in the learning experience, and communication and dialogue with the instructors. Good communication models, combined with advanced telecommunication media, can support the needs of adult learners engaged in distance education programs. communication

DeFleur \& Ball-Rokeach stated that ...the process of communication has been completed, when the internal experiences of the receiving person are more or less parallel to those intended by the communicator. The effect however, can only be ascertained by some form of sustained reciprocal communication. (in Garrison, 1989, p. 13)

Saloman (1981) explained "communication in its wider sense as a process whereby people convey knowledge, influence each other, and create and maintain a basis of shared notion which 
they then use as a personal and shared guide" (p. 38). Rountree described an educational transaction as a

... role-alternation... where students act not simply as receivers and processors of teacher-messages but also as generators and senders of messages (about themselves, their ideas, their perceptions, their experiences) which the teacher values and allows to change his personal perspective on the student, the subject under discussion, his own feelings, or some other feature of the situation. (in Garrison, 1989, p. 15)

Garrison (1989) agreed with Rountree when he stated that knowledge depends upon what one does with information and how it is integrated into existing cognitive structures through interaction with others. Knowledge is awareness developed through critical analysis. The function of education is to develop the skills of critical analysis. (p. 6)

Garrison (1989, p. 13) believed that "understanding the educational transaction in distance education depends upon understanding the communication process". Peters referred to communication in distance education as a shared experience. Sewart called it mediations while Moore used the term dialogue (Garrison, 1989,). Regardless of the term used, good communication allows the media used in a distance education program to work in conjunction with the principles 
of adult learning. At the opposite extreme, communication can be "...mediated by technology that often limits the form, frequency, and immediacy of the messages" (Garrison, 1989. p. 227). Larsen stated that "if our understanding of communication interactions do not keep pace with advances in technology, we will be unprepared to put that technology to use in a productive way" (in Garrison, 1989, p. 20).

Rowntree contended that communication is sparse in education, and in a distance education setting, where books, films and lectures are predominant, there is often one way transmission of information. Education with one way transmission can be seen as "manipulative and may be regarded as indoctrination" (in Garrison, 1989, p. 14). Store and Armstrong stated "the need for interaction in education is necessary and the use of media with one-way communication and no dialogue raised basic questions regarding the legitimacy of an educational transaction" (in Garrison, 1989, p. 15).

Wedemeyer wrote that "in distance education we have something of a paradox - distance education is dependent upon communications technology, but effective communication and instruction are considered independent of these devises" (in Garrison, 1989, p. 17). Garrison \& Shale explained that in traditional face-to-face education, transmission of information and discussion is often represented by a lecture followed by a discussion period. In distance education the 
course content is often prepared on print or tape and transported to the student.

Interaction required to close the communication loop is an activity separate from the transmission of information and frequently is supported by a medium different from that used to distribute the content. Without the opportunity for sustained two-way communication, the emphasis will be on the preparing and transmitting of content, and negotiation for restructuring content to suit the learner is restricted. (in Garrison, 1989, p. 19)

In today's distance education programs, there is often more emphasis given to preparing or packaging course information and less time devoted to two-way communication. Winn wrote that

...it is through the sound application of basic principles of communication and instruction, not through bigger and fancier gadgets, that we will be able to enhance distance education through technology. The devices of communication may be remarkably successful at making information available to students but the way information is delivered has little effect on the way it is understood. We can only facilitate good understanding by good planning and sound instruction. (in Garrison, 1983, p. 18) 
Garrison took issue with Holmberg's use of guided didactic conversation in correspondence education as a substitute for communication and interaction with a teacher/tutor. "The fact that there may be a form of internal dialogue when students interact with print materials does not meet the requirements that there be some opportunity for negotiation of meaning" (1983, p. 18).

In distance education, communication needs to be concerned with the role of feedback and how media facilitate or hinder communication. Store and Armstrong (in Garrison, 1989) mentioned five characteristics of feedback: immediacy, regularity, explanatory as opposed to judgmental, conciseness, and clarity. Many distance education programs provide judgmental feedback which confirms if a student is right or wrong. However, this does not meet the criteria of two-way communication since there has been no mutual influence.

To understand the role of communication in distance education, Garrison (1989, p. 21) presented a conceptual ordering of the differences among modes of communication found in distance education. The model illustrated that communication that can be used to both deliver and support education at a distance.

1. One Way Communication 
1. Direct (no electronic transmission)- lecture, print, audio/video cassettes

2. Mediated (electronic transmission)- broadcast (television, radio)

2. Two-Way Communication

1. Direct-face to face dialogue

2. Mediated - teleconferencing

i. Real

a) Immediate- audio, video, computer conferencing, telephone

b) Delayed - electronic mail

ii. Simulated-intelligent computer assisted learning (ICAL- using expert systems, technology to simulate a sophisticated teacher)

The Shannon mathematical theory of communication (1949) based on the statistical concept of communication had a profound effect on the development of most communication theories. Shannon and weaver adapted it to address engineering problems and presented it as a schematic diagram of communication. Figure 2 depicts the Shannon Weaver communication model as a one way linear process involving a communication source, a message, a channel of conversation and a receiver. 


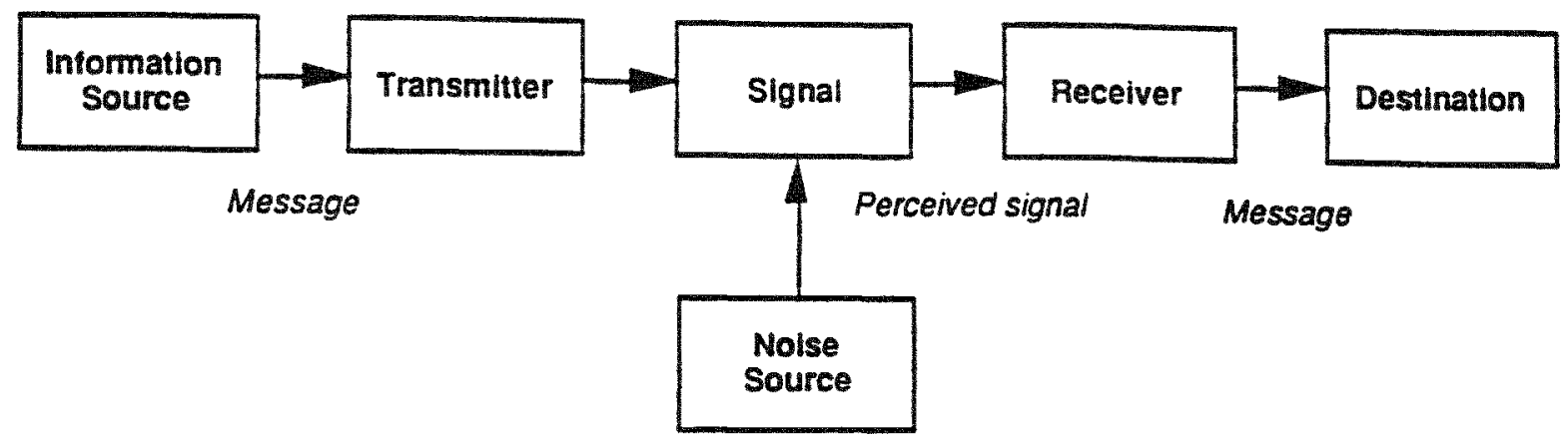

Eigure 2. The Shannon-Weaver Communication Model

Note From "In Support of a Functional Definition of Interaction", by E.D. Wagner, 1994, The American Journal of Distance Education, 8 (2), p. 22. Copyright 1994, by The American Journal of Distance Education. Reprinted with permission.

Schramm adapted the Shannon Weaver Model for human communication problems and added a feedback loop in Figure 3 to include the idea that both parties in a communication model need to be active and information must be exchanged in both directions. Field of experience is added to show how experience and context influence the interpretation of transmitted information. 


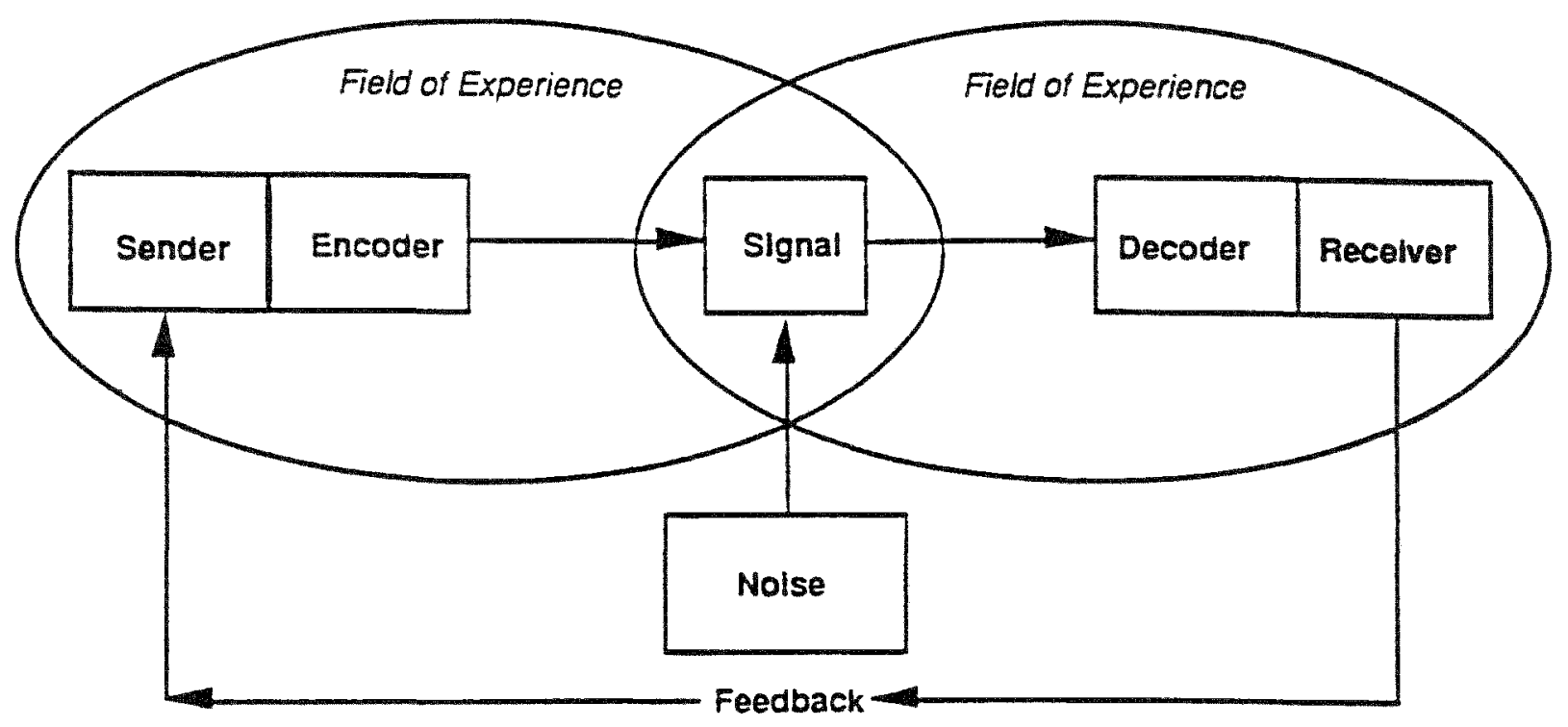

Eigure 3. The Shannon-Schramm Communication model showing information exchanged in both directions.

Nete From "In Support of a Functional Definition of Interaction", by E.D. Wagner, 1994, The American Journal of Distance Education, 8(2), p. 23. Copyright 1994, by The American Journal of Distance Education. Reprinted with permission.

Chute adapted the Shannon-Weaver and Schramm models to help distance educators visualize media with communications. He added examples of message transmission media (Eigure 4) such as a source (in addition or in place of an instructor) for transmitting information for instruction. He cautioned that media is only a means for sending information and that information needs to be transmitted interactively between 
instructor and students or information to be learned.

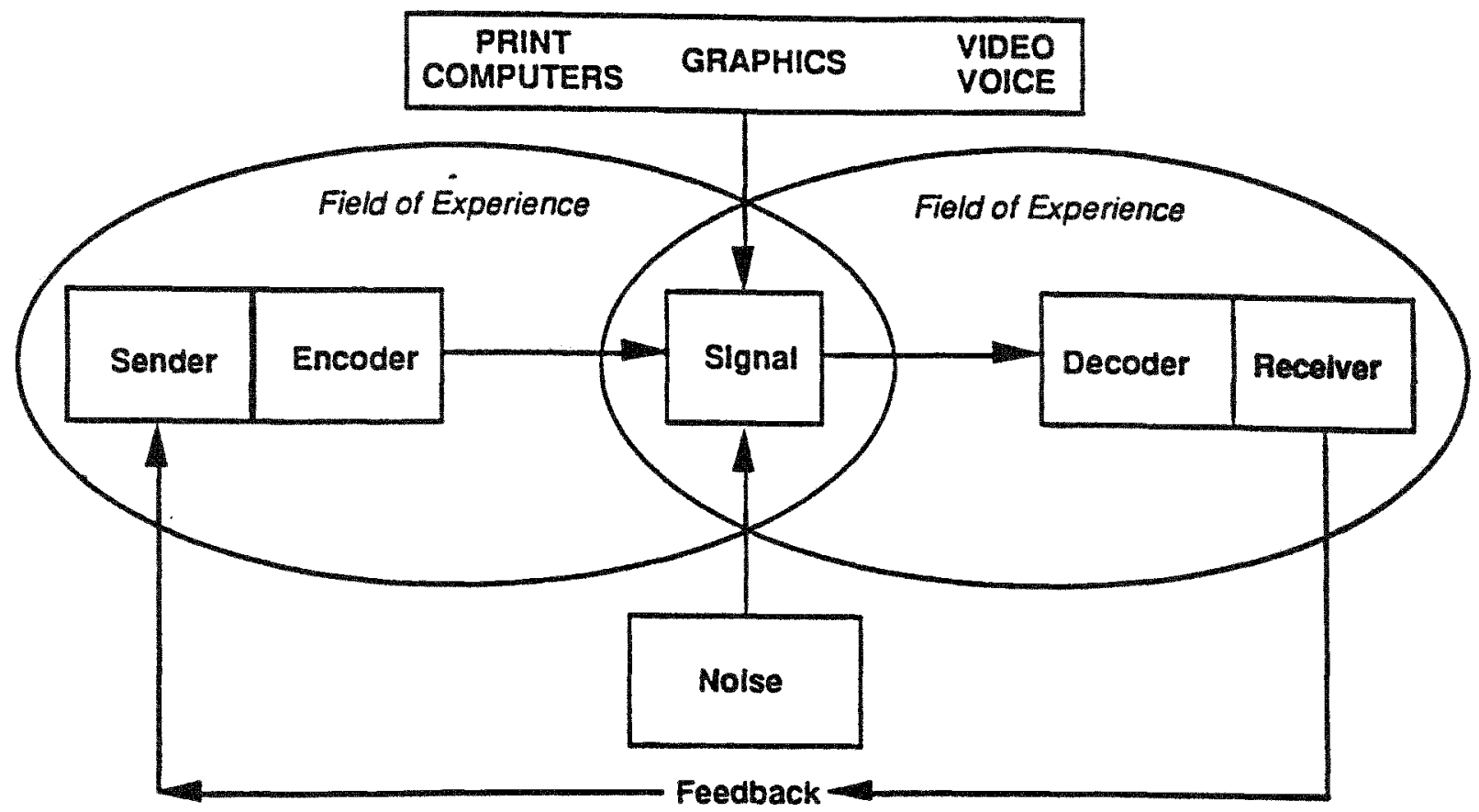

Figure 4. The Shannon-Shramm Communication Model Adapted by Chute showing the mechanics of interactive telecommunications.

Note, From "In Support of a Functional Definition of Interaction", by E.D. Wagner, 1994, The American Journal of Distance Education 8 (2), p. 24. Copyright 1994, by The American Journal of Distance Education. Reprinted with permission.

In the Interactive Information Transport Model (Figure 5), wagner explained that transmission is accommodated by a variety of transport; coaxial cable, twisted copper wire, fiber optics, satellite transmission, 
microwave transmission, and broadcast and narrowcast television transmission... The network facilities provide a means of switching, multiplexing and bridging signals to direct the electromagnetic information to their intended destinations. The terminal equipment consists of the telephones, fax machines, modems, codecs, cameras, monitors, and computers that transform the electromagnetic signals into pictures, letters and figures that represent the information sent from the source to the receiver (Wagner, 1994, pp. 25).

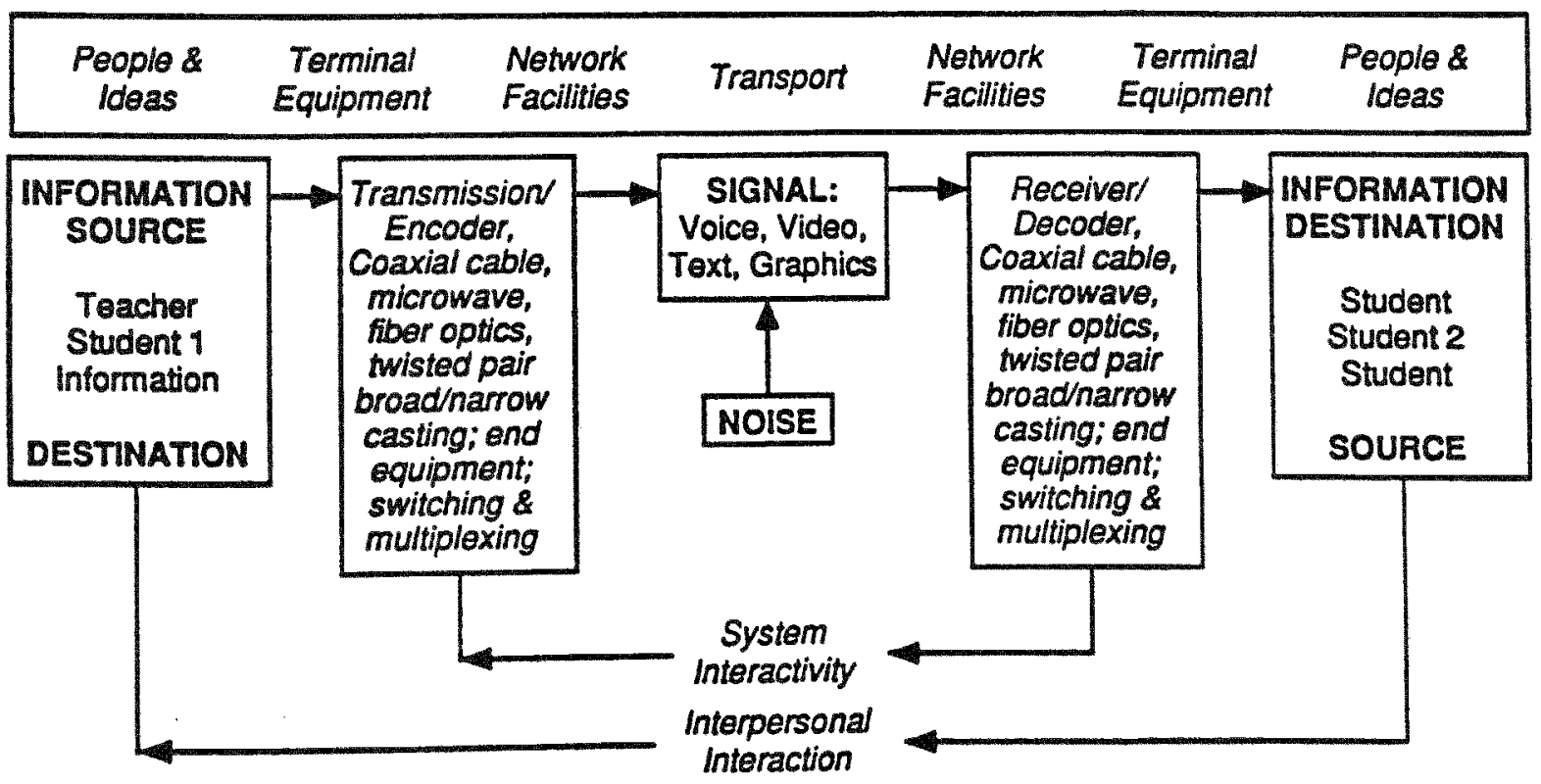

Eigure 5. An Interactive Information Transport Model showing system interactivity as well as interpersonal interaction. Note. From "In Support of a Functional Definition of Interaction", by E.D. Wagner, 1994, The American Journal of Distance Education, 8(2), p. 25. Copyright 1994, by The 
American Journal of Distance Education. Reprinted with permission.

Wagner's contention is that effective instructional delivery of voice, video, text and data signals depends not on the particular media/technology used but on the establishment of effective two-way communication that takes into account the students' personal experience and environment.

Education needs to be a shared event where the experiences of those receiving information are parallel to those intended by the communicator, and that all parties have the opportunity to influence each other. In distance education, there is sometimes only a transfer of information between parties and little communication. Good communication allows the media used in a distance education program to work in conjunction with the principles of adult education.

Several studies on interaction, achievement and satisfaction in distance education have been conducted in university and the military settings. Several are reviewed in the empirical review section and are classified under the headings of university or military.

\section{Empirical Review}

In the empirical review section there are some studies based on small numbers of subjects. Many studies conducted in distance educational settings have used small numbers of 
subjects and many have been conducted on non-adult populations. Those conducted in the military arena usually use large sample sizes and pertain to adult learners. University setting

In 1989 Ritchie and Newby conducted a study comparing the factor of interaction in distance learning programs with that available in the traditional classroom. The study compared the influence of the environment in which instruction was delivered on the frequency and type of interactions, performance, and student attitudes. A comparison was made between interaction in a traditional face-to-face classroom, a studio classroom (live instructor), and a distance classroom equipped with two-way audio. Twenty-six undergraduate subjects were randomly assigned to one of the three groups. Group one was a traditional classroom with an instructor present; group two was a TV broadcast studio classroom with an instructor (live studio) and group three was a studio classroom with television monitors and no instructor (distance). Instruction from the Iive studio was broadcast to the distant studio. The live studio group, as well as the traditional classroom, could see the instructor at all times. The distant class alternated between a view of the instructor and the printed materials. The instructor delivered the same content to each of the groups. After instruction, a pencil and paper performance 
test and attitudes survey were administered. Combined group comparisons indicated a significant difference in participant achievement for the three groups of subjects. A multigroupgroup comparison of test scores showed the distance group scored significantly higher than the studio group while the traditional group did not differ from either of the other two groups. Perhaps the difference in tests results was due to the confusion or lack of attention of those within the studio group due to unfamiliar cameras, microphones and lights.

Students in the traditional classroom interacted twice as often as the combined total of the studio and distance groups. This collaborated other studies that have shown that interaction in normal, face-to-face meetings occurred more often than during televised meetings. Those participants who experienced more interaction also reported feeling more at ease and more enjoyment of the instruction. Participants at the distant site reported enjoying teleconferencing less but felt they accomplished more. Those in the normal classroom rated instruction significantly more enjoyable than those in the distance group, while those in the studio group reported enjoying instruction to a significantly greater degree than those in the distance group. No difference was found to exist between the enjoyment of those within the traditional versus those in the studio group.

Significant differences were also found in the amount of 
perceived comfort experienced in the learning situation. The traditional classroom rated it higher than the studio group or the distance group. The opportunity to ask questions was perceived to be greater in the traditional setting when compared with either the studio group or the distance group. When asked about their perception of involvement, those in the distance group rated their experience significantly lower than those in either the studio or normal classroom setting. In this study distance students experienced less interaction, less involvement, less ability to ask questions, and less overall enjoyment. More positive perceptions were reported by the traditional group who interacted most often. Even if interaction does not effect performance, attitudes may affect drop-out rates.

In the Fall semester of 1982 Wagner and Craft, at Arizona State University, used instructional television fixed service (ITFS) for the first time to televise eighteen courses on campus to five corporate locations. This allowed employees to take classes during working hours and save the time that normally would be spent commuting to campus.

In 1986, 52 courses were presented by distance to 26 receiving sites with over 700 students. An 18 item survey was developed to assess student attitudes toward the system. A total 194 students returned the surveys. One of the questions on the survey dealt with participant satisfaction 
with the ITFS system. The overall mean for all students indicated attitudes were more favorable than neutral. Over 92: off the students strongly agreed or agreed that the main reason for enrolling in the class was because it was offered at their location. Ninety-one percent agreed they would take another ITFS course if offered. Least favorably responses were concerned with not being able to hear questions and comments from the students in the studio. Students also assigned a less than satisfactory rating to items that referred to how tests and homework were returned. Student attitudes were quite favorable toward most components of the system.

Fulford and zhang (1993) examined learner perception of interaction in relation to learner satisfaction in a course delivered by interactive television using ITFS and point-topoint microwave signals to connect six classrooms affiliated with a teacher training program at the University of Hawail. The two-credit two-semester course in the study was offered for 10 after school sessions. Two-hundred and thirty-three learners participated though not all participants were present on all instructional days. A total of 123 participants provided complete data in the three sessions examined in the study. Instruction was delivered only to receive-site classrooms; there were no participants at the origination site. 
The findings suggested that when learners perceived the level of interaction during class to be high, they were more satisfied with instruction then when they perceived the level of interaction to be low. Systems that allowed learners to comment during class positively influenced learning and satisfaction. However, overall classroom interactions may have a stronger impact on learners than a perception of personal interaction. Vicarious interaction within the class as a whole may have resulted in greater learner satisfaction than did the engagement of each participant. In distance education programs there is usually insufficient time to allow every student to participate in the discussion. However, the study found that by maintaining frequent interaction, all students remained alert since, no one knew who would be called on next. Classroom interactivity has the potential to keep all students alert and help make them feel an integral part of the class whether or not they participate all the time.

Denton, Clark, Rossing and $O^{\prime}$ Connor (1982) conducted an inquiry to examine the potential of two-way television as an instructional medium for medical faculty at the college of Medicine at Texas A\&M University. Instruction was delivered to students approximately 85 miles from campus to help reduce the time spent on transportation for professors. Presentations were made by seven volunteer medical faculty 
who taught for nine months from March through November, 1982. One-half of the presentations were made through two-way interactive television and one-half by professors in front of the class. The Classroom Observation system (COS) form, based on Gagne and Briggs events of instruction, was developed to obtain data regarding the instructional moves of the professor during class presentations, oral and behavioral communication, and media support. An observer recorded observations at one minute intervals across all four dimensions.

Observation data showed that faculty used similar instructional strategies regardless of presentation mode. The length of period of stimulus presentation (lecture) recorded under the events of instruction tended to be greater during remote class mode than for live instruction. There is some concern that the unique capabilities of two-way television was not integrated into the remote presentations. However, testing showed the performance of students were at least as high on material presented over two-way television as on material presented by professors during live class. Wilkes and Burnham (1991) attempted to identify which factors contributed to the satisfaction of learners in electronic distance education (EDE). They knew that highly motivated learners were willing to endure almost any educational environment or process to achieve a passing 
grade, but felt that more than grades needed to be examined to evaluate educational experiences. The study took place in 1988 with 156 students, 83 undergraduates and 73 graduate students at Utah State university. They were taught by audio coupled with electronic writing boards. A comparison group of 85 participants, 34 undergraduates and 51 graduates in extension program studies was taught by traditional methods with the instructor physically present.

The independent variables included the motivation of the participants, demographic data and course data. The dependent variables were participant perception of the learning environment in the areas of satisfaction, material environment and involvement. The traditional group scored significantly higher than the EDE group in all areas. Involvement was far more related to satisfaction in the EDE group than it was in the traditional setting group. The study showed that time and work demands seem to be the main reasons why students in EDE drop out of classes as opposed to motivation. There appeared to be little practical relationship between motivation and participants' satisfaction.

The authors stated that many adult distance programs invest large amounts of energy to tailor their courses to the needs, motives and expectations of learners hoping to raise participants satisfaction ratings. The results of this study 
suggested that participant satisfaction is mainly independent of the initial motives of beginning students and sources of satisfaction may be found elsewhere. They wrote that perhaps external variables were more influential than adult learner characteristics and therefore, adult learner characteristics may not have as much relationship to satisfaction as previously suggested. The researchers cautioned that an EDE system can exaggerate an instructor's weaknesses so distance education programs need to focus on the human element and the instructor in order to maintain students and increase program size.

\section{Military setting}

In September, 1992 Lehman and Kinney published a study of 252 soldiers for the Department of the Army that compared training effectiveness of video teletraining (VTT) instruction transmitted through satellite using television with one and two way communication. A noncommissioned officer's common leader training course was chosen for the study. The study was to determine if teletraining with oneway or two-way video and reconfigured instructional materials was as effective as traditional live instruction. The four groups in the study included instruction with one way VTT with modified course materials, two-way VTT with modified course materials, traditional instruction with modified course materials and traditional instruction with traditional 
course materials. Modified course materials were reconfigured to allow for more student interaction by including stories, anecdotes and personal experiences. Workbooks were distributed to students for notetaking and study.

In the one and two way video groups, students received live instruction over a color monitor and were able to communicate with the instructor and the other sites using microphones. The instructor taught the class in front of a camera with no live students present. In the one-way group the instructor could not see the students nor could the students see the other students at the remote sites but they could hear the audio connection between the other sites and the instructor. In the two-way group the instructor could see and hear the students and the students could see and hear the instructor as well as the students at the other sites. Results showed that soldiers trained with one-way VTT had significantly higher posttest scores than soldiers who were trained with two-way VTT or soldiers trained with traditional instruction using traditional course materials. Soldiers who were trained with one-way VTT scored equivalent to soldiers trained with traditional instruction using modified materials. Soldiers trained with traditional resident instruction using modified materials scored significantly higher than soldiers trained with traditional 
instruction using traditional materials. Instructors preferred teaching with VTT using modified materials over traditional training using non-modified materials because of more interaction, and most students concurred.

In the one way group, 58\% replied there were problems being able to participate as much as they wanted to, while none in the two way group gave that reply. Over $63 \%$ of soldiers in the one-way VTT group said they would have learned more through traditional instruction while less than 25: in the two-way VTT groups agreed. The majority of respondents felt the instruction was effective, but over $45 \%$ did not state an opinion. The conclusion drawn by they study was that VTT with modified course materials was an effective training strategy.

Simpson, Pugh and Parchman (1991) conducted a project for Navy personnel on alternative video teletraining technologies over a six month period involving over 743 naval students. The project explored technologically costeffective ways to train personnel who are remote from training resources. The study compared training effectiveness and user acceptance of live instruction and six different alternative video teletraining technologies (VTT). The most successful technology allowed continuous two-way audio communication between classrooms with either two-way or one-way video. Instructors preferred two-way video and so did 
the students who wanted to see their classmates in other classes.

The difference between live and all VTT was small but statistically significant. Live classroom students scored about two points higher than VTT students. The difference between one-way video and two-way video was small. using two-way video compared to one-way did not appear to improve student performance. One way video students scored one and five tenths points higher than two-way video students. Possibly the burdens of two-way video puts more strain on the professor. Students attitudes were measured with a postcourse questionnaire in the six categories of instructor, audio visual aids, tests and homework, overall assessment of instructor and course, course content and form of instruction. Students at the VTT local site gave slightly higher ratings than students in the remote sites though they were small and not statistically significant. All students perceived instructor performance to be outstanding, but those in the remote location gave lower ratings on the audio transmission for loudness and clarity. Eighteen percent of students in the remote classes felt VTT provided fewer opportunities to ask questions while most felt VTT had no effect on the opportunity to ask questions. Thirty percent in the local and remote classes expressed a preference for traditional instruction. However, students in remote sites 
were almost twice as likely to prefer VTT as those in local classes.

Naval trainers contend good quality audio is more critical to training success than good video quality. Students can learn from a lecture without observing the instructor, but can not learn from observing without hearing. The navy intends to work on refining the audio in VTT and as a result of its success with VTT will test the application of VTT beyond lecture based courses to include hands on labs and small group activities.

\section{Summary}

Chapter two described how distance education has met individual learning needs of participants often in ways not possible in large traditional classes. Ideally, students can work at their own pace and receive individual feedback from the instructor. The possibility of students taking a more active role in their own education by setting objectives, choosing methods for study, selecting resources and helping determine evaluation strategies can enable them to grow far beyond traditional students.

Distance education theorists and writers, however, caution that transmission of information, regardless of the media used, is not education. Students must be expected to do something with the information received. It is not enough to have system interactivity but also interpersonal 
interactivity. The type of communication used to interact with students plays a large role in reducing the distance between instructor/institution and student. Sometimes, students have hardly any communication with an institution and learn only what they perceive necessary even though this may differ from the institution's expectations. Other times, instructors may overstructure classes that use interactive communications and miss out on the unique capabilities of the medium. Some writers believe that dialogue with distance students, whether live or asynchronous, must be conversational and relaxed because it easy to remember information conveyed this way and certainly less intimidating. Other practitioners have integrated modern educational theories with distance education to substantiate that distance education is a sub-set of education.

In most of the studies reviewed, students at the instructor-based site rated interaction, satisfaction, enjoyment and the opportunity to ask questions higher than students at the distant sites.

In several studies, the distant learning sites rated attitudes toward distance learning higher than groups that had not tried it. Perhaps, students and professor need to experience distance learning before being asked to rate it. Some distant learning sites stated they accomplished more than in a traditional class but experienced less involvement 
and enjoyment. Some students believed they would have learned more in a traditional class.

Grades of students in some studies at studio sites were lower than the live site or distant site. Perhaps, the cameras and iights in the studio served as distractors. Instructors, as well as the students might benefit from an orientation to distance learning and allow more time to accustom themselves to the new environment.

In one study, distance learning students using modified materials (more interactive) achieved test scores equal to students in a traditional class with modified materials. One-way students cited not being able to participate as much as they would like, and believed they would have learned more through traditional means. It appeared that the perception of enjoyment may be as important for some students as actual grades. One-way videotraining students with modified materials ranked satisfaction levels much higher than traditional classes with non-modified material( less interactive). Use of interactive materials yields higher ratings in traditional and distance learning.

Problems with the loudness and clarity of the audio system was often mentioned in studies making it difficult for students to hear the other locations. Audio is more important than video because a class can continue even if the video portion is interrupted but the audio is still 
operating.

In some studies (Simpson, Pugh, Parchman, 1991)

instructors preferred two-way video because they could see all the sites and the students could see each other. Frequent interaction between sites, with the professor randomly calling on students, showed that all students stayed alert during class. The potential for all students to be called on at any time during the class is a strong motivator. Perceived overall classroom interaction by students is more important than the actual number of personal interactions each participant has with the instructor and other students during each class meeting.

One study (Wilkes \& Burnham, 1991) showed that students drop-out of distant education courses because of time and work demands as opposed to motivational factors. The authors contended that external variables played a more influential role than adult learning characteristics. Perhaps more focus should be on how to help students balance school and work demands. However, these researchers caution that electronic communication can exaggerate an instructor's weakness and must be an area for continuing improvement.

Since each institution operates in an environment peculiar to itself, it is necessary to examine distance learning programs in the framework of the specific context and structure under which they operate. Chapter 3 describes 
a quasi-experimental design of an undergraduate televised course in an urban multi-ethnic environment. 


\section{CHAPTER 3}

\section{METHODOLOGY}

This study is a comparison of the academic achievements and attitudes of students between the instructor-based site of a televised course and the distant site. The demographic make-up of the students was compared to ensure that statistical comparisons were valid.

This section describes the methodological rationale for the experimental and quasi-experimental design of the study and the subjects who participated in the study. Four instruments for data collection were used along with students' records, and several interviews of students and the site administrator at the distant site were conducted. The data was analyzed using chi square tests to compare group frequencies to see if an event occurred more frequently in one group than another and $T$-tests to see if there was a significant difference between the means of the two groups. Methodological Rationale

The experimental method was used to investigate possible cause and effect relationships. Gay (1992) states "the researcher manipulates at least one independent variable, controls other relevant variables, and observes the effect on one or more dependent variables" ( $p$. 349). The independent variables are responsible for the effect, while the dependent variables (the differences or changes) result from 
manipulation of related independent variables.

"In an experimental study, the researcher is in on the action from the very beginning; the researcher forms or selects the groups, decides what is going to happen to each group, tries to control all other relevant factors besides the changes that she or he has introduced..."(Gay, 1992, p. 350). After a period of time, a test or some similar measurement helps determine if there is a significant difference between the groups (Gay, 1992).

Experimental designs can be single-variable designs involving one independent variable, or factorial involving two or more independent variables. Single-variable designs can be pre-experimental, true experimental, or quasiexperimental. A true experimental design is always preferable to a quasi-experimental design, whereas a preexperimental design is never considered a good choice.

A good experimental design has random assignment of subjects to groups. A posttest is used to compare scores on the dependent variables. In regards to this study, since it was not possible to randomly assign subjects to groups and to control and manipulate all relevant independent variables, a hybrid quasi-experimental design with non-equivalent groups was used. Instead of a pretest, a pre-analysis of the subjects was be conducted, based on demographic data. Post measures were grades, course completion rates, pass rates, 
and attitudes gathered from feedback forms and interviews.

$$
\text { According to Gay (1992) to check on the internal }
$$

validity of an experiment, one asks if the independent variable really produced a change in the dependent variable. To check on the external validity one asks if the results can be generalized outside of the experiment.

\section{Subjects}

The total population for this study was approximately 650 students taking Organization and Management (MAN 3025), an undergraduate, introductory, three credit hour course required for all students in the College of Business Administration. The subjects for this study were 89 students who registered for the section of the course using Instructional Television Fixed Service (ITFS), television transmission via microwave, to transmit the class from the instructor site to the distant site. ITFS has one-way video and two-way audio communication.

Forty-six students were located at the instructor-based site of the televised course at the main campus in southern Dade County. Forty-three students were located at the distant site in northern Dade County. At the completion of the study the subjects in each site were compared.

\section{Rilot Study}

During the Fall 1994 term, a pilot study was conducted for a distance education course with subjects at the 
instructor-based site and approximately 22 distant sites throughout the Broward and Dade County school system. The instructor had taught this class numerous times as a traditional class, but this fall 1994 was the first time it had been taught as a distance course.

A number of factors were observed at the remote sites that were beyond the control of the professor due to the number of sites, the fact that the sites were not the physical property of the university and were often large open school media centers, and the lack of compliance on the part of the school systems to supply the requested equipment. Some students were very involved in the remote class while others disturbed neighbors talking about unrelated topics. Some wandered around the room and most did not respond to the instructor's request for phone-in participation. Several of the participants felt that others at their site interfered with their ability to learn. Many felt it was easy to "turn off" because the instructor could not monitor their behavior. Participants raised many questions among themselves concerning assignments; however, few called the professor for clarification during or following the broadcast. Students at some sites mentioned not remembering the phone number designated for calling the professor during class time despite the fact that the phone number was on screen numerous times during each broadcast. 
The placement of the telephone at some distant sites was remote from the monitor necessitating participants leave their seats and move out of view of the broadcast. When the video portion of the program was not operating, one participant used a hand-held phone and heard the instructor. Unfortunately, none of the others could hear. At some locations students were seated at separate and distant tables scattered throughout the room making viewing so difficult that they tended not to pay attention to the professor or classmates at other tables. Students, at the site who were seated at a round table opposite the television screen with a telephone located in the center of the table, had a high rate of participation.

Many participants felt uncomfortable "breaking in" on the professor during the broadcast to ask questions. Several students mentioned that if they were at the instructor site, they could raise their hands and not have to interrupt the class to get the instructor's attention. They could also speak to the instructor during breaks or after class. Many students felt uncomfortable calling the professor after class since they did not know the professor well. This was despite of the fact that the professor had multiple face-to-face sessions for orientations, midterms and finals, had additional office hours for distance students to phone or visit her on campus and made special visits between 
class days to teachers at their sites to try to help them feel comfortable interacting with her.

As a result of the pilot, the following suggestions were proposed: limit the distant site to one controlled environment, hire a site-administrator for the distant site to assist the professor and the students, purchase additional telephones to allow students to communicate with the instructor and place students' desks or tables in optimum position for viewing and class participation.

The study

Organization and Management (MAN 3025), the distance education course used in this study, began in the 1995 Spring semester. The course instructor was a professor of strategic Management in the Management and International Business Department at the School of Business. He had taught this class numerous times as a traditional class, but the Fall 1994 semester was the first time he taught it as a distance course. When interviewed he talked about the problems related to the technology which sometimes resulted in poor audio transmission; his inability to know what students were doing at the distant during class; his concern that students at the distant site might not be doing their reading assignments, and difficulty in returning exams, proctoring of exams, and evaluating students at a distance.

For this study, the university assigned a classroom 
approximately $20^{\prime}$ by $30^{\prime}$ with built-in tables. Approximately 30 students could be seated around the outside of the Ushaped table and inside the U-shape table was a large rectangular table seating 15. Two televisions were located at the front of the classroom (open end of the U-shape). All the students faced the two monitors and were in close approximation to each other. Seven 'press to talk' microphones connected to the speaker telephone were located at the rectangular table. To allow participants equal access to the microphones, the site administrator prepared a seating plan each week assigning different students seats near the microphones.

A student in the class at the distant site was hired as a site administrator to help resolve some of the problems observed during the pilot. The functions of the job were: take attendance, remind students to take their seats by the microphones, monitor the system for technical problems, contact the technicians if needed, remind students of proper listening etiquette when necessary, distribute test grades, distribute postcards to students to gather comments about the course, and collect questions from the students to relay to the professor.

At the instructor-based site in South Dade, the professor presented the lectures in a normal classroom setting except for the cameras, microphones, and television 
monitors in the room. The instructor was never able to broadcast from the distant site because no broadcast facilities were available.

The independent variables were location and technical and structural interventions (microphones, siteadministrator, seating) at the distant site. The dependent variables were grades, course completion rate, pass rate, ratings from the interim evaluation form, the Distance Education Evaluation form (DEE), the overall attitudes toward the distance education experience, and the instructor evaluation rating.

Instrument and Data collection

The demographic data collected at the beginning of the course from the students at the instructor site and the distant site provided information on age, sex, ethnicity, marital status, number of children, student status, undergraduate major, and employment status. The college level Academic Skills Test (CLAST) scores were collected from university student records. CLAST is an achievement test that measures communication and mathematics skills through four subtests. They include English language skills, reading and mathematics. Information on course completion rates, pass rates, and final grades were gathered at the end of the term from student records.

At the mid-point of the semester an interim evaluation 
form from the Division of Continuing Education was

distributed to the two sites. The form had 13 items and used a three point Likert scale to rate the following items: organization of the course, syllabus, interactive study guide, video broadcast, audio quality, visual projections, time to copy notes, handouts, objectives and expectations, lectures, participation and interaction, and questioning. An open-ended section asked for comments and changes to make the course more effective.

At the end of the semester, the Distance Education Evaluation (DEE) form, a five page instrument developed by a sub-group of the university Distance Education Task Force was administered at both sites. The previous term it was piloted and no reliability testing was conducted. For this experiment Cronbach's coefficient alpha levels were conducted and presented in Table 1. The data indicated that the Distance Education Evaluation form was a reliable instrument. 
Reliability Estimates for the Distance Education Evaluation

Eerm

Topic

Reliability estimate

(Cronbach alpha)

Total for Variables

.93

Organizational Factors

.83

Technical Analysis

.90

Pedagogical Analysis

.84

This instrument consists of three sections. The Organizational Factors asked students to rate 11 items on a four point Likert scale. The Pedagogical Analysis section had eight item and the Technical Analysis section had 13 items. A final section asked for additional feedback on any areas not covered in the survey, as well as for positive and negative experiences encountered during the course. To obtain one measurement for an overall attitude toward the distance education experience, several items from the Organizational Factors section, the Pedagogical Analysis section and the Technical Analysis section were combined. The Instructor (IE) Evaluation forms from the school of Business were collected at the end of the term to compare feedback on the instructor from the sites. Use of this form was necessary because there was little or no evaluation of 
the instructor on the DEE form.

Treatment of Data

The data collected in this study were used to answer the basic research question and the five specific research questions discussed in chapter one. The basic research question was: If certain technical and structural interventions are implemented at the distant site of a televised course, how does the performance of students and their attitudes and perceptions at that site compare with that of students at the instructor-based site? This question was answered by the following five specific research questions. Each question is now presented.

Question 1. Is the demographic make-up of students at the instructor-based site and distant site comparable?

Source of data: demographic survey, student records Specific data to be analyzed: age, sex, ethnicity, marital status, number of children, student status, major, employment status, CLAST scores

Analysis of the data: Chi square statistic for demographic data; Chi square for CLAST scores

Question 2. How does the course completion rate compare between the instructor-based site and the distant site utilizing the three interventions of a site facilitator, multiple telephones, and a pre-configured classroom at the distant site of a televised course? 
Source of data: grade list

Specific data to be analyzed: compare numbers of students who dropped out of course after drop-add period or received an incomplete grade

Analysis of data: Chi square statistic

Question 3. How do the final grades of students at the instructor-based site and the distant site compare utilizing the interventions in question two?

Source of data: final course grades Specific data to be analyzed: final grades for each student Analysis of data: T-test statistic

Question 4. How do pass rates of the instructor-based site and the distant site compare with the distant site utilizing the interventions in question two?

Source of data: final course grades

Specific data to be analyzed: number of students with passing grade or better

Analysis of data: Chi square test

Question 5. How do the attitudes and perceptions of students at the instructor-based site and the distant site compare? Source of data: interim evaluation form, Distance Education Evaluation form, overall attitudes toward distance education experience, instructor evaluation form, interviews of students at the distant site and the site administrator Specific data to be analyzed: compare site ratings for which 
data was collected on the above

Chapter three presented an overview of the quasiexperimental design of a study of a three credit course in the school of Business. Four instruments for data collection were described as well as the interviews of some students at the distant site and the site-administrator. 


\section{CHAPTER 4}

\section{ANALYSIS Of The DATA}

A hybrid quasi-experimental design with non-equivalent groups compared the achievements and attitudes of students at the instructor-based site and the distant site of a televised undergraduate course in management. The independent variables originally selected were a site-administrator at the distant site, a room set-up that facilitated shared or participative learning, and the availability of seven microphones for students at the distant site to communicate with the instructor-based site. However, the room assigned by the university had tables and chairs affixed to the floor and could not be moved as originally planned. To adjust to this constraint, each week the site-administrator assigned different students seats near the microphones to allow equal access to communicate with the live site.

The dependent variables were final grades, course completion rate, pass rate, ratings from the interim evaluation form, the Distance Education Evaluation (DEE) form, the instructor evaluation form, and interviews of the students and site-administrator at the distant site.

\section{Data Analysis}

To answer the basic research question: if certain technical and structural interventions are implemented at the distant site of a televised course, how does the performance 
of the students and their attitudes and perceptions at that site compare with that of students at the instructor-based site, five specific research questions were addressed.

1) Is the demographic make-up of students at the instructor-based site and distant site comparable?

2) How does the course completion rate compare between the instructor-based site and the distant site utilizing the three interventions of a site facilitator, multiple telephones and a pre-configured classroom at the distant site of a televised course?

3) How do final grades of students at the instructor-based site and the distant site compare utilizing the interventions in question two?

4) How do the pass rates of the instructor-based site and the distant site compare utilizing the interventions in question two?

5) How do the attitudes and perceptions of students at the instructor-based site and the distant site compare on the interim evaluations, the Distance Education Evaluation forms, instructor ratings, the distance education experience ratings and interviews of the site administrator and the distant site students?

Question one

Data were collected from the students at the beginning of the course through a questionnaire and from the students' 
records to determine the similarity of the groups. Table 2 shows the demographic make-up of all 89 students with 46 at the instructor-based site and 43 at the distant site according to age, sex, ethnicity, country of origin, marital status, number of children, entering status to the university, current student status, school, major and work status. Through Chi-square analysis, the only significant difference found between the sites was ethnicity, $(p<.05)$. Fifty-two percent of all students were of Hispanic origin. Sixty-seven percent were Hispanic at the instructor-based site compared to $35 \%$ at the distant site. The distant site had 28\% Caucasian students compared to $13 \%$ at the instructorbased site and three times as many African American students as the instructor-based site. 
Table 2

Demographic Responses by Location

Location $N /\left(\frac{\%}{\%}\right)$

Variable

Total

Iive

Distant

Age

$$
18-24
$$

35

(39) 18

(39)

$17 \quad(40)$

$25-34$

44

(40) 21

(46)

23

(53)

35 plus

10

(11) 7

(15)

$3(7)$

Gender

Female

Male

*Ethnicity

Hispanic

Non-Hispanic

Caucasian

African American

Asian
55

34

46

$18 \quad(20)$

6

(13)

12 (28)

16

9 (10) 5

(11)

Note. $* p<.05$.

Table continued 
Table 2, continued

Location $\mathrm{N} /\left(\frac{\circ}{\circ}\right)$

Variable

Total

Live

Distant

Origin

U.S.

47

(53)

27

(59)

20

(47)

Other

42

(47)

19

(41)

23 (53)

Marital Status

$\begin{array}{lcccccc}\text { Married } & 13 & (22) & 7 & (25) & 6 & (19) \\ \text { Divorced } & 4 & (7) & 0 & (0) & 4 & (13) \\ \text { Single } & 42 & (70) & 20 & (71) & 22 & (68) \\ \text { Widowed } & 1 & (2) & 1 & (4) & 0 & (0)\end{array}$

Children

Yes

$\begin{array}{llllll}13 & (21) & 3 & (10) & 10 & (31)\end{array}$

No

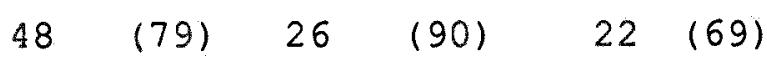

Entering Status

Community College

transfer

$\begin{array}{llllll}47 & (54) \quad 22 & (49) & 25 & (57)\end{array}$

Florida International

$\begin{array}{lcccccc}\text { University } & 9 & (10) & 4 & (9) & 5 & (12) \\ \text { Non-community } & 8 & (9) & 6 & (13) & 2 & (5) \\ \text { college transfer } & & & & & & \\ \text { Non-degree } & 24 & (27) & 13 & (29) & 11 & (26)\end{array}$

Table continued 
Table 2, continued

Location $\mathrm{N} /\left(\frac{0}{2}\right)$

Variable

Total

Live

Distant

Current Status

Junior

$\begin{array}{llllll}58 & (65) & 30 & (70) & 28 & (61)\end{array}$

Senior

$6 \quad(18$

(16)

9 (20)

Lower Division

11

(12)

7

(7)

8

(17)

Graduate

4

(5)

3

(7) 1

1 (2)

College

Business

$\begin{array}{lllllll}\text { Administration } & 57 & (64) & 28 & (61) & 29 & \text { (67) } \\ \text { Other } & 32 & (36) & 18 & (39) & 14 & \text { (33) }\end{array}$

Major

$\begin{array}{lcccccc}\text { Accounting } & 20 & (23) & 10 & (22) & 10 & (23) \\ \text { Marketing (weekend) } & 17 & (19) & 8 & (17) & 9 & (21) \\ \text { Finance } & 11 & (12) & 7 & (15) & 4 & (9) \\ \text { Marketing } & 10 & (11) & 5 & (11) & 5 & (12) \\ \text { Other } & 31 & (35) & 16 & (35) & 15 & (35)\end{array}$

Work Status

$\begin{array}{lllllll}\text { Full-time } & 28 & (31) & 13 & (28) & 15 & (35) \\ \text { Part-time } & 33 & (37) & 16 & (35) & 17 & (40) \\ \text { None } & 28 & (32) & 17 & (37) & 11 & (25)\end{array}$


Since the majority of students were in the upper division of the college, the college Level Academic Skills Tests (CLAST) scores were examined to see if there were any differences between the sites. The College Level Academic Skills Tests (CLAST) are required achievement tests mandated and given by the Florida State Board of Education for all students who wish to receive an A.A. degree or a baccalaureate degree. English language, reading and mathematics skills are tested, and a separate passing score for each of the three sections is 295. Table 3 shows the results of 75 students who completed the CLAST tests. Chi square analysis showed a significant difference between the two sites in the reading section only with the distant site scoring significantly higher, $(2<.05)$. 


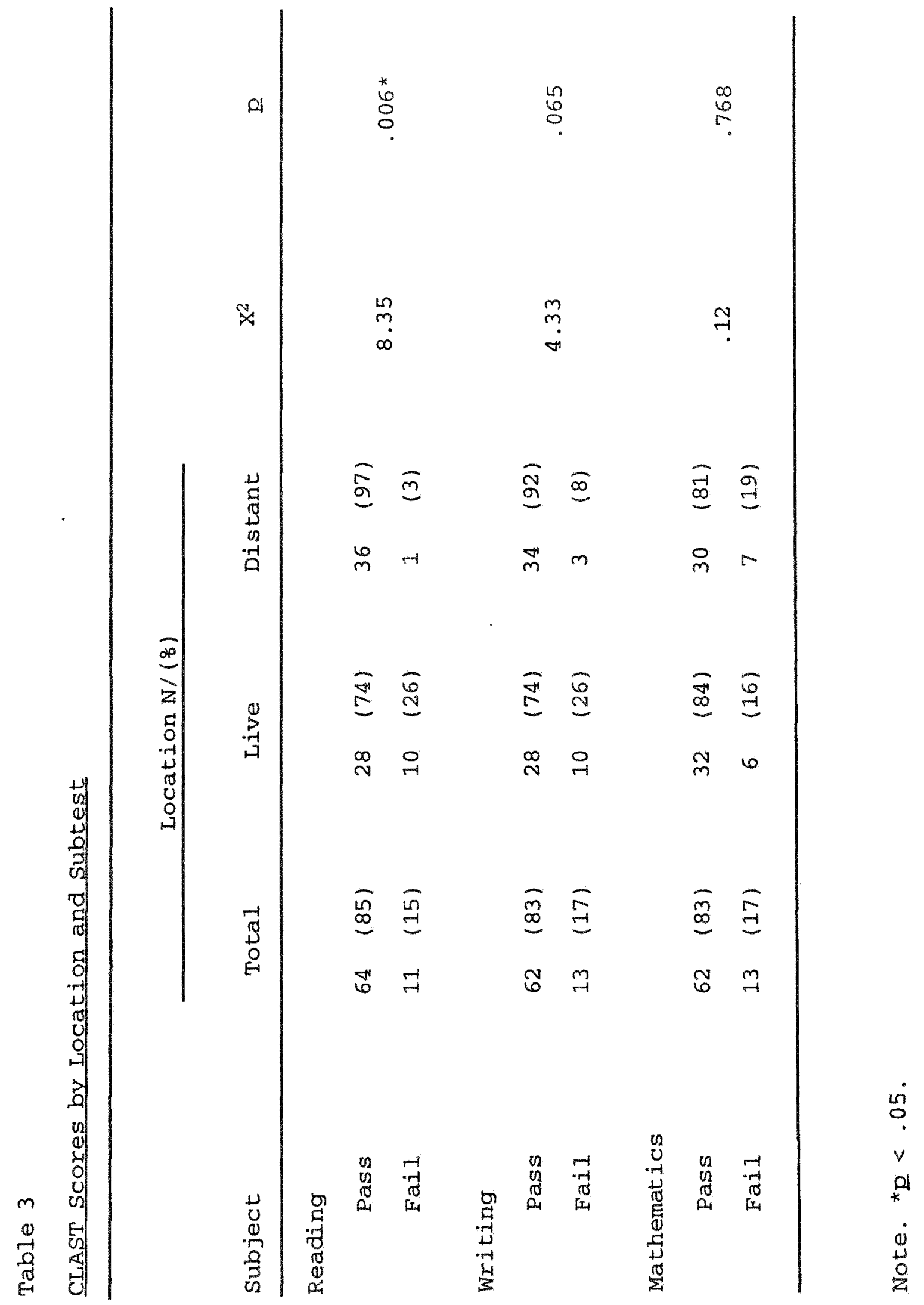


The demographic make-up of students at the instructorbased site and the distant site are comparable except for ethnicity and clast test scores for reading.

Question two

The instructor-based site originally had 46 students enrolled; two students dropped out of the class and one received an incomplete which eventually turned into a grade of $\mathrm{F}$. The course completion rate for this site was $93 \%$.

The distant site had 43 students enrolled. Two students dropped out of the class, thus the completion rate of $95 \%$. A Fisher's Exact test $(p=.998)$ supported there was no significant difference between the sites for course completion rate.

Question three

To compare the grades for each site, the letter grades were changed into point values $(A=4, B=3, C=2, D=1)$ and a T-test was performed. Table 4 shows no significant difference between the two sites for class grades. 
Table 4

Comparison of Grades Between Sites

Location

Live $(n=43) \quad$ Distant $(n=41)$

\begin{tabular}{lllllll} 
Grade & Mean & SD & Mean & SD & $t$ & $p$ \\
\hline Final & 2.13 & .98 & 1.967 & .15 & .77 & .449 \\
\hline
\end{tabular}

Question Four.

Students in the school of business and education need, in order to pass, a grade of $\mathrm{C}$ or above; all other students need a grade of $\mathrm{C}$ - or above to be considered successful. Chi square analysis on pass rates between the two sites showed no significant difference, $\left(X^{2}(1,82)=.741\right)$. The instructorbased site had a $74 \%$ pass rate and the distant site had a $65 \%$ pass rate.

Question Eive

According to Kifer (in Sorenson, 1995) attitudes are important predictors of academic success and indicators of program effectiveness. To examine the attitudes and perceptions of the students in this course, interim evaluation forms were collected at the mid-point of the semester and, final evaluation forms were collected at the 
end of the course along with instructor ratings. The evaluation forms are printed in Appendix A. In addition, nine students were interviewed at the distant site along with the site-administrator and their remarks are in Appendix C.

Interim evaluation forms. The instructor based-site with 46 students had 28 (60\%) interim evaluation forms returned while the distant site with 43 students had 33 (77\%) returned. The interim evaluation form consisted of 13 items. For analysis, the items were grouped into three sections: organizational, pedagogical and technical. Students did not answer question thirteen because of a typographical error on the form. Organizational items referred to the organization of the course including the syllabus and study guide. Technical referred to the video and audio portion of the broadcast as well as equipment and visual (graphic) materials. Pedagogical referred to course objectives, lectures, assistance, and participation. Students used the ratings of (1) very good, (2) acceptable or (3) needs to improve to rate the items. T-tests were performed on the ratings of the two sites. Table 5 shows that organizational and pedagogical ratings had significant differences, $(2<$ .05), between the two sites. 


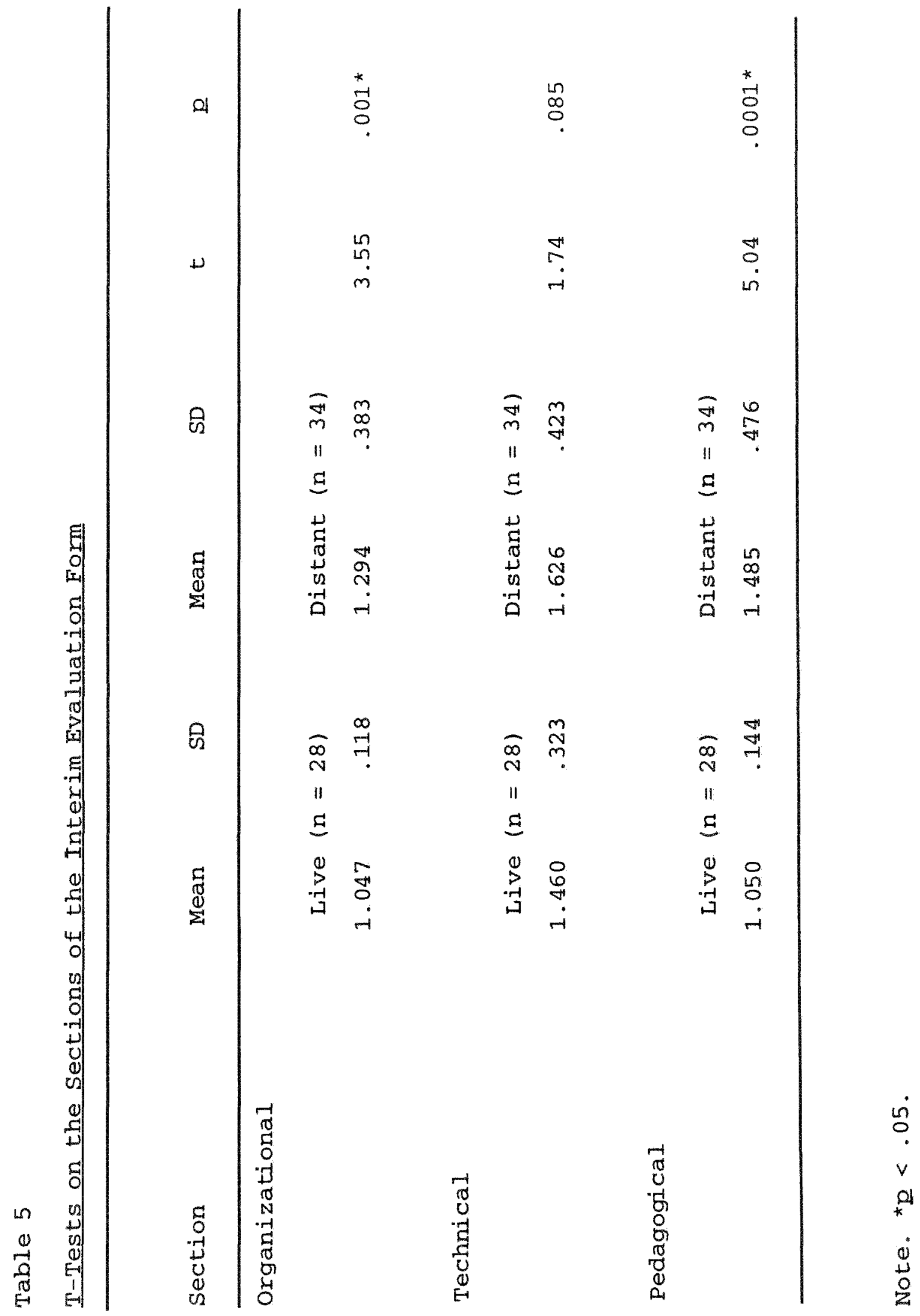


Chi square analysis was conducted on the individual items under the three sections (organizational, technical and pedagogical) of the interim evaluation form. The data were originally analyzed with Chi square, using the Likert scale ratings of $(1=$ very good, 2 = acceptable, 3 = needs to improve and $0=$ no answer, ). Several of the items had 50\% of the cells with expected counts less than 5, therefore, the data were re-run for those items using only the categories of very good and acceptable since there were very few no answers or needs to improve. Table 6 shows the results of the Chi square analysis based on the re-run data. 


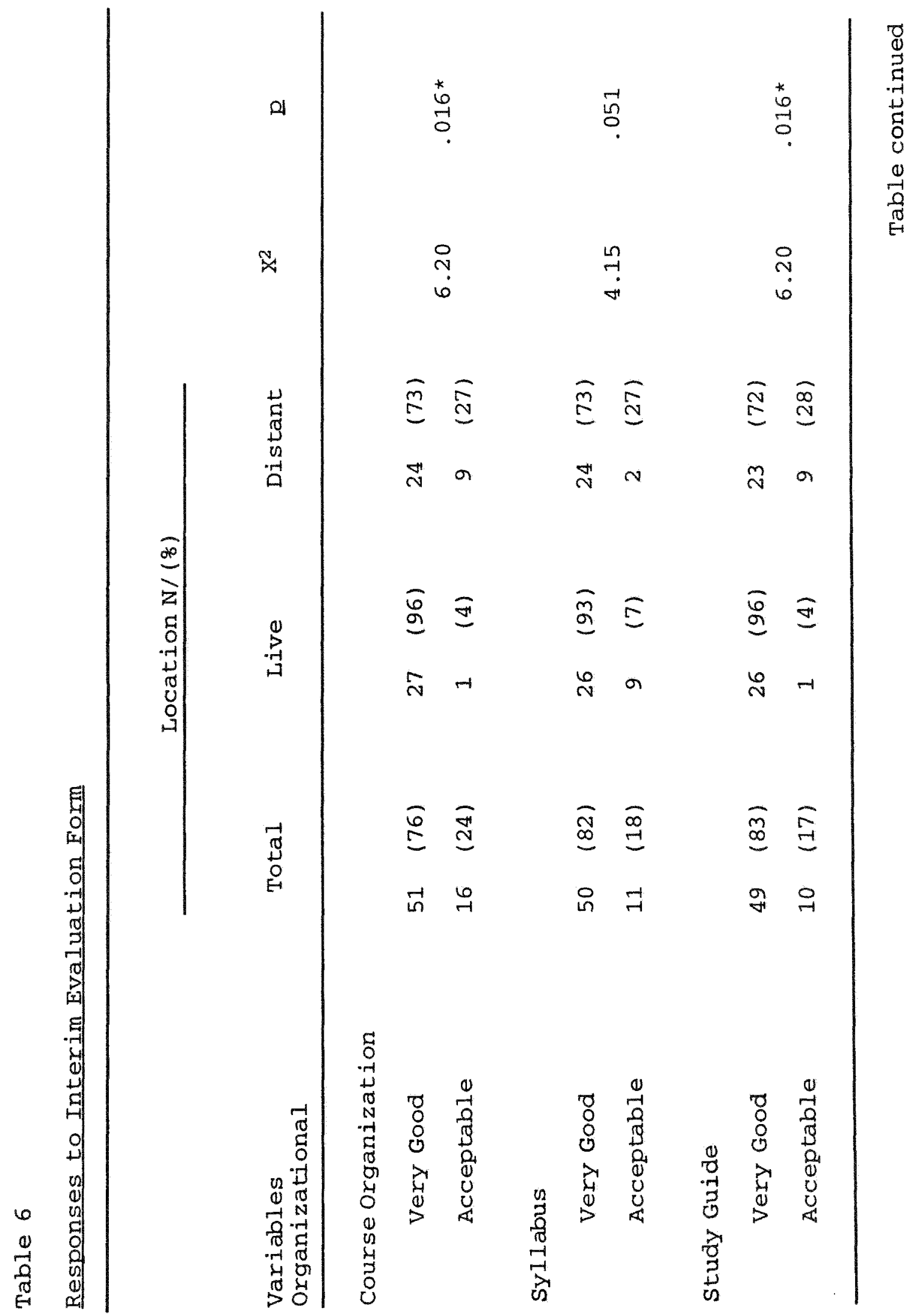




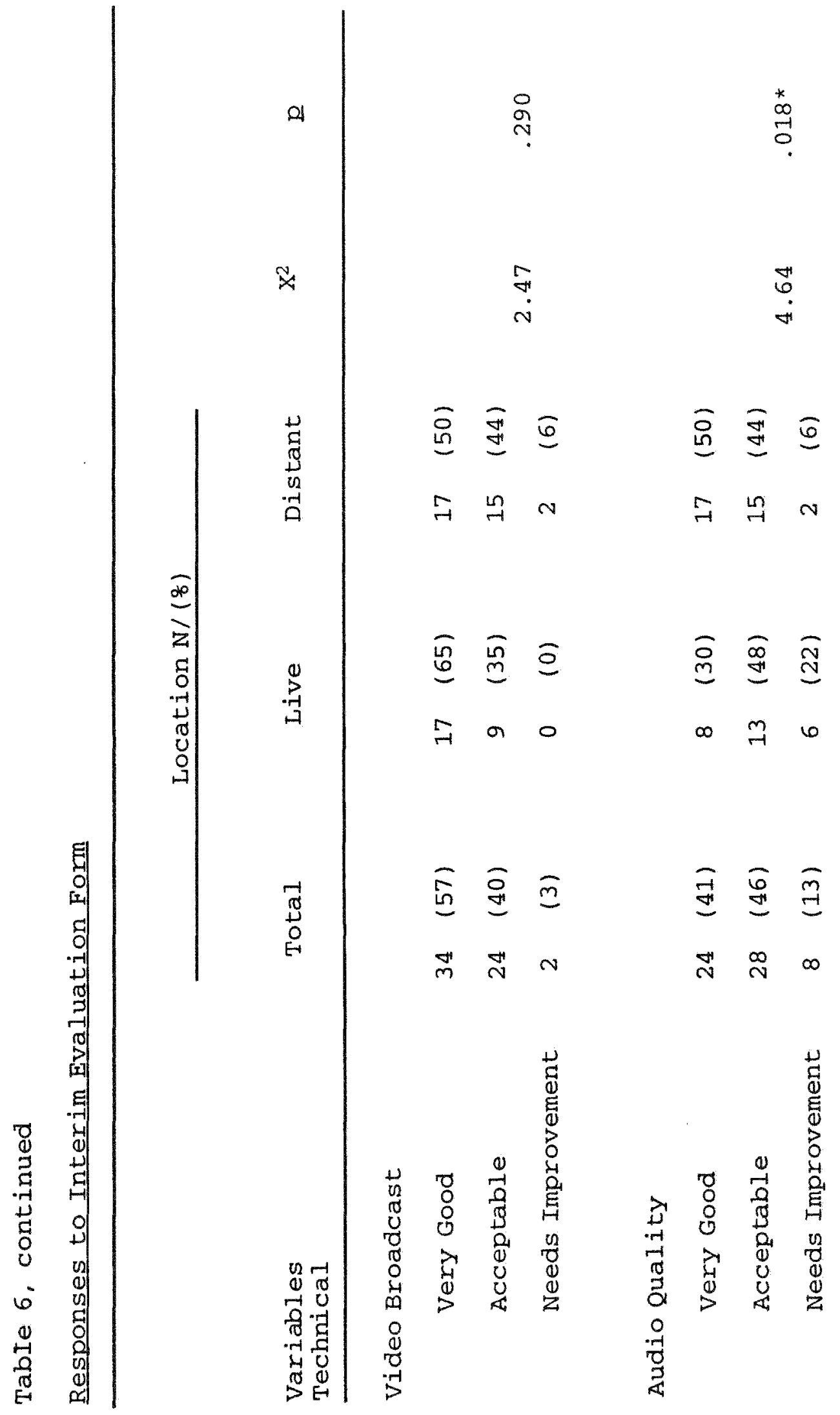




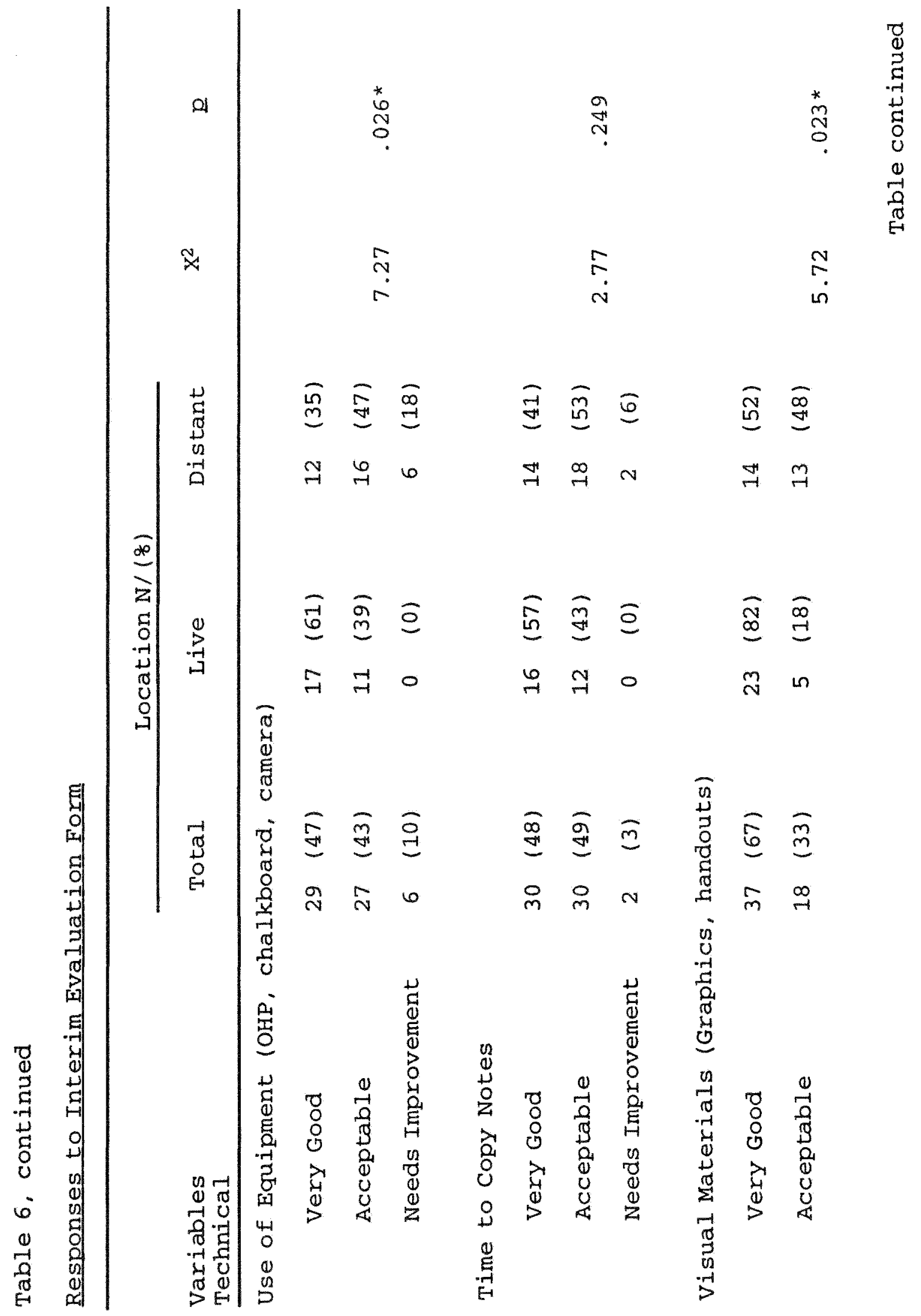




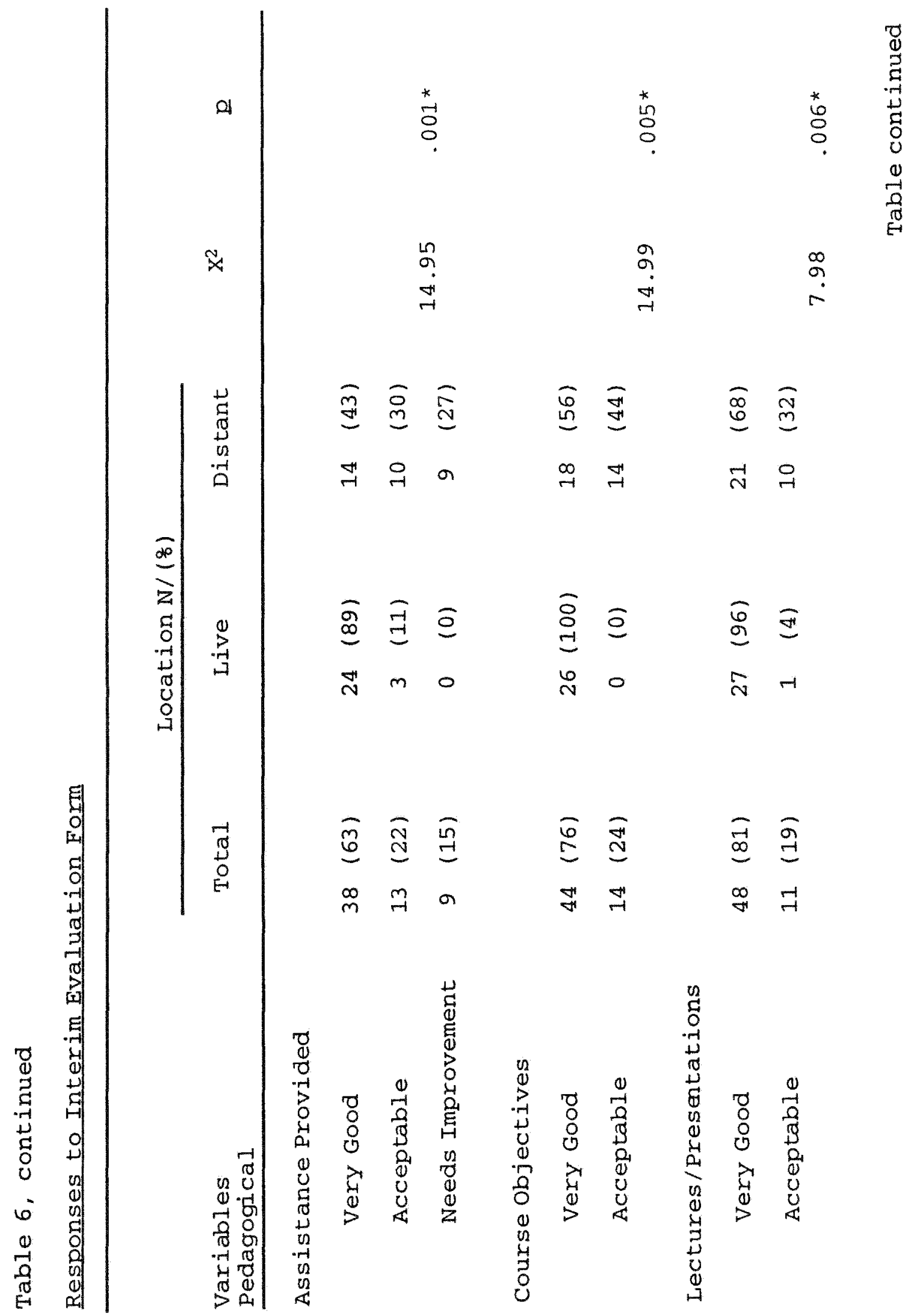




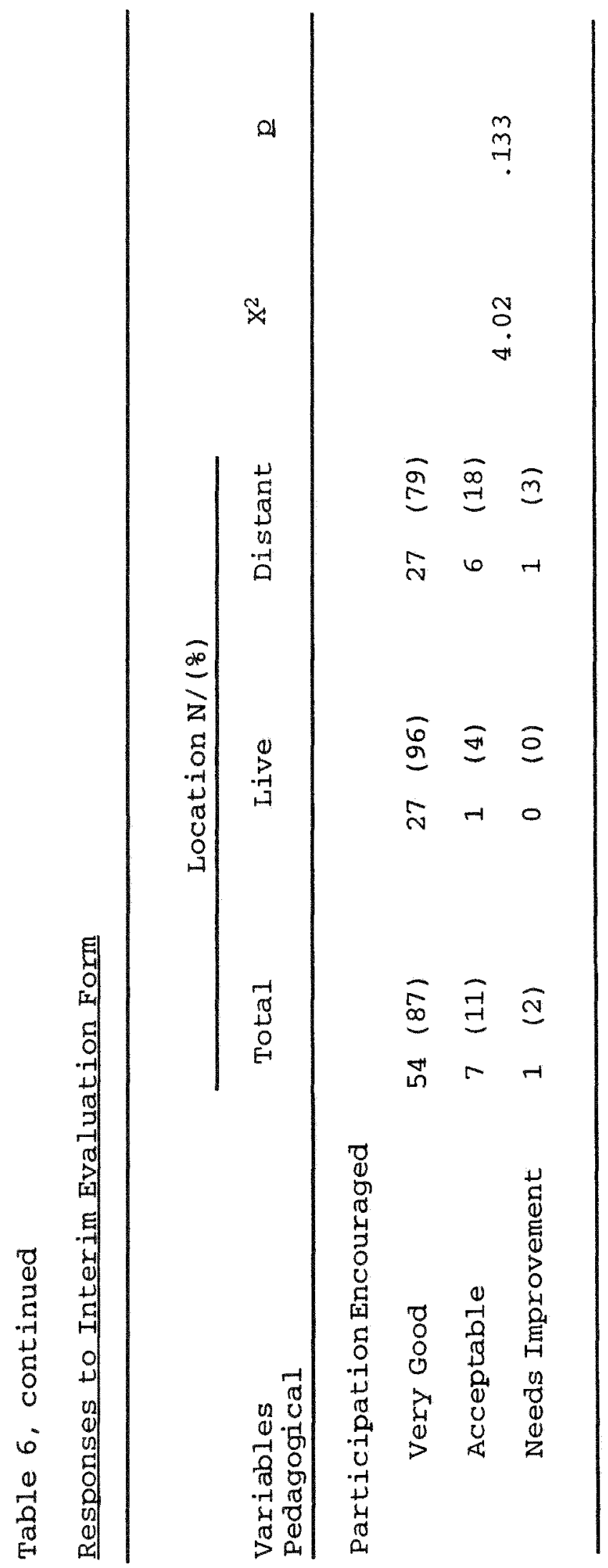

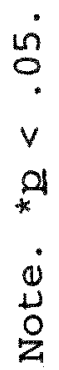


As Table 6 indicates, the items of video broadcast, audio quality, time to copy notes under technical, and the instructor encouraged participation under pedagogical showed no significant difference between the two sites. However, all of these items had a small number of students who rated them needs to improve. At the instructor-based site, more participants chose needs to improve for audio quality than those at the distant site.

Seven (58\%) of the 12 items rated in the interim evaluation form showed significant differences between the sites and one was marginal. Better ratings were consistently given by the students at the instructor-based site.

Under the organizational section, the items that were significantly different between the two sites with the instructor-based site giving better ratings were: the organization of this course and the interactive study guide, $(p<.05)$, while syllabus was marginal, $(p=.051)$. Under technical, use of equipment and visual materials had significant differences. Six students at the distant site rated use of equipment as needs to improve. Under pedagogical, responses to assistance provided when needed, course objectives and expectations, and lectures/presentations all showed significant differences between the sites. Nine students at the distant site rated assistance provided when needed as needs to improve. 
The interim evaluation form also asked students to submit any additional comments they wished to make. Table 7 shows the categories of comments and frequency of comments from both sites. The actual comments can be found in Appendix B1 and B2. At the distant site, video problems included difficulty in seeing the print, letters too small, too dark, too blurry, can not see the whiteboard, and need more time to copy the notes. Audio related comments at the distant site included inability to hear student questions from the instructor-based site. Under other, comments included too much non-subject related talking, a knowledgeable site administrator needed and need better supervision during exams. Ten students at the distant site mentioned more microphones needed for more interactivity during class. Two respondents said they were not informed this was a distance course.

At the instructor-based site, under video, comments included wanted to see students at the distant site, can not see monitors well when seated at the front of the classroom, and hanging microphones interfered with the picture on the television screen. Under audio, problems included not being able to hear the distant site students. 
Table 7

Interim comments by Both sites

Location $N\left(\frac{\circ}{8}\right)$

$\begin{array}{lcccc}\text { Variables } & \text { Total } & \text { Live } & \text { Distant } \\ \text { More Instructor visits to sites } & 15 & 0(0) & 15(100) \\ \text { Video Problems } & 14 & 4(29) & 10(71) \\ \text { More microphones } & 10 & 0(0) & 10(100) \\ \text { Audio Problems } & 12 & 6(50) & 6(50) \\ \text { Other (Improvement Items) } & 27 & 6(22) & 21(78) \\ \text { Positive course comments } & 21 & 13(62) & 8(38)\end{array}$

The DEE form is divided into three sections: Organizational Factors, Pedagogical Analysis and Technical Analysis. The items under Organizational Factors referred to the course materials, sending of materials to the instructor-based site and opportunities to receive feedback and ask questions. Pedagogical Analysis referred to comfort level in communicating with the other site and the instructor, and the opportunities available to meet other students as well as the instructor. Technical Analysis referred to the visibility of the course materials through the television and the appropriateness of the technology for the course. 
T-tests on the sections of the Distance Education Evaluation form. T-tests in table 8 were conducted on the Organizational Factors, Pedagogical Factors and Technical Analysis sections of the DEE form for the two sites. The form is shown in Appendix A. Lower numerical ratings were better than higher ratings. For these tests, ratings were collected only from those sections of the form where students rated at least $50 \%$ of the items. Several students at the instructor based site did not fill out all sections of the form because they may have felt these items were only relevant to the instructor-based site.

Table 8

T-Test on the Sections of the Distance Education Evaluation Form

$\begin{array}{lllll}\text { Mean } & \text { SD } & \text { Mean } & \text { SD } & t\end{array}$

Organizational

Live $\mathrm{n}=46 \quad$ Distant $\mathrm{n}=27$
1.81
.57
1.90
.71
$3.56 .0006 *$

Pedagogical
Live $\mathrm{n}=41$
Distant $\mathrm{n}=27$

1.87

.53

2.60

.81

4.12 .0002 *

Technical
Live $\mathrm{n}=40$
Distant $n=25$

1.37

.62

1.96

.64

3.71 .0004 *

Note, ${ }^{*} \mathrm{p}<.05$. 
Under Organizational Factors course syllabus and interactive study guide were removed from the overall section $T$ test because they were exactly the same at both sites, and the site-administrator had no control over the distribution of the syllabus and study guide. All of the other factors, such as delivery of tests, delivery of in-class hand outs, ability to send materials to the professor, ability to obtain required textbooks, ability to obtain supplementary materials, ability to access campus support services, opportunity to ask questions during class, opportunity to receive feedback on assignments and opportunity to receive feedback on quizzes and tests could be influenced by the site-administrator. The results of the T-test for the Organizational Factors section presented in table 8 showed a significant difference in ratings, $(\mathbb{R}<.05)$, between the two sites. The instructor-based site rated this section better than the distant site.

The T-test conducted on the Pedagogical Factors section of the DEE form showed there was a significant difference between the two sites on the ratings of Pedagogical Factors, $(2<05)$. The instructor-based site rated this section better than the distant site.

A T-test was conducted on the Technical Analysis section of the DEE form and included 11 of the 12 factors. I was able to read materials presented by picture-Tel was removed because Picture-Tel was not used in this experiment. The results of the 
T-test supported a significant difference, $(p<.05)$, between the two sites on the overall rating of the Technical Analysis section. The instructor-based site rated this section better than the distant site.

Statistical tests on individual items of Distance Education Evaluation form. A total of thirty individual items were rated on the DEE form under the three sections: 10 under Organizational Eactors, eight under Pedagogical Analysis and 12 under Technical Analysis. Twenty-two (73\%) items, including two marginal ones, showed significant differences between the sites on the Chi square tests and T-tests. For seventeen ( $81 \%$ ) of these 22 items the ratings of needs to improve or disagree/strongly disagree were chosen. Items under the Organizational Factors section were analyzed using Chi square analysis because there were only three choices in the rating scale for that section. The rating of does not apply was removed in this analysis because students did not choose this response. T-tests were used to analyze the items under the Pedagogical Analysis section and the Technical Analysis section because there were five choices available for rating the items. All responses were used in these analyses even from students who did not rate at least $50 \%$ of the items under each section.

The section on Organizational Factors used the rating scale of very good (1), acceptable (2) and needs to improve (3). While performing Chi square analysis, a majority of cells had 
expected counts of less than five, therefore, the rating categories for those factors were changed to very good, acceptable and when appropriate, needs to improve. Table 9 shows the results of Chi square analysis on the items that comprised the Organizational Eactors section. 


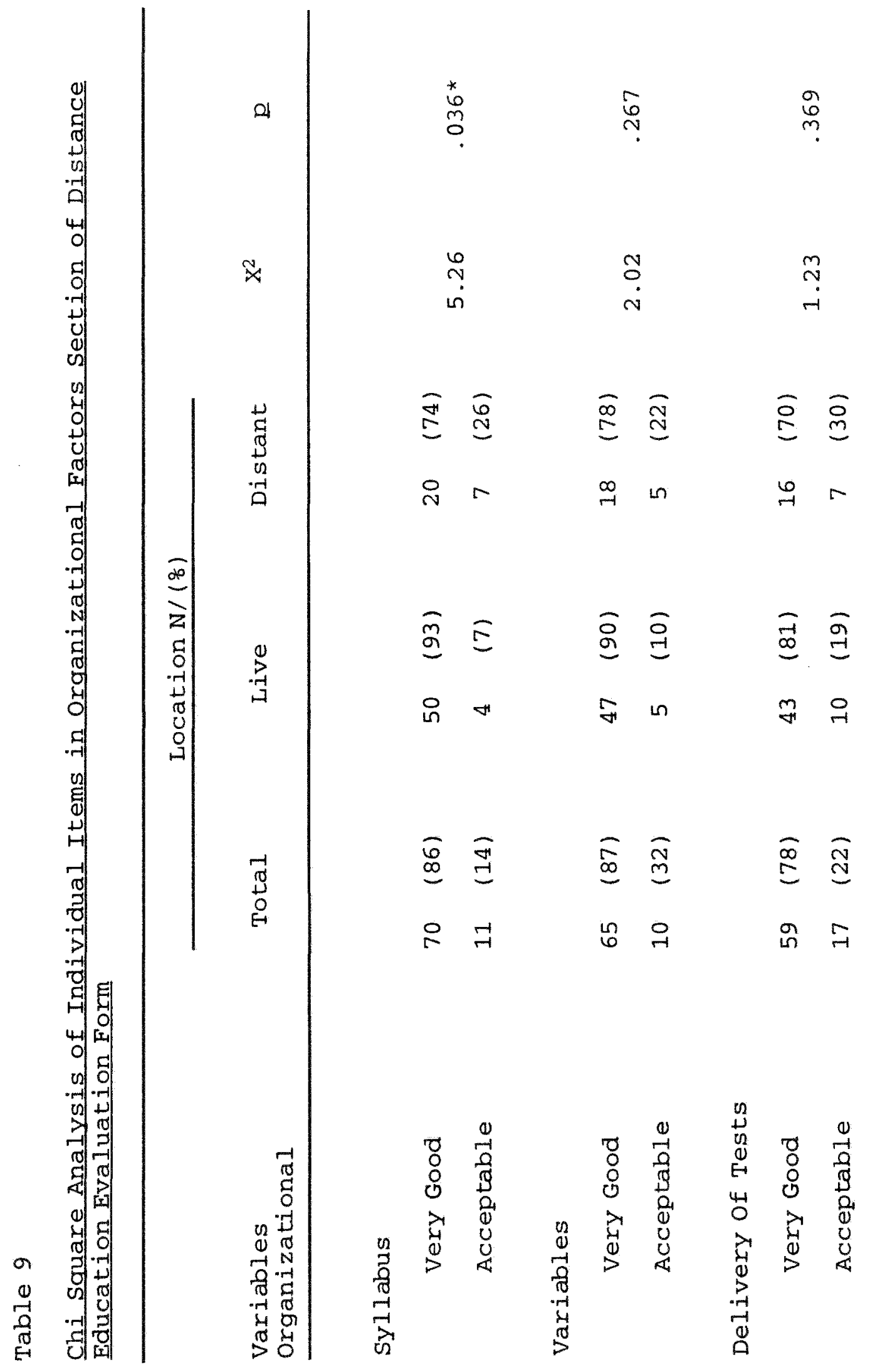




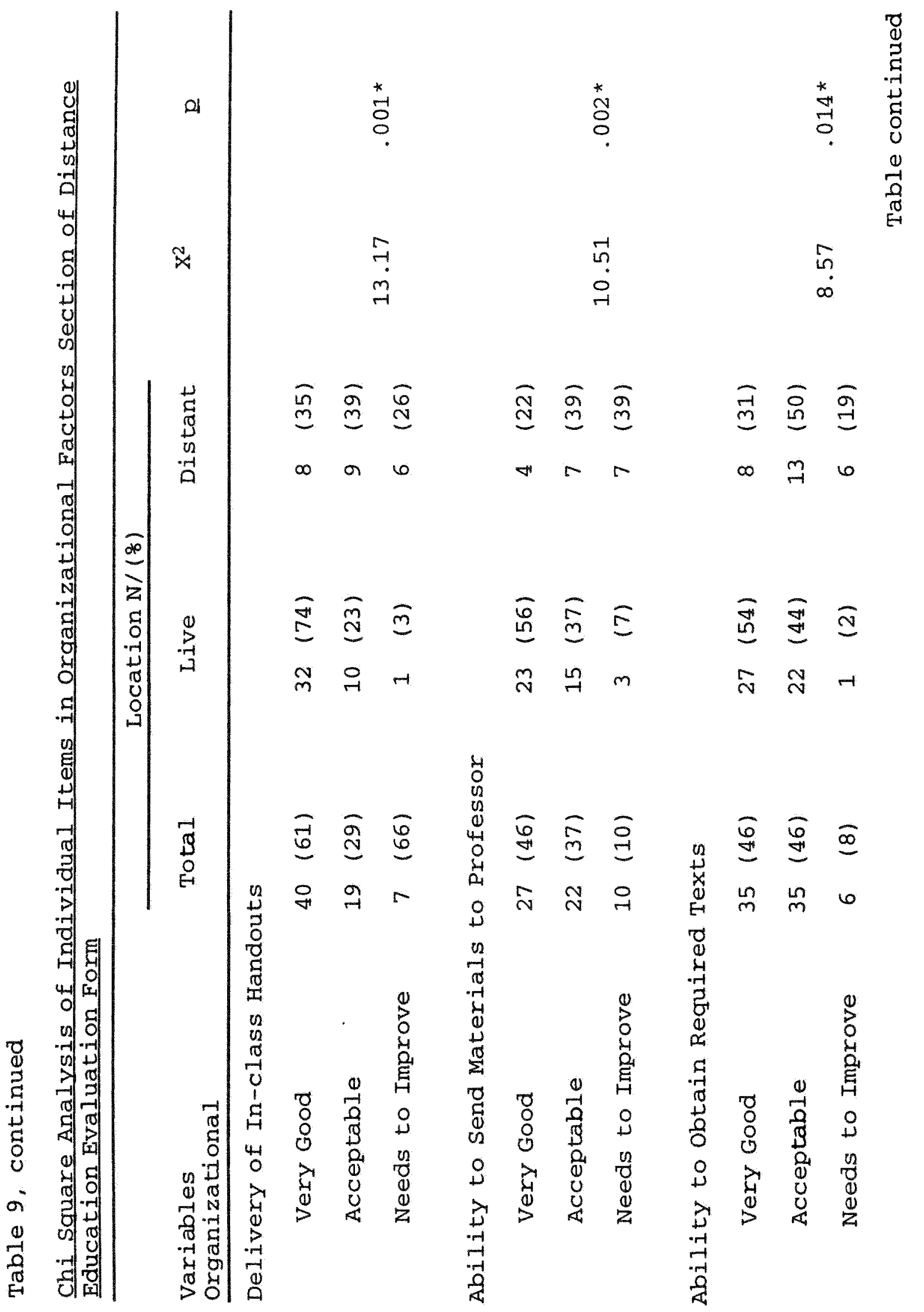




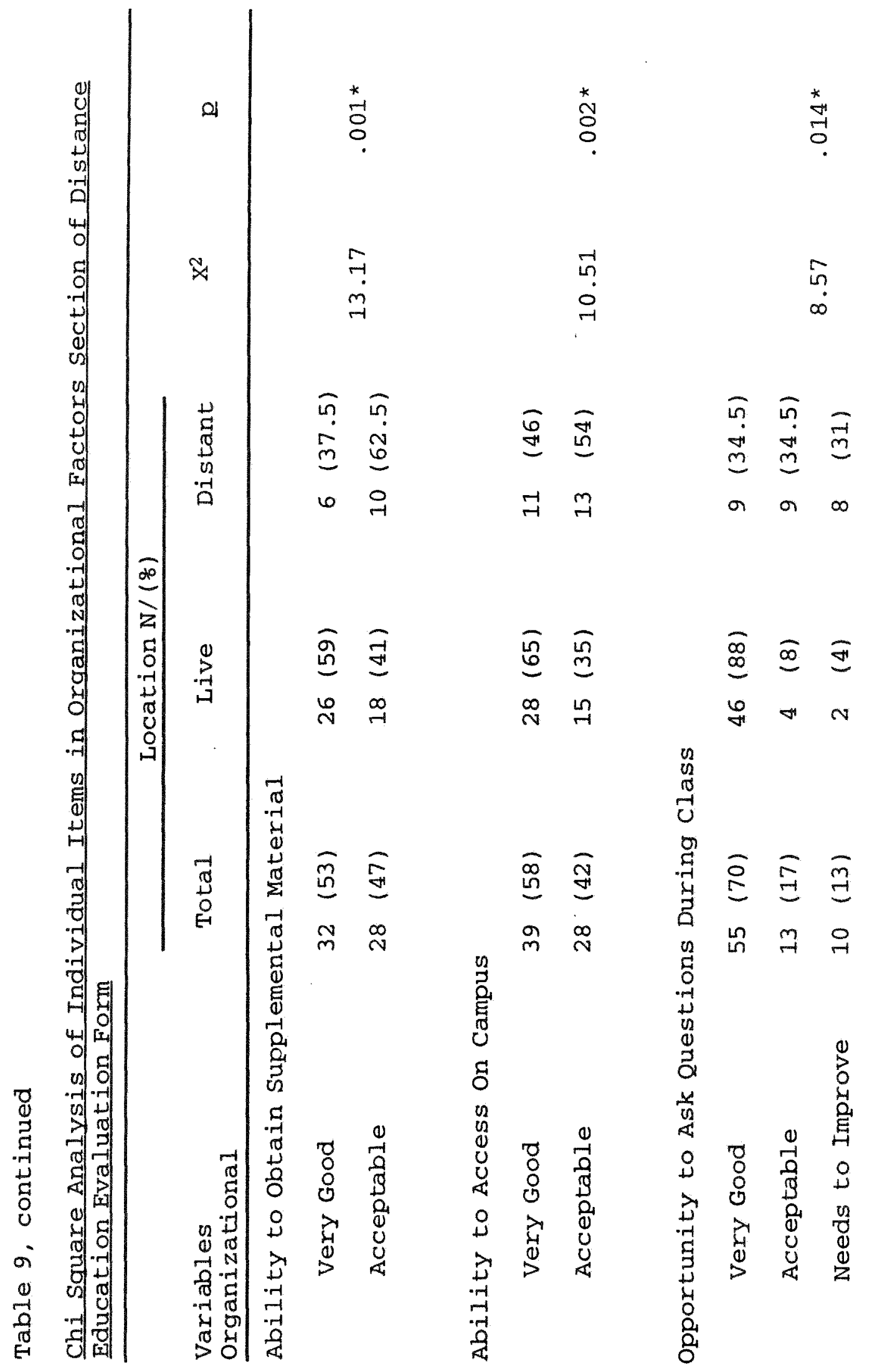

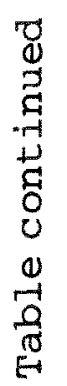




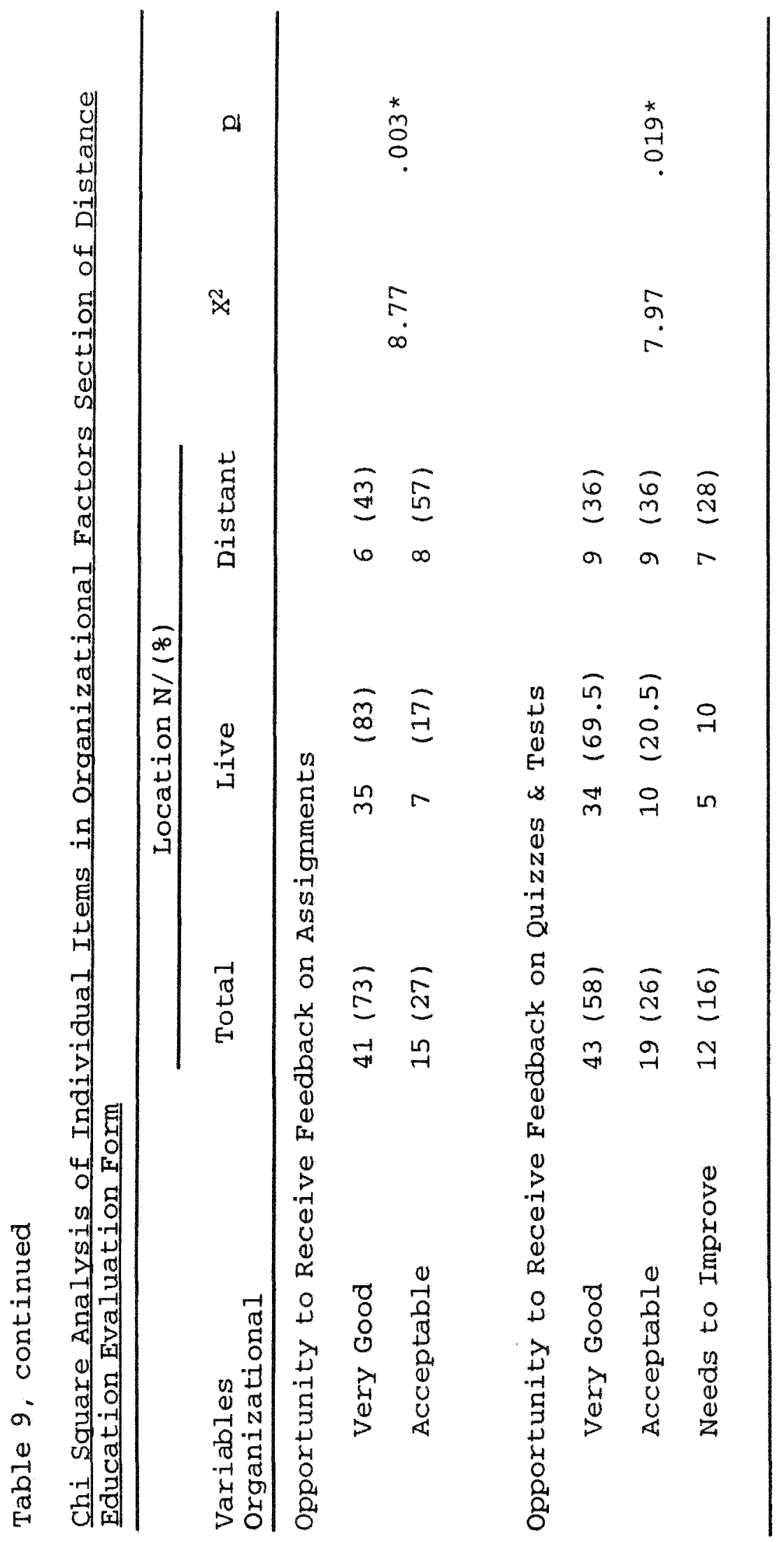

0
0
$v$
0
$*$
0
0
0
$z$ 
Seven out of 10 (70\%) items under Organizational Factors showed significant differences between the sites on ratings with the instructor-based site giving better ratings. Five out of those seven items also received rating of needs to improve by the distant site. The numbers in parenthesis in the following items refer to the frequency ratings of needs to improve. They were: delivery of in-class hand outs (6), ability to send materials to professor (7), ability to obtain required textbooks (6), opportunity to ask questions during class (8)opportunity to receive feedback on quizzes and tests (7). This item also received five needs to improve at the instructor-based site. The two items showing significant differences between the sites but with no ratings of needs to improve were course syllabus and opportunity to receive feedback on assignments. For this course, there were no written assignments.

Table 10 shows the distribution of the ratings by sites for the items under the Pedagogical Analysis section. 
Table 10

Distribution of Ratings by sites for pedagogical factors in

Distance Education Evaluation Form

Location $N /\left(\frac{\circ}{6}\right)$

Variables

Total

Live Distant

Pedagogical

Comfortable Using Audio

to Interact with Instructor

Strongly Agree

18

$(40)$

$12(52)$

6

(27)

Agree

25

(56)

11 (48)

$14 \quad(64)$

Disagree

2

(4)

0

(0)

2

(9)

Comfortable Using Audio

to Interact with other

Students

$\begin{array}{lcccccc}\text { Strongly Agree } & 16 & (41) & 10 & (42) & 6 & (40) \\ \text { Agree } & 17 & (43) & 13 & (54) & 4 & (26.5) \\ \text { Disagree } & 5 & (13) & 1 & (4) & 4 & (26.5) \\ \text { Strongly Disagree } & 1 & (3) & 0 & (0) & 1 & (7)\end{array}$

Table continued 
Table 10, continued

Ample Opportunity to

Interact with Instructor

$\begin{array}{lcccccc}\text { Strongly Agree } & 29 & (46) & 23 & (62) & 6 & (23) \\ \text { Agree } & 27 & (43) & 13 & (35) & 14 & (54) \\ \text { Disagree } & 5 & (8) & 1 & (3) & 4 & (15) \\ \text { Strongly Disagree } & 2 & (3) & 0 & (0) & 2 & (8)\end{array}$

Ample Opportunity to

Interact with Other Students

$\begin{array}{lcccccc}\text { Strongly Agree } & 25 & (45) & 19 & (53) & 6 & (30) \\ \text { Agree } & 25 & (45) & 11 & (39) & 14 & (55) \\ \text { Disagree } & 6 & (10) & 3 & (8) & 3 & (15)\end{array}$

Given Opportunity to

Meet Face-to-Face with

Professor

$\begin{array}{lrrrrrr}\text { Strongly Agree } & 29 & (49) & 26 & (72) & 3 & (13) \\ \text { Agree } & 9 & (15) & 8 & (22) & 1 & (4) \\ \text { Disagree } & 12 & (21) & 2 & (6) & 10 & (44) \\ \text { Strongly Disagree } & 9 & (15) & 0 & (0) & 9 & (39) \\ & & & & & \text { Table continued }\end{array}$


Table 10, continued

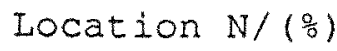

Variables

Total

Live

Distant

Given Opportunity to

Meet Face-to-Face with

Other Students

$\begin{array}{lcccccc}\text { Strongly Agree } & 12 & (25) & 9 & (33) & 3 & (14) \\ \text { Agree } & 7 & (15) & 5 & (19) & 2 & (9) \\ \text { Disagree } & 13 & (27) & 7 & (26) & 6 & (29) \\ \text { Strongly Disagree } & 16 & (33) & 6 & (22) & 10 & (48)\end{array}$

Satisfied with Presentation

of Lectures

$\begin{array}{lllllll}\text { Strongly Agree } & 43 & (65) & 33 & (80) & 10 & (56) \\ \text { Agree } & 23 & (35) & 15 & (20) & 8 & (44)\end{array}$

Felt Like an

Active participant

$\begin{array}{lcccccc}\text { Strongly Agree } & 26 & (44) & 21 & (57) & 5 & (23) \\ \text { Agree } & 26 & (44) & 14 & (38) & 12 & (54) \\ \text { Disagree } & 7 & (12) & 2 & (5) & 5 & (23)\end{array}$

Table 11 shows the results of T-tests on the individual items under Pedagogical Analysis. 


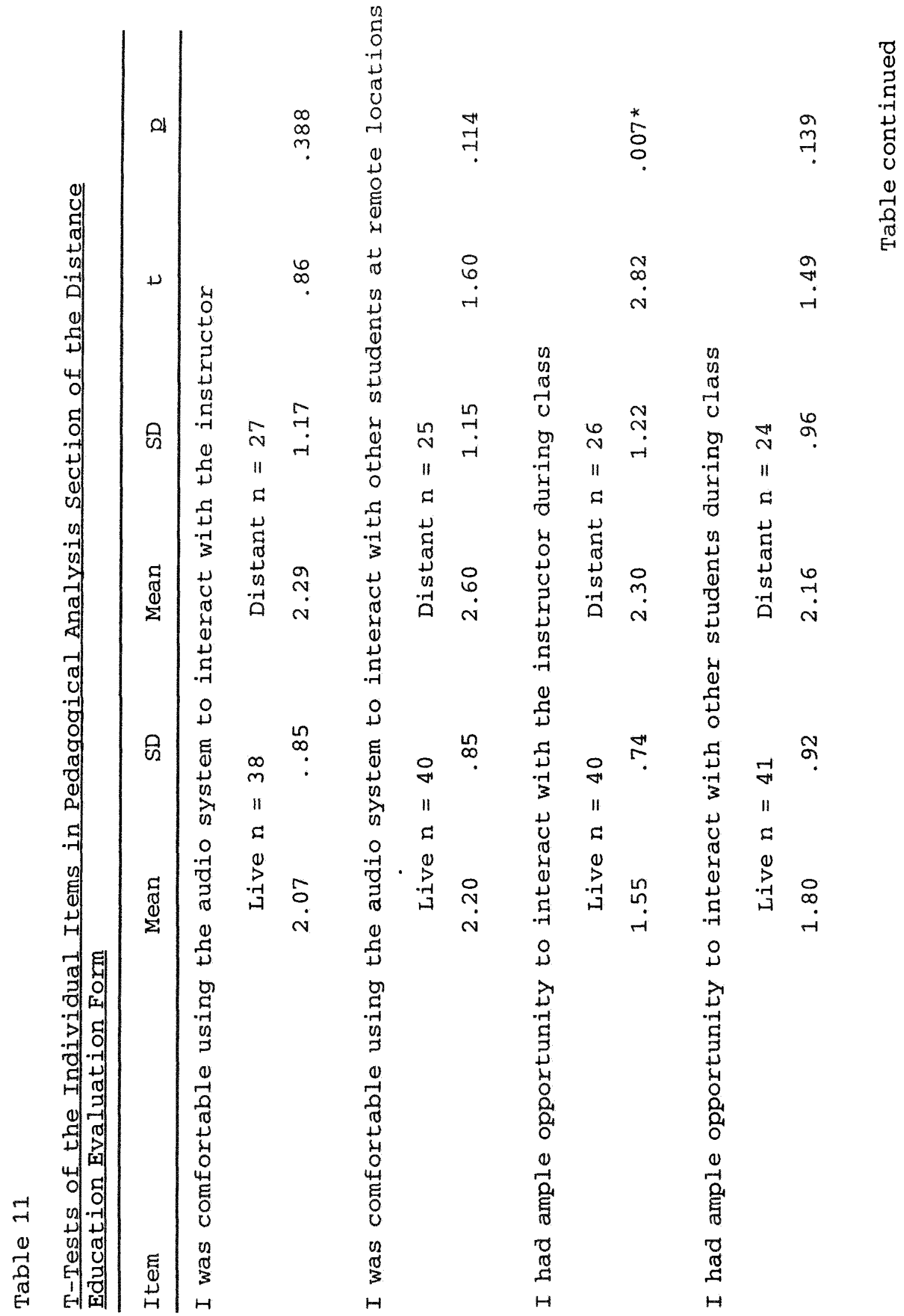




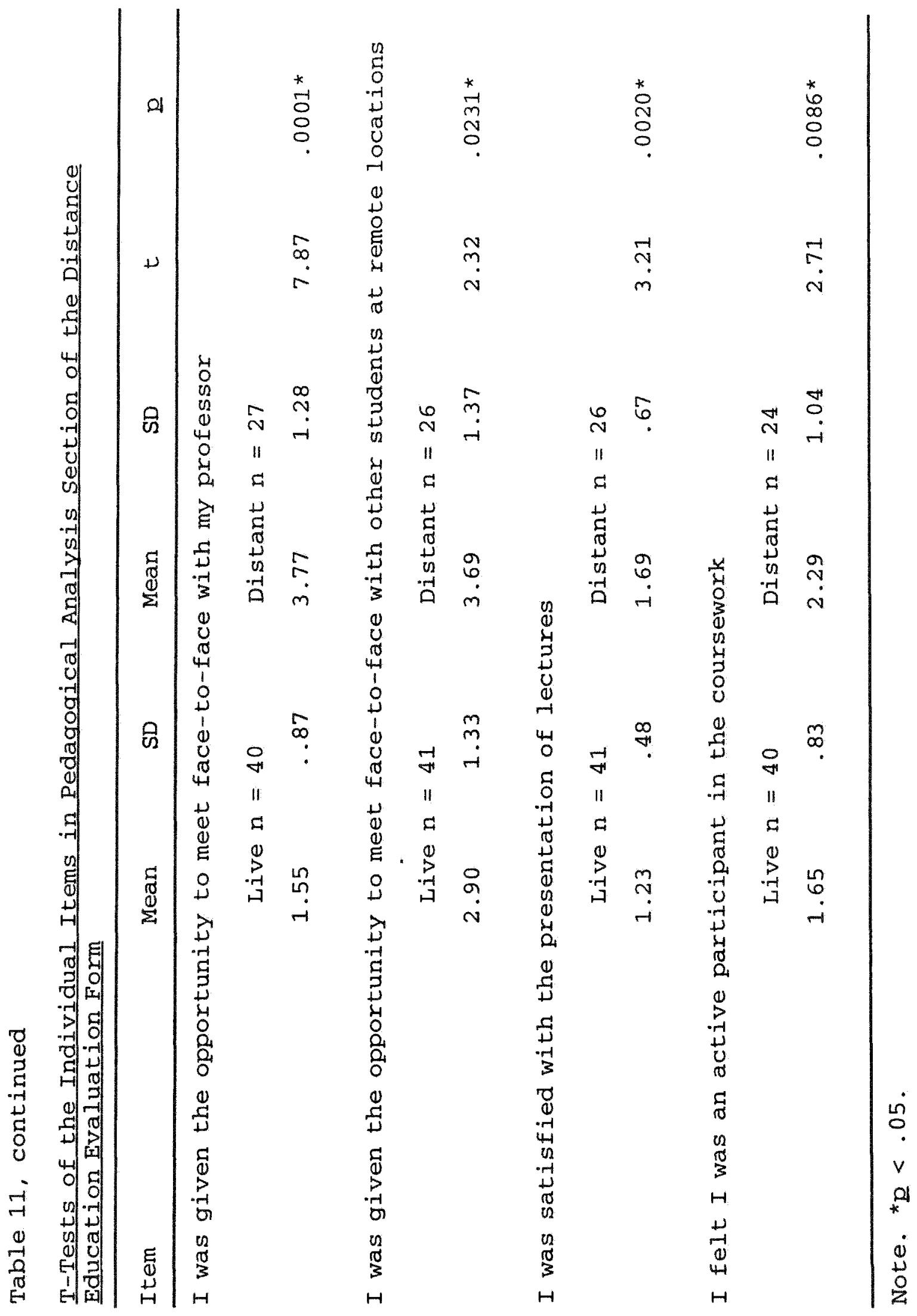


Five out of eight items (62.5\%) showed significant differences between the sites. Four of those five significant items received ratings of disagree or strongly disagree and the frequencies for them are in parenthesis next to the items. They were: I had ample opportunity to interact with the instructor during class (6), I was given the opportunity to meet face-toface with my professor, (19) I was given the opportunity to meet face-to-face with other students at remote locations (16), and I felt I was an active participant in the coursework (5). I was satisfied with the presentation of lectures showed significant differences between the sites but had no ratings of disagree or strongly disagree.

Two of the items, ample opportunity to interact with other students during class and comfortable using audio to interact with the instructor did not have significant differences in ratings between the sites but some students did rate them as needs to improve.

Table 12 shows the distribution of ratings by students at both sites on the items under the Technical Analysis section of the DEE form. 
Table 12

Distribution of Batings by Sites for Technical Analysis in Distance Education Evaluation Form

Location $\mathrm{N} /\left(\frac{0}{6}\right)$

Variables

Total

Live

Distant

Pedagogical

Classroom Quiet

Enough to Hear

$\begin{array}{lcccccc}\text { Strongly Agree } & 27 & (47) & 22 & (67) & 5 & (20) \\ \text { Agree } & 28 & (48) & 11 & (33) & 17 & (68) \\ \text { Disagree } & 3 & (5) & 0 & (0) & 3 & (12)\end{array}$

Support Personnel

Responsive to Technical

Difficulties

$\begin{array}{lcccccc}\text { Strongly Agree } & 30 & (51) & 24 & (68) & 6 & (25) \\ \text { Agree } & 24 & (41) & 9 & (26) & 15 & (63) \\ \text { Disagree } & 4 & (7) & 2 & (6) & 2 & (8) \\ \text { Strongly Disagree } & 1 & (1) & 0 & (0) & 1 & (4) \\ & & & & & & \end{array}$


Table 12, continued

Location $\mathrm{N} /\left(\frac{\circ}{\partial}\right)$

Variables

Total

Live

Distant

Technical Difficulties

Remedied in a speedy

Manner

$\begin{array}{lcccccc}\text { Strongly Agree } & 28 & (48) & 23 & (64) & 5 & (22) \\ \text { Agree } & 27 & (46) & 11 & (30) & 16 & (70) \\ \text { Disagree } & 2 & (3) & 1 & (3) & 1 & (4) \\ \text { Strongly Disagree } & 2 & (3) & 1 & (3) & 1 & (4)\end{array}$

Camera Operators Were Quick

to Provide Focus on Speakers

$\begin{array}{lcccccc}\text { Strongly Agree } & 32 & (57) & 27 & (77) & 5 & (24) \\ \text { Agree } & 21 & (38) & 7 & (20) & 14 & (67) \\ \text { Disagree } & 3 & (5) & 1 & (3) & 2 & (9)\end{array}$

Table continued 
Table 12, continued

Location $\mathrm{N} /\left(\frac{\circ}{0}\right)$

Variables

Total

Live

Distant

Camera Operators

Focused on Blackboard

Long Enough

$\begin{array}{lcccccc}\text { Strongly Agree } & 27 & (44) & 23 & (62) & 4 & (16) \\ \text { Agree } & 25 & (40) & 11 & (30) & 14 & (56) \\ \text { Disagree } & 8 & (13) & 3 & (8) & 5 & (20) \\ \text { Strongly Disagree } & 2 & (3) & 0 & (0) & 2 & (8)\end{array}$

Able to Read Materials on

Blackboard

$\begin{array}{lcccccc}\text { Strongly Agree } & 27 & (42) & 22 & (58) & 5 & (19) \\ \text { Agree } & 29 & (45) & 15 & (39) & 14 & (54) \\ \text { Disagree } & 7 & (11) & 1 & (3) & 6 & (23) \\ \text { Strongly Disagree } & 1 & (0) & 0 & (0) & 1 & (4)\end{array}$

Able to Read Materials on Overhead Projectors

$\begin{array}{lcccccc}\text { Strongly Agree } & 26 & (41) & 22 & (58) & 4 & (16) \\ \text { Agree } & 31 & (49 & 15 & (39) & 16 & (64) \\ \text { Disagree } & 5 & (8) & 1 & (3) & 4 & (16) \\ \text { Strongly Disagree } & 1 & (2) & 0 & (0) & 1 & (4)\end{array}$

Table continued 
Table 12, continued

Location $\mathrm{N} /\left(\frac{0}{5}\right)$

Variables

Total

Iive

Distant

Access to Taped Lectures

$\begin{array}{lcccccc}\text { Strongly Agree } & 26 & (50) & 21 & (64) & 5 & (26) \\ \text { Agree } & 22 & (42) & 11 & (33) & 11 & (58) \\ \text { Disagree } & 4 & (8) & 1 & (3) & 3 & (16)\end{array}$

Technology Appropriate

for Presentation of

Lecture Materials

$\begin{array}{lllllll}\text { Strongly Agree } & 29 & (53) & 23 & (64) & 6 & (32) \\ \text { Agree } & 26 & (47) & 13 & (36) & 13 & (68)\end{array}$

Technology Appropriate for

Group Presentations - Instructor site

Site (Primary Site)

Strongly Agree

Agree

Strongly Disagree

$\begin{array}{lllll}29 & (60) & 22 & (71) & 7 \\ 18 & (38) & 9 & (29) & 9\end{array}$

1 (2) $0 \quad(0)$

1

(6)

Table Continued 
Table 12, continued

Location $\left(\mathrm{N} / \frac{2}{5}\right)$

Variables

Total

Live

Distance

Technology Appropriate for

Group Presentations

Distant Site

Strongly Agree

$22(53)$

17 (74)

5

Agree

$14(33)$

3

11

Disagree

3

(7)

2

(9)

1

Strongly Disagree

3 (7)

1

(4)

2

Technology Appropriate for

Group Interaction Between

Sites

$\begin{array}{lcccccc}\text { Strongly Agree } & 24 & (47) & 20 & (67) & 4 & (19) \\ \text { Agree } & 19 & (37) & 7 & (23) & 12 & (57) \\ \text { Disagree } & 6 & (12) & 2 & (3) & 4 & (19) \\ \text { Strongly Disagree } & 2 & (4) & 1 & (3) & 1 & (5)\end{array}$

The Technical Analysis section consisted of 12 items. Table 13 shows the result of T-tests conducted on the individual items under the Technical Analysis section of the DEE form. 


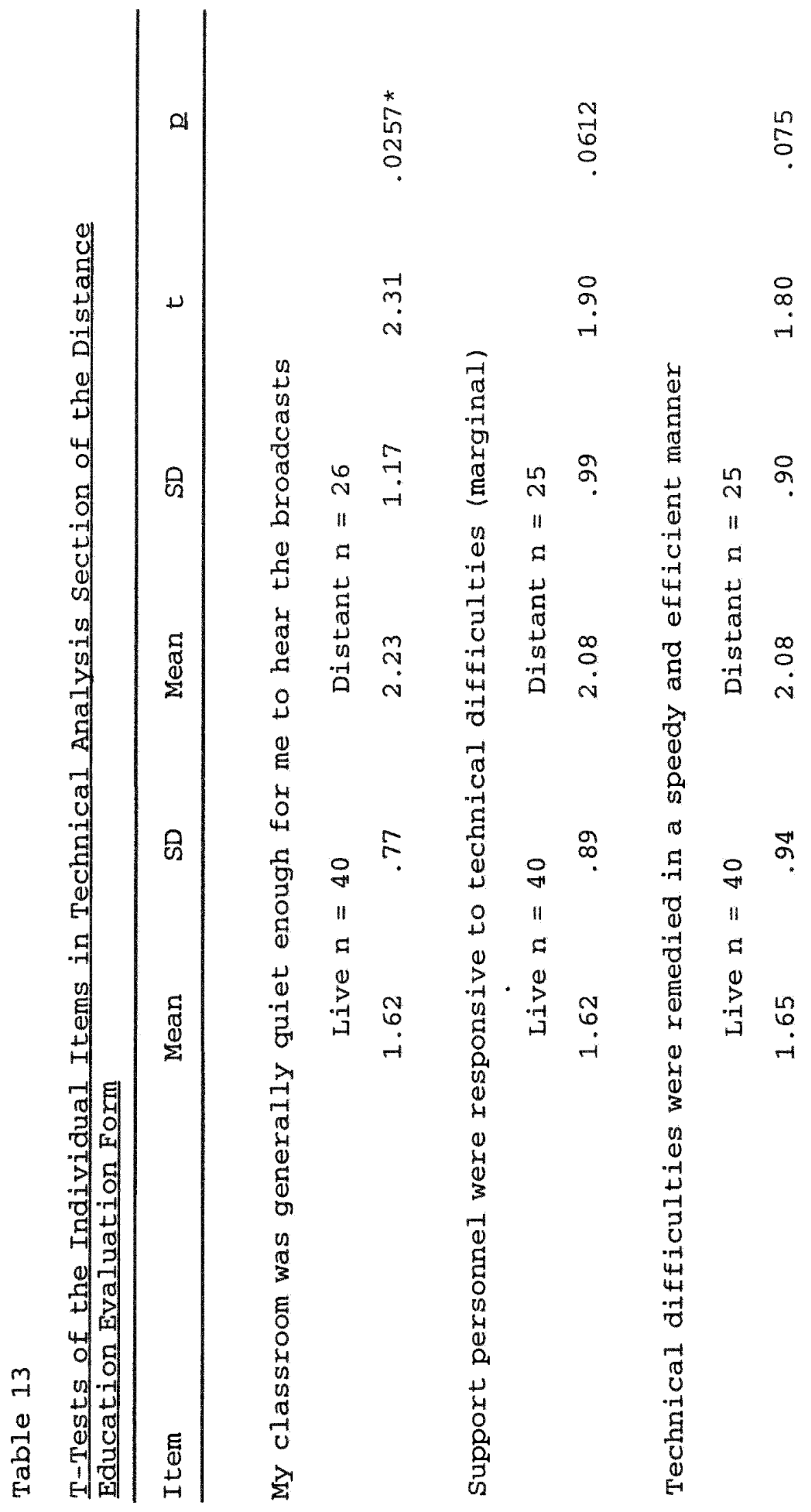




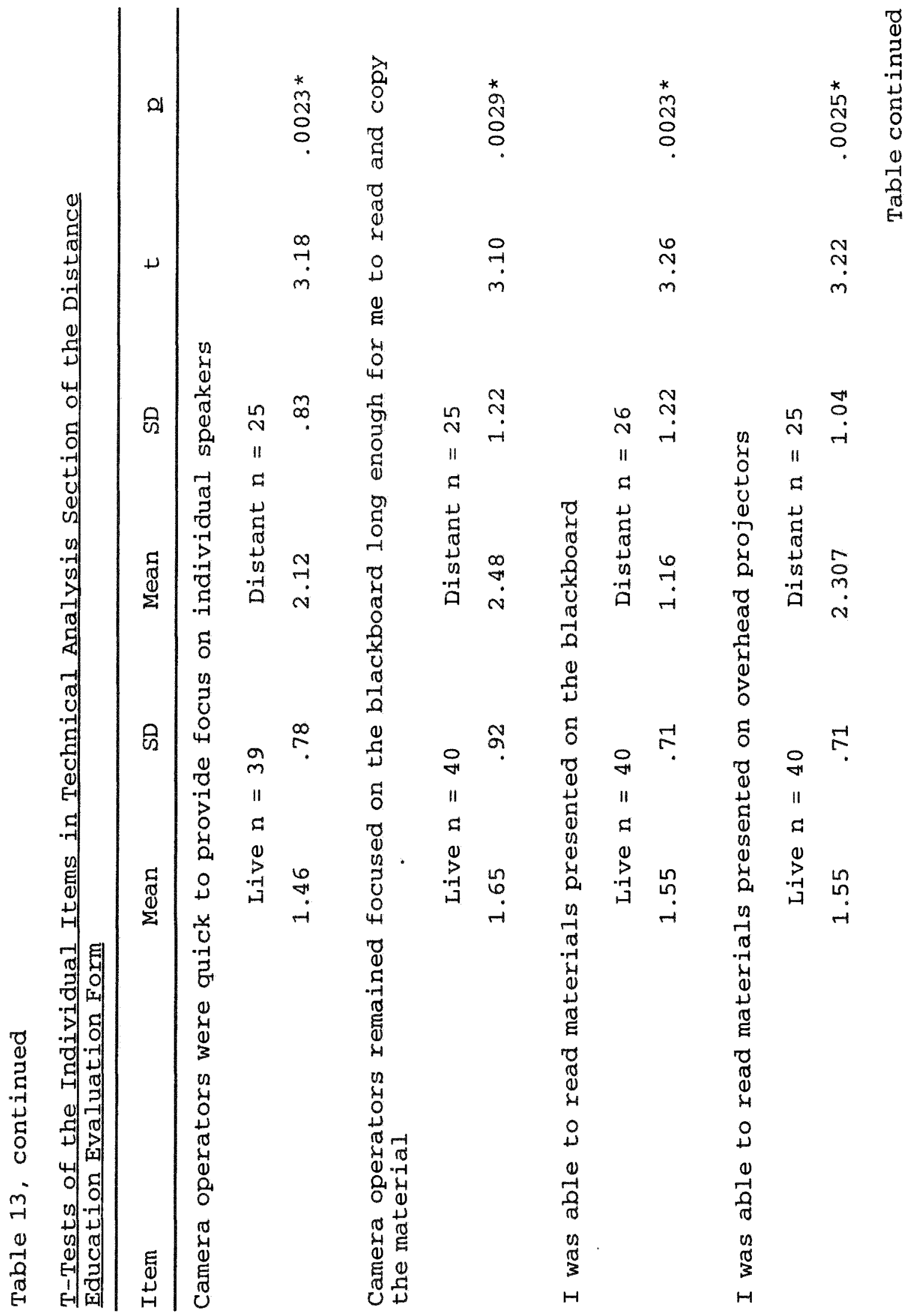




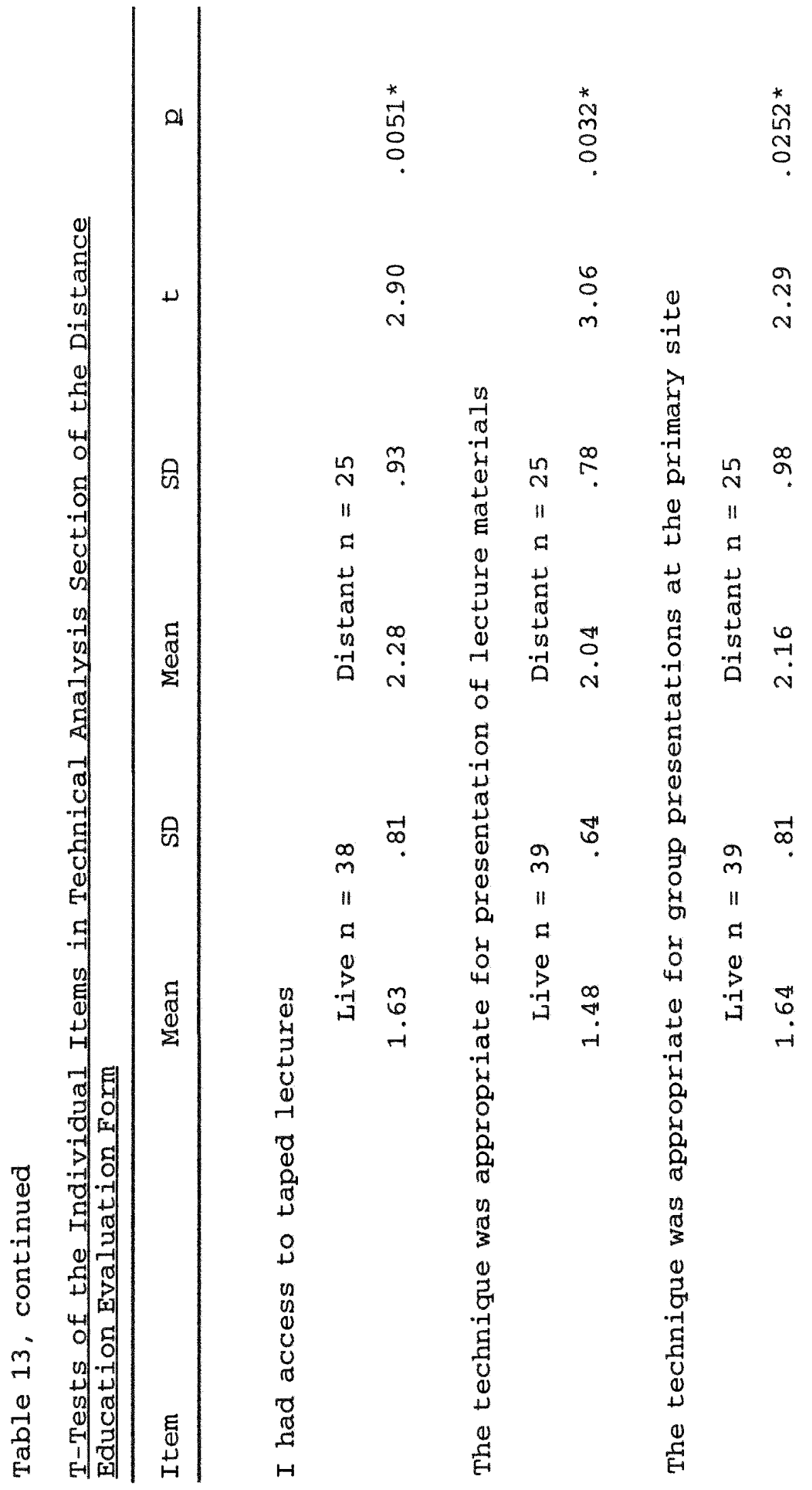

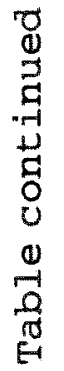




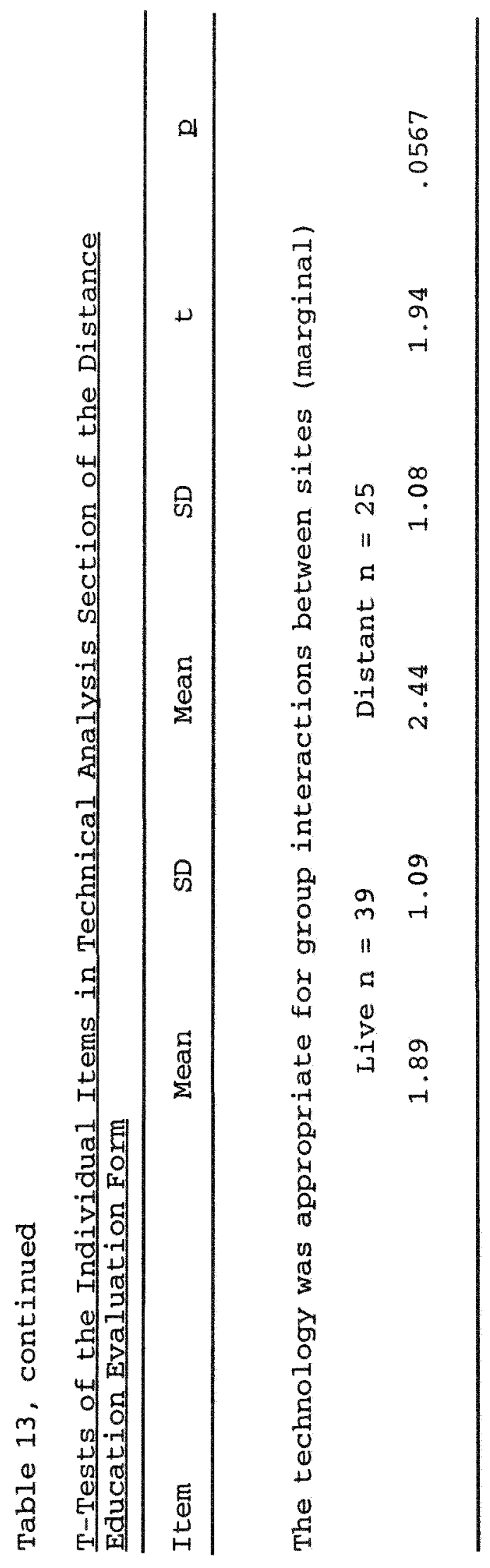

?
o
v
$*$
$\dot{0}$
$\dot{0}$
0 
Eight $(66 \%)$ were rated significantly different between the two sites and two were marginal. The instructor-based site rated this section better than the distant site. The number in parenthesis next to each item is the frequency of the rating by the distant site for disagree or strongly disagree. They were: my classroom was generally quiet enough for me to hear the broadcasts (3), camera operators were quick to provide focus on individual speakers (2), camera operators remained focused on the blackboard long enough for me to read and copy the material (7), I was able to read materials presented on the blackboard (7), I was able to read materials presented on overhead projectors (5), I had access to taped lectures for review (3), the technology was appropriate for presentation of lecture materials, the technology was appropriate for group presentations at the primary site (1) (instructor site). The two marginal items were support: personnel were responsive to technical difficulties $(\mathrm{Q}=.06)$, and the technology was appropriate for group interactions between sites, $(q=.056)$. Two items under that section did not have significant differences between the sites in ratings but had ratings of disagree or strongly disagree. They were technical difficulties were remedied in a speedy and efficient manner and techniques appropriate for group presentations at the remote site. 
The DEE form asked students to list any additional comments they wished to make. Table 14 shows the category and frequency of the comments of the two sites.

Table 14

comments by Both Sites on the Distance Education Evaluation Form

Location $/ \mathrm{N}$

Variables

Total Live

Distant

Want More Communication with Instr.

5

0

5

Poor Video Clarity

2

0

2

Desire to see Remote sites

3

3

0

Proctor Talking Interferes

during exams

2

0

2

Audio Problems

6

3

3

Limited Availability of Tapes

3

1

2

Distractions 1

2

1

1

Too Much Extraneous Talking

3

0

3

More Microphones Needed

2

0

2

Instructors Visits Needed

2

0

2

Positive Course Comments 18 12

6

1 The item Distractions refers to the comments that latecomers at the instructor-based site should be locked out because it 
it's easy to get sleepy at the televised site.

overall attitudes toward distance education experience. A summary measure of the sites' attitude toward the distance education experience was developed by combining items from the Distance Education Evaluation form's sections of Organizational Factors, Technical Analysis and Pedagogical Analysis. Table 15 shows a significant difference between the sites on their attitudes toward the distance education experience. The instructor-based site rated the experience significantly higher than the distant site

Table 15

I-Test on Sites' overal1 Attitudes Toward Distance Education Experience

Lecation

Live $n=26 \quad$ Distant $n=42$

Mean SD Mean $\quad$ SD $\quad t \quad p$

$\begin{array}{llllll}1.92 & .70 & 1.56 & .43 & 2.59 & .012\end{array}$

Note, ${ }^{*} p<.05$.

The Organizational Factors included the interactive study guide, delivery of in-class handouts, ability to send materials to the professor, opportunity to ask questions during class and 
opportunity to receive feedback on quizzes and tests. The Technical Analysis factors include classroom generally quiet enough for me to hear the broadcasts and access to taped lectures for review. The pedagogical factors include $I$ was comfortable using the audio system to interact with the instructor, I was comfortable using the audio system to interact with other students at remote locations, I had ample opportunities to interact with the instructor during class, I had ample opportunities to interact with other students during the class, I was given the opportunity to meet face-to-face with my professor, I was satisfied with the presentation of lectures, and I felt I was an active participant in the coursework.

Additional evaluations. Evaluations distributed by the Department of Management and International Business, the department offering this course, rated the factors of the instructor, contents of the course and textbooks as excellent (4), good (3), fair (2), and poor (1). The 36 evaluations at the instructor-based site had a mean score of 4.00 , while the distant site had 33 evaluations with a mean score of 3.64 .

Each week four postcards were distributed to four different students by the site-administrator at the distant site.

Students were instructed to comment about any matters related to the course content, administrative issues or personal matters. The returned cards were given to the instructor. A total of five cards were returned by five different students during the 
semester. Unfavorable comments from students were: questions from students at the other sites could not be heard, when registering for the course it was not advertised as a distance education course, constantly asking the distant site "are you there" is annoying and makes it easy to lose track of the discussion, there was difficulty in seeing the overhead projections, distance learning does not benefit the students at the distant site as much as the instructor-based site because the teacher is not physically present in the classroom, students could miss the class and the teacher wouldn't know it, I am more motivated in my other classes because the teacher is there to talk to me personally and to offer individual help, it creates a sense of laziness towards being in class each week because of the availability of the taped classes, and the system lacks motivation. Favorable comments included: distance learning is very convenient for students who have difficulty getting to the main campus, the class was interesting, it seemed as if I was in the classroom with the instructor, the professor is excellent, clear and concise in his delivery, and I learned a great deal from the course and felt it had saved much travel time. Student interviews. Some additional findings were available through interviews conducted with nine students at the distant site of the televised class when they exited the last class of the semester. The actual comments can be found in Appendix C. 
The students were asked what worked well during class, what made them unhappy, did they feel they learned as much as they would have in a regular class and did they feel they were active participants in the class. They were also invited to make any other comments they wished.

When asked what worked well (Appendix C1), comments concerned the professor, the study guides and the availability of tapes after class.

When asked what made them unhappy (Appendix C2), students commented on the need for more microphones, more interaction between the distant site and the instructor based-site and too much non-related student talking that interfered with the class.

When asked if they felt they learned as much as in a regular class (Appendix C3), the majority of the comments were favorable.

When asked if they felt they were active participants (Appendix C4) in class, half agreed and half disagreed.

Site-administrator interview. At the end of the semester additional information was collected from the site-administrator who was selected from the students at the distant site. The functions of the site-administrator were to be present at the beginning of each class to take attendance, check to see if there were any questions for the professor, ensure that students were seated according to the seating chart, distribute post cards each week to different students for course comments, 
return test grades, notify the technical staff if assistance was needed and ensure the classroom environment was conducive to learning .

At the end of the course, the site-administrator was interviewed. This person felt that lack of two-way video contributed to students showing up late to class, falling asleep, leaving early and disturbing others. The administrator also felt that since the teacher couldn't see the students, clues ordinarily available from face and body language were missed.

The site-administrator said that initially students responded well to the seating assignments. However, the first time the instructor tried to use the seating chart, the students were not in their assigned seats near the microphones because the administrator did not bring the seating chart to class. As a result, the instructor never called on students by name but allowed them to volunteer. The professor never used the seating chart again and eventually students stopped following it. Often the same students sat by the microphones each week.

Many students were embarrassed at the beginning of the term to ask questions with the microphone, but later on many seemed more relaxed. Students at the distant site were reticent about calling out answers because others at the distant site might do so at the same time and then no one would be heard. It was also difficult to interrupt the class if you felt your question might 
not be important to others.

The site-administrator felt that personal relationships with the instructor were hard to establish from a distance and feared the professor would not recognize the distant students when on campus.

The audio system was a problem for students at the distant site when students at the instructor-based site asked questions. The instructor would answer the question but the answer was difficult to follow without initially hearing the question.

The site-administrator felt that students have more camaraderie and interaction with each other at the distant site because they use each other as a resource. Some even asked others to be quiet when they were disturbed by the talking.

Proctoring during examinations was a problem. Distant site students were embarrassed to ask questions about the test over the microphone where it could be heard by the distant site and the instructor-based site. One proctor did not monitor cheating and the other proctor was so intent on circulating among students that it was distracting.

The site-administrator felt that using a student for the position was a problem because it was difficult to set-up the seating, distribute papers, try to answer questions and discipline students while trying to do your own work. It is also difficult to expect a fellow student to discipline others in the class. 
When using a site administrator in the future, it is best to have instructors choose someone who can work well with them, assign them specific responsibilities and communicate regularly. Problems that need to be resolved at the distant site are: students showing up late for class and leaving early, nonrelated conversations among students that disturb others, and limited opportunities for interaction.

In answer to the specific research question on how the attitudes and perception of students at the instructor-based site and the distant site compared as previously discussed, analysis of the evaluation forms collected at the mid-point of the semester and at the end of the semester showed significant differences in ratings between the sites. This was further collaborated with interviews with students and the siteadministrator.

\section{Chapter Summary}

Chapter 4 presented a brief description of the experiment used to answer the basic research question, if certain technical and structural interventions are implemented at the distant site of a televised course, how does the performance of students and their attitudes and perceptions at that site compare with that of students at the instructor-based site? Five specific research questions supporting the basic research question were answered by analyzing data collected from the students, the university records, evaluation forms and interviews. 
Analysis of the data showed that there were no significant differences in the performance of students but several significant difference existed between the attitudes and perceptions of students at the two sites. Even though the majority of students rated most items relating to attitudes and perception as acceptable or very good, or agree/strongly agree, there were significant differences in the ratings between the sites. For many of the items in the evaluation forms, several students, even though they were a minority, chose the ratings of needs to improve and disagree or strongly disagree.

Chapter 5 presents a summary of chapters 2 and 3 and conclusions and recommendations for distance learning and for future research. 
CHAPTER 5

SUMMARY, CONCLUSION AND RECOMMENDATIONS

This section summarizes the study as described in chapters two and three. General and specific conclusions from the analysis of the data in chapter four will be given.

Recommendations for distance education, based on this study, and recommendations for future research will be addressed.

\section{Summary}

A review of the literature for the framework of distance education, adult education and communication was conducted in Chapter 2. From the review of literature, the basic research question was developed: if certain technical and structural interventions are implemented at the distant site of a televised course, how does the performance of the students and their attitudes and perceptions at that site compare with that of the students at the instructor-based site?

\section{Theoretical Review}

In the review of literature for distance education, much information was found concerning changes that need to occur to help make learning effective in a distance environment. Wedemeyer (in Purdy \& Wright, 1992) stated it was not sufficient to place a camera and a microphone in front of a classroom without a change in any teaching techniques. He believed the changed role of teachers and learners and the environment created by technology required the role of faculty change from 
teacher centered to learner centered. The focus should be on learning rather than teaching. What students do becomes more important than what teachers do. An instructor no longer has to be the exclusive source of information. Based on this view, instructors need to learn new teaching skills, organize instructional resources for independent study and understand how technology affects learning. Instructors can no longer be content with just selecting and sharing content.

Holmberg (1981), in his theory of guided didactic conversation stated that distance education has long been criticized for encouraging rote learning. He contended that a teacher should be a facilitator of learning not just a disseminator of information and students should have activities over and above reading, watching and listening. Education needs to engage students in intellectual activities that makes them try out new ideas, reflect, compare and apply critical judgement as opposed to just receiving information. To actively involve students, he stressed interaction through rapport and communication between course developer and students through written materials.

Moore (1993) was concerned with the scarce amount of autonomy learners often have in setting objectives, choosing methods of study, selecting resource persons and media and determining evaluation strategies in distance education. He bemoaned the fact that teachers are often active while students 
are passive. He wrote the degree of control and autonomy exhibited by a student is often dependent on the type of communications used in a distance education program and the quality of the communication process between the teacher and students. The sense of distance felt by a learner is expressed by the amount of dialogue (interaction between student and instructor) and structure found in a course or program. Distance is greater when there is little dialogue. Dialogue can occur during the planning and learning phases of a course and is concerned with students' intellectual, physical and emotional needs. Moore contends that generally, programs with little transactional distance and an open structure best support the individual growth of students.

Peters (1993) described how advanced telecommunications has helped changed the character of distance education from a solitary experience to an interactive group experience. Distant students, aside from communicating with the instructor, can help each other by sharing information and serving as models.

Other distance education researchers (Holmberg, 1986) have written about the importance of incorporating the teaching models of Skinner, Ausubel, Bruner, Rogers and Gagne into distance education.

\section{Empirical Review}

In the empirical review section in Chapter 2 some studies 
showed that the subjects at the instructor-based site rated instruction more enjoyable with greater involvement and greater opportunities to ask questions than students at the distance site. Many subjects assigned a less than satisfactory rating to not being able to hear questions and comments from students at the instructor-based class and many were dissatisfied with how tests and homework were returned to them.

Studies (Fulford \& Zhang, 1993; Lehmman \& Kinney, 1992) show that when distance learners perceived the level of interaction during class to be high, they were more satisfied with the instruction. Overall classroom interactions, whether or not each individual student participated, had a strong impact on learners perception of personal interaction. Even though there is not usually enough time to allow every student to participate in a discussion, frequent interaction keeps all students alert since no one knows who will be called.

Lehman \& Kinney's (1992) study demonstrated that participants in the one-way video, two-way audio groups felt they were not able to participate as much as they wanted to while none in the two-way audio, two-way video group gave that response. Over $63 \%$ of the audio-only group said they would have learned more through traditional instruction while less than $25 \%$ in the two-way video and audio group agreed. Instructors also preferred two-way audio and two-way video. 
In summary, distance education researchers and writers concur that a successful distance education program is possible using the principles of instructional design, combined with detailed up-front planning and employing open two-way communication and flexibility in course structure.

\section{The Study}

In the Spring, 1995 semester, a study was conducted to compare the performance and attitudes and perceptions of students at the instructor-based site and the distant site of a televised course in the school of Business at a major state university. The class was broadcast from the main campus through instructional television fixed services which is one-way video and two-way audio. The instructor was able to broadcast from only the main campus and did not visit the distant site.

As a result of the pilot study conducted the previous term, a site-administrator, who was a student in the distant class, was hired to assist the professor and the other students at the distant site. One of the functions of the site administrator was to ensure that all students had equal opportunity to communicate with the instructor and the students at the instructor-based site. Seats near the microphones were assigned to different students for every class session. Other functions of the site administrator were taking attendance, calling for technical assistance when needed, distributing tests and 
assignments, answering student questions, distributing postcards to selected students each session to collect comments and monitoring student behavior.

As a result of the pilot study, it was also decided to arrange the room set-up to encourage participative learning and ensure good viewing. However, for this study, the university assigned a room approximately $20 \times 30$ feet with permanent built-in seating and tables. Approximately 30 students were seated around the outside of a U-shaped table and about 15 were seated at a rectangular table inside the U-shaped table with the microphones.

The independent variables were the technical and structural interventions (site-administrator, placement of the microphones, room set-up) at the distant site and the dependent variables were performance as measured by grades, course completion rate, and pass rate and attitudes and perception ratings from the interim evaluation form, Distance Education Evaluation (DEE) form, the instructor evaluation form and interviews with students and the site-administrator at the distant site.

\section{Conclusions}

In order to answer the basic research question, five specific research questions were answered. Following is the presentation of each question, the data collected for the analysis of the question and the results of the analysis. 


\section{Question 1}

Is the demographic make-up of students at the instructorbased site and the distant site comparable?

The demographic data collected from student questionnaires and university student records supplied information on age, sex, ethnicity, place of origin, marital status, number of children in student's family, entering status to the university, current student status, school, major, employment status and CLAST scores. The analysis of the data shows the only significant differences between the sites was ethnicity and CLAST reading pass rate. Therefore, the answer to question one is the demographic make-up of students at the two sites is the same except for ethnicity and CLAST reading scores.

\section{Question 2}

How does the course completion rate compare between the instructor-based site and the distant site utilizing the three interventions of a site facilitator, multiple telephones, and a pre-configured classroom at the distant site of a televised course? The instructor-based site had a $93 \frac{\circ}{1}$ completion rate. Forty-six students were originally enrolled, two dropped-out of the class and one received an incomplete grade which eventually turned into an $F$ grade. The distant site had 43 enrolled and two dropped-out of class for a $95 \%$ completion rate. Therefore the answer to question two is there is no significant difference 
between the sites on course completion rate.

\section{Question 3}

How do the final grades of students at the instructor-based site and the distant site compare utilizing the interventions in question two? To compare the average grade for each site, the letter grades were changed into points. A 4.0 was equal to an A grade. The instructor-based site had a mean grade of 2.131, and the distant site had a mean grade of 1.967. A T-test was conducted and the results showed there was no significant difference between the sites for grades. Therefore, the answer to question three is there is no significant difference between the sites for grades.

\section{Question 4}

How do pass rates of the instructor-based site and the distant site compare with the distant site utilizing the interventions in question two? Thirty-one students (74\%) at the instructor based site were successful in passing the course while 26 (65\%) were successful at the distant site. A Chi square test showed there was no significant differences in pass rates between the sites. Therefore, the answer to question four is there is no significant difference between the sites in pass rates.

\section{Question 5}

How do the attitudes and perceptions of students at the 
instructor-based site and the distant site compare on organizational, pedagogical and technology factors, the distance education experience rating, instructor ratings, and interviews with students and the site administrator at the distant site?

The T-tests conducted on the interim evaluation forms showed a significant difference between the two sites on the ratings of the organization and pedagogical sections while technical was marginal. The instructor-based site rated these sections better than the distant site.

The T-tests conducted on the Distance Education Evaluation (DEE) form showed a significant difference between the two sites on the ratings of the Organizational Factors, Pedagogical Factors and Technical Analysis sections. The instructor-based site also rated these sections better than the distant site.

The T-test conducted on the overall distance education experience also showed a significant difference between the two sites with the instructor-based site giving better ratings. Students at the instructor-based site also rated the instructor higher on the department's teaching evaluations than the students at the distant site.

Therefore, the answer to question five is there is a significant difference between the two sites on attitudes and 
perception as demonstrated by the ratings between the two sites on the interim evaluation form, the Distance Education Evaluation from, the distance education experience rating and interviews with students and the site-administrator at the distant site. When these differences occurred, the distant site ratings were always less favorable than the instructorbased site.

Having answered the five specific research questions, the basic research question can now be answered. The basic research questions asked: If certain technical and structural interventions are implemented at the distant site of a televised course, how does the performance of students and their attitudes and perceptions at that site compare with that of students at the instructor-based site? In answer to the basic research question, this study demonstrated that students at the two sites showed no significant differences in performance as demonstrated by grades, course completion rate and pass rate. However, several significant differences existed in attitudes and perception ratings between the sites.

Several significant differences in attitude and perception ratings between the sites pertained to items that were common and identical toboth sites such as organization of the course, the course study guide, course syllabus, 
course objectives and expectations, and lecture/presentations. Under items related to technology, the use of equipment, videobroadcast, audio quality, ability to read materials from the board, technology appropriate for presentation of lecture materials, and technology appropriate for group presentations at the primary site were also rated significantly higher by the instructor-based site. The instructor-based site rated pedagogical items such as: assistance provided when needed, opportunity to ask questions, opportunity to interact with the instructor and other students during class, classroom quiet enough, opportunity to receive feedback on assignments, quizzes and tests, felt like an active participant, ability to send materials to the professor and delivery of in-class hand-outs significantly better than the distant site.

It is encouraging to note, however, that the majority of students on the two evaluation instruments for all items chose at least the ratings of acceptable or agree, even though several students chose needs to improve or disagree/strongly disagree for many of the items. All of the students at both sites agreed or strongly agreed they were satisfied with the presentation of lectures and the technology was appropriate for presentation of lecture materials. 
Recommendations

Recommendations discussed here are for future distance learning programs based on the results of this study and for future research in the field of distance education.

Recommendations for Future Distance Learning Programs

Recommendations for future programs to improve the attitudes and perceptions of participants at the distant site are based on the detailed analysis of the items in the interim evaluation form and the DEE form. Recommendations are given for each evaluation instrument and for the specific items in each section (organizational, pedagogical, technical) that were rated significantly different between the sites.

Interim Evaluation

The items rated on the interim evaluation were divided into three sections: organizational, technical and pedagogical. Seven of ten items rated under the three sections showed significant differences between the sites and one was marginal.

erganizational section. Organization of course, study guide and syllabus (marginal) were rated significantly different between the sites even though these items were identical for both sites. This is the first distance education course these students have taken and they may be 
reacting to the huge differences between traditional education and distance learning. Students may profit from an orientation session, before beginning the course, whether live, videotaped or through some other medium on how a distance education course differs from a traditional course.

Technical section. The use of chalkboard, overhead projector/camera and other devices along with visual materials were rated significantly different between the sites. Students did not experience the same visual acuity as the live site. Material must be carefully planned and prepared before class using a large enough font for visual materials. Copies of visual materials can also be sent to the distant site in advance of the lecture.

Redagogical section. There was a significant difference between the sites' ratings on assistance provided when needed even though a site administrator was present at the distant site for each class session. Moore (1995) wrote about the importance of a site-administrator for all sites of a distance education class. This was further reinforced by the experience of the pilot study and the class used for this study.

For this experiment, the site administrator was chosen from a group of students who volunteered for the position. The site administrator was not provided an opportunity to 
meet or talk with the instructor previous to the beginning of the semester.

A site administrator should act as the eyes and ears of the instructor and relay information on a regular basis. This person needs to feel comfortable enough with the instructor to relay student requests for information and ensure that students' questions are answered. The ideal site-administrator needs to be knowledgeable about the subject matter, be able to communicate easily with students, have their respect and confidence, be competent in the technical aspect of the medium, be able to handle administrative procedures and have some instructional competence. A graduate student or a student who previously took the course, received a good grade, and communicates well would make an excellent candidate. The site-administrator for this study was enrolled in the class and found it difficult to keep current in class work while helping others. Based on my study, I recommend a site-administrator who is not a current student always be present at every distant site of a televised course.

Course objectives and expectations, and lectures/presentations were rated significantly different between the two sites. An orientation session to distance learning might help dispel differences in ratings. The 
orientation session should include the differences between traditional education and distance education, the expectations of the instructor for participation of the distant site students during class, communication with the instructor during and after class, evaluation of students' work and students' expectations for the class. Distance Education Evaluation form

Thirty items were rated under the three sections of Organizational Factors, Pedagogical Factors and Technical Analysis. Twenty-two were rated as significantly different between the sites.

erganizational factors. Delivery of in-class handouts and ability to send materials to the professor were rated significantly different between the sites. To address this problem, the site-administrator can work with the university mail system or utilize the postal service to develop a reliable system for distribution of materials.

opportunity to ask questions during class was limited by the small number of microphones available at the distant site. The site-administrator felt it was difficult for some students to interrupt the class with a question since others might not feel it was important. During class breaks, before class or immediately after class, the professor can take questions from the distant site by telephone with or without 
the use of the microphones. This would allow the distant students more time to communicate with the instructor.

An instructor needs to check frequently with students at the distant site for questions. Telephone, fax or computer email can be used for student questions during class or outside of class. The site-administrator can also relay questions to the instructor. Feedback on tests and quizzes can be handled in the same way.

Redagogical factors. There were significant differences between ratings at the sites on I had ample opportunities to interact with the instructor during class. Ideally each participant should have a microphone or a response key pad to communicate with the instructor. About $25 \%$ of the distant students requested more microphones for communication.

During the experiment the site-administrator tried to encourage students to interact with the professor by rotating seats near the microphones. However, the same students each week took the seats near the microphones and answered the instructor's questions. Fulford and zhang (1993) feel that randomly calling on distant students creates an overall feeling of participation that can have a stronger impact than an individual perception of personal interaction. Based on my study, I agree that an instructor can encourage more participation from students by randomly calling on them. If 
many different students are involved in the class discussions, students have a perception of personal interaction even if they are not called on.

Almost $50 \%$ of the students at the distant site disagreed with the statement, I was given the opportunity to meet faceto-face with the instructor. Many of them requested the instructor visit the distant site. The instructor did not visit the distant site because it was not possible to broadcast from that location. There was also a significant difference between the sites on the rating I was given the opportunity to meet face-to-face with other students at remote locations. Occasionally joint class meetings can be arranged so the instructor and students at both sites can meet in person, or perhaps the instructor can schedule a class meeting at the distant site. Increased familiarity between the instructor and the distant site might encourage more participation during class.

All of the students agreed or strongly agreed with satisfied with presentation of lectures. The instructor was an excellent lecturer, very knowledgeable and related well to the students. These are important qualifications for all instructors but are especially necessary for distance education instructors.

Technical analysis. Several students at the distant 
site disagreed that the classroom was generally quiet enough for me to hear the broadcasts. The site-administrator felt little control over students showing up late for class, leaving early, falling asleep and disturbing others talking about non-related topics.

When an instructor frequently and randomly calls on students by name, this helps students remain alert during class. Small group activities between the sites or at each site involves the students in their work.

It is difficult for a classmate to serve as a siteadministrator and monitor the behavior of other students. A site-administrator who is not enrolled in the class would find this an easier role.

The instructor needs to have on-going evaluation of the class by the students at the distant site to ensure their needs are met. This can be conducted through the siteadministrator or directly with students.

Students at the distant site experienced more visual problems as evidenced by their unfavorable ratings for the use of equipment and visual materials. They complained of not being able to read the materials presented on the blackboard or the overhead projector, and that the camera operators were not focused long enough to allow them to read and copy the material. Large print on visual materials may 
lessen the problem, or hard copies of the materials can be sent to the distant site in advance of the class by facsimile, regular mail or computer mail. The distant site can also use their own overhead projector to show materials. These interventions entail more up-front planning by the instructor.

Technology appropriate for group presentation at the instructor site was rated lower by the distant site. Since students sometimes experienced difficulty in hearing the instructor and seeing the visuals, perhaps they felt it would be too challenging to have other participants involved in the presentations. Group presentations from the distant site using ITFS are possible if students produce a video in advance and send it to the instructor-based site to be played during class. Live audio group presentations from the distant site can be broadcast during class.

A system that allows each student equal opportunity to ask questions, and interact with the instructor during class enables all students to actively participate. Providing an orientation session for new distance students and establishing support systems helps students begin a course with realistic expectations and confidence. Giving students an opportunity to meet with the instructor, and possibly other students, breaks down barriers to communication. Open 
communication channels to the instructor outside of class is important. A site-administrator at the distant site who serves as the instructor's eyes and ears and can offer support to students is important for any distant education program. Better use of technology and better preparation of visuals can improve the audio and visual portions of a distance course so students do not miss out on important information. Hopefully, these suggestions will improve the difference in ratings between the attitudes and perceptions of students at a distant site.

\section{Recommendations for Future Research}

Motivation has been cited as an important factor in maintaining student enrollment in distance education. Christopher (in Barry \& Runyan, 1995) concluded, on the basis of statistical analysis of test scores, especially for shorter courses, that distant students learned at least as well as resident students and that students' attitudes towards courses were positive. Most distance education research has been conducted on short courses; it is now necessary to determine if the attitudes and motivation required to complete several distance education courses or an entire degree program can be maintained.

In North America, according to Moore (1995) the most common form of distance education is when students at distant 
locations are added on to existing traditional classes. This kind of teaching is more work for the instructor and more intensive than face-to-face teaching. According to Beaudoin (1990), Strain (1987) and Gunawardena (in Olcott and Wright, 1995), the role of faculty needs to change when working in distance education. Some changes include shifting the role of the instructor to one of facilitator and changing from an instructor centered system to a student centered system. Instructors need to reevaluate how to present course information and how to structure interactive sessions.

Some writers in the field have suggested that some students are more successful in distance education because of learning style differences. Some students prefer teachercentered instruction while others are more self-directed. Some students enjoy learning new information through reading while others enjoy a variety of media. More research needs to be conducted to decide if certain learners are more disposed to success in distance education, and if it is necessary to present materials in several media to meet different learning styles.

According to olcott and Wright (1995), many instructors are hesitant to become involved in distance education because they visualize increased work with lack of time, fears of reduced student interaction, technical problems with 
transmission and administrative problems such as distribution of course materials. Colleges need to research the most effective ways to help instructors prepare for their new roles.

While instructors are faced with new challenges, Lalande, (1995) states that students who learn at a distance are also faced with new challenges. They include more isolation, needing additional help and dealing with multiples roles and responsibilities, problems relating to inadequate study skills, time management, learning style, career indecision, and confusion about goals. As a result, it is possible that off-campus students are at a higher risk for attrition, low grades, or decreased learning. Further research needs to be conducted to determine how barriers to distant education can be reduced for students.

\section{Summary}

According to Verduin and Clark (1991) by the year 2000, the United States will be responsible for educating more than 50 million workers. At the same time, colleges will be faced with a shortage of faculty due to institutions not replacing departing faculty and less people choosing college teaching as a career. The majority of college students will be working adults living at home and involved in many support roles. Distance education can be the answer to educating and 
training large numbers of adults who like to learn on their own and at their own convenience and pace.

Modern communication technology can easily support learner independence as well as interaction between other students, the instructor, experts, data bases and a variety of sources of information.

The study described earlier demonstrated that there is no significant difference in the performance of students at the instructor-based site or the distant site of a televised course. However, significant differences occurred when attitudes and perceptions were compared. Several suggestions were made on how to improve these ratings.

As distance education continues to grown and colleges offer complete undergraduate degree programs through distance learning, attitudes will become a more critical factor. Research needs to be conducted to determine what role attitudes play in preventing drop-outs. Further research also needs to be conducted on how to help traditional instructors successfully perform in a distance education environment. 
References

Amundsen, C. (1993). The evolution of theory in distance education. In D. Keegan (Ed.), Theoretical principles of distance education (pp. 61-79). London: Routledge.

Baath, J. A. (1983). A list of ideas for the construction of distance education courses. In D. Sewart, D, . Keegan \& B. Holmberg (Eds.), Distance education: International perspectives (pp. 276-288). London: St. Martin's Press. Beaudoin, M. (1990). The instructor's chaninging role in distance education. The American Journal of Distance Education 4(2), 21-29.

Be1l, R. D. \& Tight, M. (1993). Qpen universities: A british

tradition. Buckingham, England: Open University Press. Bosworth, D. P. (1991). Open learning. London: Cassell Education Limited.

Boyd, R. D. \& Apps, J. W. (1980). A conceptual model.. In R.D. Boyd \& J. W. Apps (Eds.), Bedefining the discipline of adult education (pp. 1-15). San Francisco: Jossey Bass Inc. Brookfield, S. D. (1986). Understanding and facilitating adult learning, San Francisco: Jossey Bass Inc. Burge, L., \& Haughey, M. (1993). Transformative learning in reflective practice. In T. Evans \& D. Nation (Eds.), Reforming open and distance education ( $p p .88-112$ ). London: St. Martin's Press. 
Clenell, S., Peters, J., Sewart, D. (1988). Teaching for the open university In D. Sewart, D. Keegan, B. Holmberg (Eds.), Distance education: International perspectives (pp. 327-338). London: Routledge.

Coldeway, D. (1989). Distance education as a discipline. Journal ef Distance Education 4 (1), 55-72.

Cookson, P. S. (1990). Persistence in distance education. In M.G.

Moore (Ed.), Contemporary issues in american distance

education (pp. 192-206) England: Pergamon Press.

Cross, P. (1981). Increasing participation and facilitating

learning. San Francisco: Jossey Bass.

Crotty, T. (June 30, 1995). The Constructivist Paradigm. DEOS-I

The Distance Education online Symposium.

Cyrs, T. E., \& Smith, A. S. (1990). Teleclass teaching: A resource

guide (2nd ed.) Las Cruces, NM: New Mexico State University.

Daniel, J.S., \& Marquis, C. (1988). Interaction and independence:

Getting the mixture right. In D. Sewart, D. Keegan, B.

Holmberg (Eds.),

Distance education: International perspectives (pp. 339-359). London: Routledge.

Denton, J. J., Clark, F.E., Rossing, R. G., O'Connor, M. J. (1982). An examination of instructional strategies used with two-way television. Journal of classroom interaction, 19(2), $12-20$. 
Department of the Army. (1992). Distributed training pilot: Videe teletraining reserve component (VTT-BC) training effectiveness analysis (TEA). White Sands Missle Range, NM: CPT Lehman, A. , L. Kinney, P.A. Dirr. P. J. (1990). Distance education: Policy consideration for the year 2000. In M.G. Moore (Ed.), Contemperary issues in american distance education (pp. 397-405) England: Pergamon Press.

Evans, T., \& Nation, N. (1993). Reformations in open and distance education. In T. Evans \& D. Nation (Eds.), Reforming open and distance education (pp. 7-15). London: St. Martin's Press.

Fulford, C. P., \& Zhang, S. (1993). The critical predictor in distance education. American Journal of Distance Education. $I(3), 8-21$.

Garrison, D. R. (1989) . Understanding distance education. London: Rout ledge.

Garrison, D. R., \& Baynton, M. (1987). Beyond independence in distance education: The concept of control. American Journal of Distance Education, 1(3), 1-13.

Gay, L.R. (1992). Educational Research (4th ed.) NY: Macmillan Gibson, C. C. (1993). Towards a broader conceptualization of distance education. In D. Keegan (Ed.), Theoretical principles of distance education (pp. 80-92). London: Routledge. 
Gillard, G. , (1993). Deconstructing contiguity. In T. Evans \& D. Nation (Eds.), Reforming open and distance education (pp. 182-195). London: St. Martin's Press.

Gorham, J., (1988). The relationship between verbal teacher immediacy behaviors and student learning. Communication Education, $37,40-53$.

Holmberg, Borje (1981). Status and trends of distance education. New York: Nichols Publishing Co.

Holmberg, Borje (1986). Growth and structure of distance education. London: Croom Helm.

Holmberg, Borje (1988). Course development. In D. Sewart, D. Keegan, B. Holmberg (Eds.), Distance education: International perspectives (pp. 321-327). London: Routledge.

Holmberg, Borje, (1989). Theory \& practice of distance education. London: Routledge. Hudspeth, D. R., Brey, R. G. (1986). Instructional telecommunications, New York: Praeger. Jarvis, P. (1995). Adult and continuing education (2nd ed.). London: Routledge Jarvis, P. (1993). The education of adult and distance education in later modernity. In D. Keegan (Ed.), Theoretical principles of distance education (pp.165-175). London: Routledge. 
Jones, A. , Kirkup, G. , Kirkwood, A. (1993). Dersonal computers fer distance education. NY: St. Martin's Press.

Keegan, D. (1990). Eoundation of distance education. (2nd ed.) NY: Routledge.

Kidd, J. R. (1973). How adults learn. (Rev. Ed.). Chicago: Follett Publishing.

Klivens, J. D. (1991). Teaching at a distance over interactive televisien. Augusta Maine: University of Maine at Augusta. Knowles, M. (1973). The adult learner: A neglected species. Houston: Gulf Publishing Co. Knowles, M. (1975). Self directed learning. Chicago: Follett. Knowles, M. (1980). The modern practice of adult education (rev. Ed.). Englewood Cliffs, NJ: Prentice Hall Regents. Knowles, M. (1990). Aneglected species. (4th ed.) Houston: Gulf Publishing Co.

LeBlanc, G. (1991). Bridging the distance: Supporting distance education faculty and staff at the university of Maine at Augusta. Augusta, ME: Center for Distance Education. Ljosa, E. (1993). Understanding distance education. In D. Keegan (Ed.), Theoretical principles of distance education (pp. 175188). London: Routledge.

Ljosa, E., Sandvold, K. E. (1988). The student's freedom of choice within the didactic structure of a correspondence course. In D. Sewart, D. Keegan, B. Holmberg (Eds.), Distance education: International perspectives (pp. 291-315). Iondon: Routledge. 
Lockwood, F. (1994). Encouraging active learning: models appropriate for self-instruction. In F. Lockwood (ed.), Materials production in open and distance learning (pp. 8995). London: Paul Chapman.

Long, H. B. (1983). Adult \& Continuing Education. N Y: Teachers College, Columbia University.

Maslow, A.H. (1968). Towards a psychology of being (2nd ed.). NY: D.Van Nostrand Co.

Mezirow, J. (1981). A critical theory of adult learning and education. Adult Education 32(1).

Moore, M., G. (1989). The effects of distance learning (paper for the Congress of the United States, Office of Technology Assessment)

Moore, M. G. (1993). Theory of transactional distance. In D. Keegan (Ed.), Theoretical orinciples of distance education (pp. 22-38). London: Routledge.

Moore, M. G. (1995). The five c's of the local coordinator. The American

Journal of Distance Education 2(1), pp. 1-5.

Navy Personnel and Development Center. (1991). Emperical

composition of alternative video teletraining technolegies (TR-92-3). San Diego: Simpson, H., Pugh, H. L., Parcham, W. 
Oliver, E. L. (1994). Video tools for distance education. In B.W. Willis (Ed.), Distance Education strategies and toels. (pp. 65-195). Englewood Cliffs, $N$ J: Educational Technology Publications.

Ostendorf, V. A. (1989). Teaching through interactive television.

Littleton, Co: Virginia A. Ostendorf, Inc.

Peters, 0. (1983). Distance teaching and industrial production: A comparative interpretation in outline. In D. Sewart, D. Keegan \& B. Holmberg (Eds.), Distance education: International perspectives (pp. 95-113). London: Croom Helm. Peters, 0. (1993). Distance education in a postindustrial society. In $D$. Keegan (Ed.) + Theoretical principles of distance education (pp. 39-60). London: Routledge. Portway, P. S. \& Lane, C. (1994). Guide to teleconferencing \& distance learning. San Ramon: Applied Business telecommunications.

Purdy, L., \& Wright, S. (1992). Teaching in distance education: A faculty perspective. The American Journal of Distance Education 6(3), pp. 2-4.

Rekkedal, T. (1983). Research and development activities in the field of distance study at NKI-Skolen, Norway. In D. Sewart, D. Keegan, B. Holmberg (Eds.). Distance education:

International perspectives (pp. 211-220). London: Croom Helm. 
Ritchie, H., \& Newby, T. (1989). Classroom lecture/discussion vs . live televised instruction: A comparison of effects on student performance, attitude and interaction. The American Journal of Distance Education, 3(3), 1-10.

Rogers, C. (1951). Client centered therapy. Boston: HoughtonMifflin.

Rumble, G. (1986). The planning and management of distance education. New York: St. Martin's Press.

Saloman, G. (1981). Communication and education. Beverly Hills: Sage publications.

Sammons, M. (1990). An epistemological justification for the role of teachers in distance education. In M.G. Moore (Ed.), contemporary issues in american distance education (pp. 151162) England: Pergamon Press.

Simonson, M. R., Schlosser, C., \& Anderson, M. (1993).

Encyclopedia of distance education research in Iowa. (draft) Iowa State University: College of education. Strain, John (1987). The role of the faculty member in distance education. American Journal of Distance Education 1(2), 6165.

Thorpe, M. (1988). Evaluating open and distance learning. Essex, London: Longman. 
Thorpe, M. (1994). Planning for learner support and the facilitator role. In Fred Lockwood (Ed.), Materials production in open and distance learning (pp. 147-151). London: Paul Chapman.

Threlkeld, R., \& Brzoska, K. (1993). Research in distance education. In B. Willis (Ed.), Distance Education strategies and tools (pp.41-62).

N J: Educational Technology Publications. Toffler, A. (1985). The adaptive corporation. New York: McGraw Hill.

Toffler, A. (1990). Powershift. New York: Bantam Books. Tough, A. (1971). The adult's learning projests. Toronto: Institute for Studies in Education. Verduin, J. R. , \& Clark, T. A. (1991). Distance education: the foundations of effective practice. San Francisco: Jossey Bass Inc. Wagner, E. D., (1994). In support of a functinal definition of interaction. American Journal of Distance Education 8(2), 629.

Wagner, N. \& Craft, E. H. (1988). Instructional television fixed service in Arizona. American Journal of Distance education $2(1), 1-7$. 
Walker. R. (1993). Open learning and the media: Transformation of education in times of change. In T. Evans \& D. Nation (Eds.), Beforming open and distance education (pp. 15-35). London: St. Martin's Press.

Wedemeyer, C.A. (1983). Back door learning in the learning society. In D. Sewart, D. Keegan, B. Holmberg (Eds.). Distance education: International perspectives (pp. 128-140). London: Croom Helm.

Wedemeyer, C. A., Najem, R. E. (1969). AIM: Erom concept to reality: The articulated media program at Wisconsin. New York: Syracuse University.

Wilkes, C.W. \& Burham B. R. (1991). Adult learner motivation and electronic distance education. The American Journal of

Distance Education 5 (1), pp. 43-50.

Wlodkowski, R. J. (1985). Enhancing adult motivation to learn. San Francisco: Jossey Bass Inc.

Winn, W. (1979). What makes a difference in learning from media. Journal of Biocommunication $6(2), 14-18$.

Willis, B. (1993). Distance Education: A practical guide.

Englewood Cliffs, NJ: Educational Technology Publications. 
Appendix A

Data Collection Instruments 


\section{MAN 3025 Organization \& Management} Term: January 1995

Please take the time to fill out this form. Your information is valuable to us as we seek to improve the distance education courses offered at FIU.

SOCIAI SECURITY NUMBER:

NAME :

LOCATION OF CLASSROOM: please circle (North Miami University Park)

AGE : $\quad 18-24$

$25-34$

$35-44$

OVER 44

ETHNICITY: NON HISPANIC CAUCASIAN

AFRICAN AMERICAN

HISPANIC ASIAN OTHER

MARITAL STATUS: MARRIED

DIVORCED SINGLE NUMBER OF CHILDREN: STUDENT STATUS: FULL-TIME (12 or more credits) PART-TIME

UNDERGRADUATE MAJOR:

NUMBER OF CREDITS EARNED TOWARD DEGREE TO DATE: IS THIS COURSE REQUIRED FOR YOUR DEGREE? YES No EMPLOYMENT: FULL-TIME PART-TIME NONE 


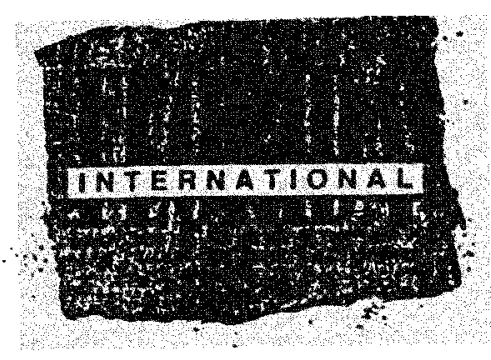

\section{E M O R A N D U M}

'INTERIM EVALUATION FORM

TO: DISTANCE LEARNING STUDENTS

FROM : $\quad$ PATRICK WAGNER

DATE: FEBRUARY 23, 1995

RE : $\quad$ FEEDBACK

During this, our "pilot year" to initiate Distance Learning I ask that you help in establishing formative evaluation data.

Thank you for your imput.

1. I am enrolled in course \# Instructor

2. I have taken the courșe at the following location:

3. Please use the rating scale: 1 = very good

2 = Acceptable

ORGANIZATIONAL

3 = Needs to improve

1. The organization of this course: $\quad \begin{array}{llll}1 & 2 & 3\end{array}$

Comment :

2. The course syllabus

Comment:

3. The Interactive Study Guide Comment:

TECHNICAL

4. The video broadcast

Comment:

5. The audio quality

Comment:

$1 \quad 2 \quad 3$

123

6. The use of chalkboard, overhead projector/camera and other devices

123

Comment: 
7. Time to copy notes and formulas Comment :

8. Visual materials, graphics, handouts $1 \quad 2 \quad 3$ Comment:

9. PEDAGOGICAL provided when needed 1423 Comment :

10. Course objectives and expectations $\quad 1 \quad 2 \quad 3$ Comment:

11. Class lecture/presentations Comment:

$1 \quad 2 \quad 3$

12. The instructor encouraged participation and interaction Comment:

13. The instructor demonstrated effective questioning strategies. Comment :

other:

Is there a recurring problem when viewing the video tapes or live broadcast?

What changes would you like to see to make the course more effective? (i.e. quality of production, administration, etc.) 
During this, our "pilot year" of initiating Distance Learning, we value the input of all students and faculty who have been a part of the program during the Fall Semester. Your completion of this survey is greatly appreciated.

\section{I am enrolled in:}

Name of Course

$\operatorname{Day}(\mathbf{s})$ and Time(s)

Name of Professor

For students who attended classes at an on-campus location:

I attended classes primarily in:

$\begin{array}{lll}- \text { VH } 163 & \text { (University Park) } \\ \text { VH } 307 & \text { (University Park) } \\ \text { ACl } 226 & \text { (North Miami) } \\ \text { ACl 227 } & \text { (North Mlami) } \\ \text { UB 150 } & \text { (North Miami) }\end{array}$

The instructor originated classes from my primary location (checked above):

- always

- somewhat more than half the time

_ half the time

- somewhat less than half the time

- never

For students who attended classes at an off-campus location:

Please fill in the specific off-campus site you attended:

The primary format used for the classes I attended was: viewing of pre-recorded video taped classes only. television viewing of live instruction with a phone-in for interaction from my site. fully live and interactive video and audio from and to all locations.

During the course of the semester, did the students from the off-campus sites meet as a group with the on-campus students and instructor?

- Yes No

If yes, what was the purpose(s) of the meeting(s)? 
Please ate the listed factors on the following scale. Place a check mark in the column that reflects your opinion.

\section{Very good Acceptable}

Course Syllabus

Interactive Study Guide

Delivery of tests

Delivery of In-class

hand outs

Ability to send materials to professor

Ability to obtain required textbooks

Ability to obtain supplementary materials

Ability to access campus support services

(1.a. - likrary, computer lats)

Opportunity to ask quesions during class

Opportunity to receive feedback on assignments

Opportunity to receive feedback on quizzes and tests

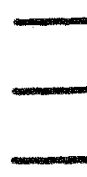

$-$
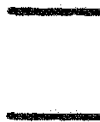

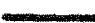
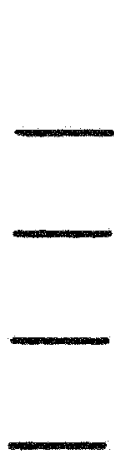

Needs to Improve

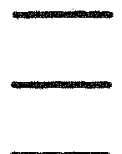

$-$
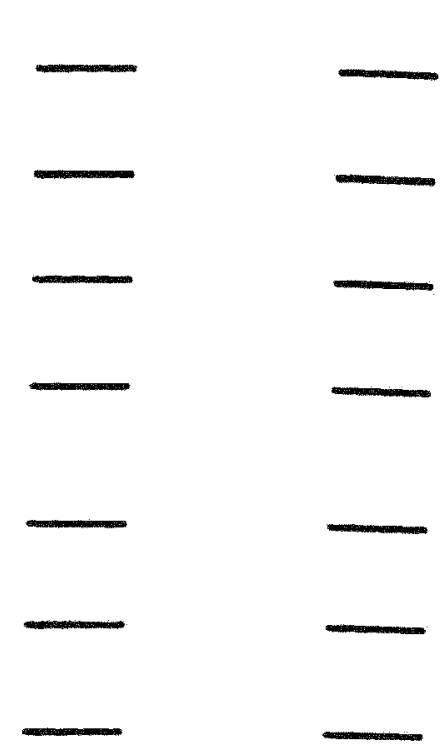

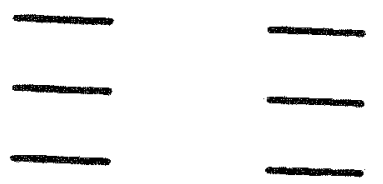
not Apply
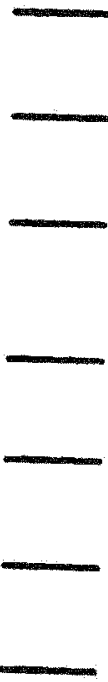

Who was your primary contact for obtaining materials and tests?

Who did you contact to arrange delivery of class assignments, quizzes and tests to the instructor? 
Please check the reasons why you chose to enioll in a Dlstance Education course rather than a traditional lecture setting. CHECK ALL ANSWERS THAT APPLY

It enabled me to take a course I would have otherwise been unable to take due to Inability to attend the course on either campus.

It saved me travel time, but I would have attended anyway if it was held on either campus.

It was the only section offered

It was the only remaining open section

It comveniently fit my schedule

Other

Please rate the listed factors on the following scale. Place a check mark in the column that reflects your opinion.

\begin{tabular}{|c|c|c|c|}
\hline $\begin{array}{l}\text { Strongly } \\
\text { Agree }\end{array}$ & Agreo & $\begin{array}{c}\text { No } \\
\text { Opinion }\end{array}$ & Dlsagree \\
\hline
\end{tabular}

I was comfortable using the audio

system to interact with the instructor.

I was comfortable using the audio system to interact with other students at remote locations.

I had ample opportunities to interact with the instructor during ciass.

I had ample opportunities to interact with other students during class.

I was given the opportunity to meet face-to-face with my professor.

I was given the opportunity to meet face-to-face with other students at remote locations.

I was satisfied with the presentation of lectures.

I felt I was an active participant in the coursework.

How well did the use of this technology meet your objectives for leaming the course material? 
Please rate the listed factors on the following scale. Place a check mark in the column that reflects your opinion.

My classroom was generally Strongly Agreo Agree No
Opinion

quiet enough for me to hear the
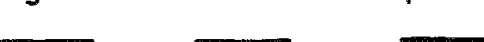
Disagree broadcasts.

Support personnel were responsive to technical difficulties.

Technical difficulties were remedied in a speedy and efficient manner.

Camera operators were quick to provide focus on individual speakers.

Camera operators remained focused on the blackboard long enough for me to read and copy the material.

I was able to read materiais presented on the blackitoard.

I was able to read materials presented on overnead projectors.

I was able to read materiais presented by Pleture-Tel graphics projector. (FPL \& FIU VH 307 / $L B$ B 150 onty)

I had access to taped lectures for review.

The technology was appropriate for presentation of lecture materials.

The tectinology was appropriate for group presentations at the primary site.

The tectinology was appropriate for group presentations at the remote site.

The technology was appropriate for group interactions between sites.

The facilities would benefit by the addition of: 
Plezse use this page to provide additional feedback...

Are there areas we need to ask you about that are not covered in this survey?

Tell us the positive and negative experiences you have encountered while participating in our pilot program of distance education. Remember, your comments provide direct feedback in the growth and development of future course work. Thank you. 


\section{COURSE OUESTIONNAIRE \\ (Department of Management \& International Business)}

course \#

Professor

Please comment below on the following aspects of this course (Please circla one):

1. Instructor:

Excelient

Good

Eaiz

Poor

Comments:

2. Content of course:

Comments:

3. Textbook:

Comments:

4. Other comments:
Excellent

Good

Fair

Poor

Excellent Good Fair Poor

Excellent Good Fair poor


Appendix B

Students Comments on Evaluation Instruments 
Table B1

Distant Site's comments on Interim Evaluation / (Erequency)

Easily distracted (2)

No supervision

Not all details can be seen

Communicate with more than one

student at distant site

More telephones, interactivity,

microphones needed (10)

Instructor will know students by

visiting both campuses

Teacher should rotate locations

to the distant site (15)

Difficult to see print on

television (7)

Sound has an echo but need to

turn it up and loudness causes

headaches

Writing needs to be larger

Not informed at enrollment this

was a distance course
Need better auditory

transmission so professor

doesn't have to repeat (6)

Sound has an echo but need to

turn it up and loudness causes

headaches

More people need to be motivated

to participate

Too much non-related talking

Need proctor most of the time

Enlarge writing on the board

Bring tapes home to view

Instructor talks too much

sometimes

Television is in one location so

some find volume of television

too loud and others can't hear

Multiple speakers would give

better volume

Course schedule should specify

it is a video class 
Table BI, continued

Distant Site's Comments on Interim Evaluation/Erequency)

Needs to be more personalized to encourage participation and interaction

Sometimes people call in and professor doesn't know who it is Students should interact with other students as well as the professor

Need to zoom in better

Need assistant professor or someone who knows material in class (4)

Need more definitions and clear and specific notes

Need more time to copy notes 
Table B2

Instructor-based Site's comments on Interim Evaluation (Erequency)

Sometimes difficult to hear

questions from students at other

site (2)

It would be better to see other

campus

Unable to view video tapes

because no monitors available

\section{(2)}

I believe students at distant

site have problems with sound

Disclose it is a distance course

at registration

Need better way to communicate

with distant site

Need better equipment for video

and audio

Audio is important because of lengthy communication

Camera should be a wide angle

Move monitors forward to

chalkboard because can't see

them easily

Television is distracting
Nice to be able to see person

speaking at distant site

Reception sometimes too low

Hanging mics interfered with

picture at times 
Table B3

Distant site's comments on Distance Education Evaluation Form (Erequency)

Not the same as coming to class, Students talk over instructor words get lost

Camera's focus not so clear

On power failure day, tape had Jokes and personal stories make only half the lecture it difficult to focus on main Tapes not available at the point of lecture and makes me library when I need it (2) feel sleepy (2)

Instructor should visit sites Negative experience - found it prior to staring class to hard to communicate with coordinate with siteinstructor when I had a problem administrator More two-way communication More input needed from remote devices needed in room (2) site Left message for professor but

Get lost at times did not get return call

Video can be improved

Instructor makes me sleepy

Negative experience because hard

to communicate with instructor when there is a problem proctor talking interferes

Alternate between sites (2)

Difficult to hear at times

Toe much talking at site (2) 
Table B4

Instructor-based site's comments

en Distance Education Evaluation

Eorm/(Erequency)

Not able to get tapes for review

at library; leave them til

course ends

Sometimes technical difficulties

It would be better to see

distant site (3)

Need better audio; can't hear

distant site (3)

I would not like to attend

distant site

Sometimes takes too long to get

going

Lock out late students

Takes too long to get started 
Appendix C

Students Interviews 
Table C1

Distant Site Answers to what Worked We1I? / (Erequency)

Good teacher

Professor well suited

Liked instructor(2)

Fun teacher

Liked presentations

Liked format of class

More courses should be available

Presentations never dull

Study guide helpful

Everything worked well (2)

Review with video tapes is good

Convenient to go to the library and view tapes

Liked informality because instructor not present and felt at ease

Liked interactive study guide

Outline helpful 
Table c2

Distant Site Answers to what Made You Unhappy? /(Erequency)

Proctoring on exams not done well

Twenty-one chapters were too much to read

Not enough time for discussion

A handful of students took the bull by the hand and answered for the rest of the distant site Professor doesn't ask if you have questions

Not enough microphones (2)

Couldn't ask questions because

it is hard to interrupt the professor

Hard to say something not faceto-face

Everyone did not have the opportunity to speak because of limited microphones
Need more communication

Would be easier to ask

questions in person because only six microphones limited

discussion

Wanted to speak but no

microphone available

One person would hang on to the microphone and not give it up Same people each week took the microphone

Can shout out answers but student with the microphone doesn't have to report your answer

One person monopolizes the microphone Need to encourage others to use microphones

Table continued 
Table C2, continued

Distant Site Answers to What Made you Unhappy? (Frequency)

Person at microphone doesn't ask others for input

Students talking made a lot of noise

Hard for people in the back of the room to speak out

Need better proctor for exams

Lots of talking among students interfered with the class

Teacher needs to be there to prevent talking

Some students tended to talk and made it difficult to hear

Too much talking in small groups

Professor doesn't know who is talking

Would like to have some classes here

Professor should come to site once in a while

Writing not clear last three classes

Some technical glitches 
Table 63

Distant Site Answers to Did You Eeel

You Learned as Much as in a Regular Class? (Frequency)

Felt I learned as much (6)

Did not feel I leaned as much (2)

Learned a lot, but would have had more chance to ask questions if professor were at the site and I could ask questions after class Not sure if I learned as much Can't always see well from back of room 
Table c4

Distant site Answers to Did you Feel You Were an Active

Rarticipant? (Erequency)

Eelt I was an active participant 2

Felt active because group gave answer and tried to include us all

Eelt involved

Don't always feel active because when you tell a person near the microphone your answer they might not use it

Did not feel like an active participant 2

When I was assigned to the table with microphones I could talk

I wanted to sit at the table with the microphones more often 
VITA

April 2, 1941 Born Bronx, New York

1962

B.S., Education

New York University

New York, New York

$1962-1965$

Social Studies Teacher

New York, New York

$1972-1979$

Special Education teacher, Bridgewater, New Jersey

1978

Master in Education

Trenton State College

Trenton, New Jersey

1978

Phi Kappa Phi induction

1978

State of Florida

Teaching Certificate

$1979-1982$

Director of Training and Human Resources

AAA International Couriers

Miami, Elorida

1982-1985 Vice President Sales and Marketing

AAA International Couriers

Miami, Florida

1985

Certificated Vocational Rehabilitation

Counselor, Human Resource Counselor

State of Florida

1985

Dale Carnegie Group Eacilitator

Miami, Elorida

$1985-1989$

Deming Prize facilitator

Florida Power \& Light Company

Miami, Elorida

1989-1995

Education Specialist

Instructional Designer

Instructor

Florida Power \& Light Company

Juno Beach, Florida 
Consultant in Adult Learning and Distance Learning Juno Beach, Florida

1996

Iisted in International WHO's WHO in Distance Learning

Bonn, Germany

PRESENTATIONS

Cordover, P. P., (April, 1993). Bridging the Distance in Distance Education. Paper presented at the conference of the National Society for Performance and Instruction, San Francisco, California.

Cordover, P. P., (April, 1994). What Drives Distance Education: Technology or Instructional systems Design? Paper presented at the conference of the National Society for performance and Instruction, Chicago, 1994.

1995 - present Private consultant in distance education and adult learning 